\title{
Mobilisation strategies after hip fracture surgery in adults (Review)
}

\author{
Handoll HHG, Sherrington C, Parker MJ
}

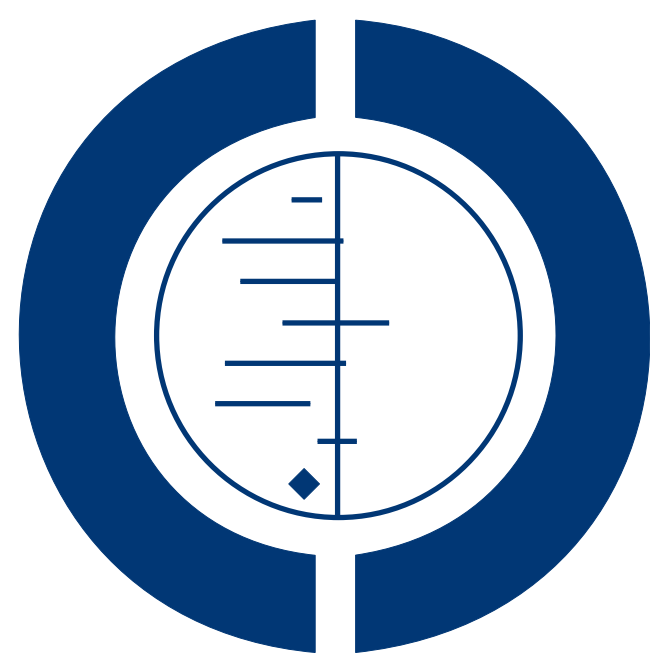

THE COCHRANE COLLABORATION $^{\circledR}$

This is a reprint of a Cochrane review, prepared and maintained by The Cochrane Collaboration and published in The Cochrane Library 2006, Issue 4

http://www.thecochranelibrary.com

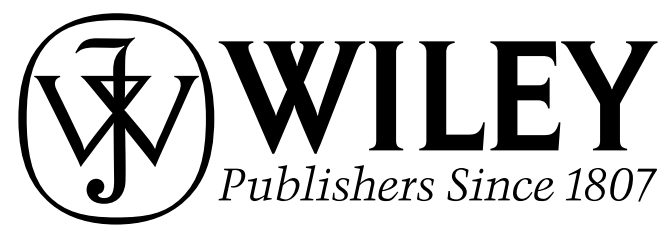

Mobilisation strategies after hip fracture surgery in adults (Review)

Copyright $\odot 2006$ The Cochrane Collaboration. Published by John Wiley \& Sons, Ltd 
TABLE OF CONTENTS

ABSTRACT . . . . . . . . . . . . . . . . . . . . . . . . . . . .

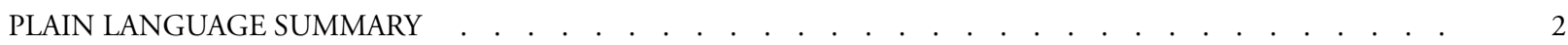

BACKGROUND . . . . . . . . . . . . . . . . . . . . . . . . . . . . . . . . . . . . . 2

OBJECTIVES . . . . . . . . . . . . . . . . . . . . . . . . . . . . . . . . . . . . . . . 3

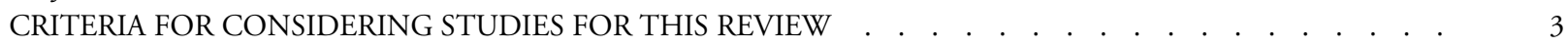

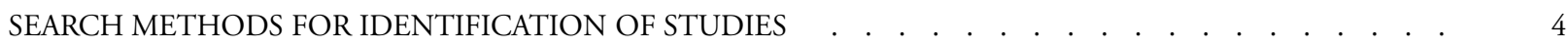

METHODS OF THE REVIEW

DESCRIPTION OF STUDIES

METHODOLOGICAL QUALITY . . . . . . . . . . . . . . . . . . . . . . . . . . . . . . . . . 7

RESULTS . . . . . . . . . . . . . . . . . . . . . . . . . . . . . . . . . . . . . . . . . 8

DISCUSSION . . . . . . . . . . . . . . . . . . . . . . . . . . . . . . . . . . . 13

AUTHORS' CONCLUSIONS . . . . . . . . . . . . . . . . . . . . . . . . . . . . . . . . . 16

NOTES . . . . . . . . . . . . . . . . . . . . . . . . . . . . . . . . . . . . . . . . 17

POTENTIAL CONFLICT OF INTEREST . . . . . . . . . . . . . . . . . . . . . . . . . . . . . . 17

ACKNOWLEDGEMENTS . . . . . . . . . . . . . . . . . . . . . . . . . . . . . . . . . . . . . . . . . . . . 17

SOURCES OF SUPPORT

REFERENCES . . . . . . . . . . . . . . . . . . . . . . . . . . . . . . . . . . . . . 18

TABLES . . . . . . . . . . . . . . . . . . . . . . . . . . . . . . . . . . . 20

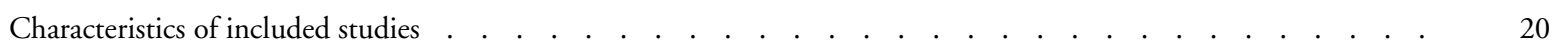

Characteristics of excluded studies ．．．．．．．． . . . . . . . . . . . . . . . . . . . . . 27

Characteristics of ongoing studies . . . . . . . . . . . . . . . . . . . . . . . . . . . . . . 27

ADDITIONAL TABLES . . . . . . . . . . . . . . . . . . . . . . . . . . . . . . . . . . . . 31

Table 01. Types of outcome measures sought in versions of the review before Issue 4, $2004 \quad$. . . . . . . . . 31

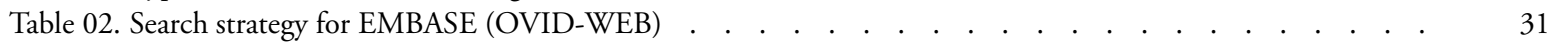

ANALYSES . . . . . . . . . . . . . . . . . . . . . . . . . . . . . . . . . . . . . . 32

Comparison 01. Early versus delayed weight bearing . . . . . . . . . . . . . . . . . . . . . . . . 32

Comparison 02. Intensive versus usual physiotherapy ．． . . . . . . . . . . . . . . . . . . . . 32

Comparison 03. Weight-bearing exercises versus non-weight-bearing exercises . . . . . . . . . . . . . . 32

Comparison 04. Quadriceps training programme . . . . . . . . . . . . . . . . . . . . . . . . 33

Comparison 05. Treadmill gait training versus conventional gait training . . . . . . . . . . . . . . . . 33

Comparison 06. Neuromuscular stimulation versus placebo . . . . . . . . . . . . . . . . . . . . . 33

Comparison 07. Intensive physical training versus placebo activities (started post-discharge) ． . . . . . . . . 33

Comparison 08. Home-based exercises programme (started at 22 weeks) versus control . . . . . . . . . . . 34

Comparison 09. Home-based weight bearing exercises programme (started at 22 weeks) versus control _ . . . . . 34

Comparison 10. Home-based non-weight bearing exercises programme (started 22 at weeks) versus control . . . . $\quad 34$

Comparison 11. Home-based weight bearing versus non-weight-bearing exercises programme (started at 22 weeks) . $\quad 35$

Comparison 12. Home-based exercises programme (started at 7 months) _ . . . . . . . . . . . . . . . 35

INDEX TERMS . . . . . . . . . . . . . . . . . . . . . . . . . . . . . . . . . . . . . . . . . 35

COVER SHEET

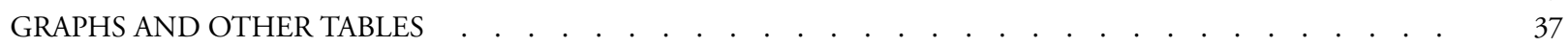

Analysis 01.01 . Comparison 01 Early versus delayed weight bearing, Outcome 01 Mortality . . . . . . . . . . 37

Analysis 01.02 . Comparison 01 Early versus delayed weight bearing, Outcome 02 Non-union (fixation failure) . . $\quad 38$

Analysis 01.03. Comparison 01 Early versus delayed weight bearing, Outcome 03 Avascular necrosis . . . . . . 38

Analysis 01.04. Comparison 01 Early versus delayed weight bearing, Outcome 04 Unfavourable outcome (death, failure 39 or infection)

Analysis 02.01. Comparison 02 Intensive versus usual physiotherapy, Outcome 01 Adductor muscle strength (kp) at $9 \quad 39$ weeks

Analysis 02.02. Comparison 02 Intensive versus usual physiotherapy, Outcome 02 Orthopaedic complication (as reason for withdrawal from trial)

Analysis 02.03. Comparison 02 Intensive versus usual physiotherapy, Outcome 03 Length of hospital stay (days) . . 40

Analysis 02.04. Comparison 02 Intensive versus usual physiotherapy, Outcome 04 Withdrawal from trial by patient . 41

Mobilisation strategies after hip fracture surgery in adults (Review)

Copyright ( 2006 The Cochrane Collaboration. Published by John Wiley \& Sons, Ltd 
Analysis 02.05. Comparison 02 Intensive versus usual physiotherapy, Outcome 05 Non-completion of training programme

Analysis 03.01. Comparison 03 Weight-bearing exercises versus non-weight-bearing exercises, Outcome 01 Unable to walk at all or without two sticks or a frame . . . . . . . . . . . . . . . . . . . . . . . . . . .

Analysis 03.02. Comparison 03 Weight-bearing exercises versus non-weight-bearing exercises, Outcome 02 Unable to do a lateral step-up unsupported or with one hand alone

Analysis 03.03. Comparison 03 Weight-bearing exercises versus non-weight-bearing exercises, Outcome 03 Gait parameters .

Analysis 03.04. Comparison 03 Weight-bearing exercises versus non-weight-bearing exercises, Outcome 04 Physical Performance and Mobility Examination score (0:failure to 12 :top score $)$. . . . . . . . . . . . . . . . . .

Analysis 03.05. Comparison 03 Weight-bearing exercises versus non-weight-bearing exercises, Outcome 05 Strength measures (newtons)

Analysis 03.06. Comparison 03 Weight-bearing exercises versus non-weight-bearing exercises, Outcome 06 Balance

Analysis 03.07. Comparison 03 Weight-bearing exercises versus non-weight-bearing exercises, Outcome 07 Subjective rating of pain, fall risk, balance, sleep quality and general health

Analysis 03.08. Comparison 03 Weight-bearing exercises versus non-weight-bearing exercises, Outcome 08 Fracture fixation problems

Analysis 03.09. Comparison 03 Weight-bearing exercises versus non-weight-bearing exercises, Outcome 09 Total length of stay in hospital (days)

Analysis 03.10. Comparison 03 Weight-bearing exercises versus non-weight-bearing exercises, Outcome 10 Participant's perception of exercise programmes

Analysis 04.01. Comparison 04 Quadriceps training programme, Outcome 01 Leg extensor power (watts) . . . .

Analysis 04.02. Comparison 04 Quadriceps training programme, Outcome 02 Mortality . . . . . . . . . .

Analysis 05.01. Comparison 05 Treadmill gait training versus conventional gait training, Outcome 01 Failure to regain pre-fracture mobility

Analysis 05.02. Comparison 05 Treadmill gait training versus conventional gait training, Outcome 02 Gait velocity (metres/minute)

Analysis 06.01. Comparison 06 Neuromuscular stimulation versus placebo, Outcome 01 Failure to regain pre-fracture mobility

Analysis 06.02. Comparison 06 Neuromuscular stimulation versus placebo, Outcome 02 Unable to 'tandem stand' (postural instability)

Analysis 06.03. Comparison 06 Neuromuscular stimulation versus placebo, Outcome 03 Gait velocity (walking speed over 15.25 metres) (metres/second)

Analysis 06.04. Comparison 06 Neuromuscular stimulation versus placebo, Outcome 04 Leg extensor power (watts/ kilogram)

Analysis 06.05. Comparison 06 Neuromuscular stimulation versus placebo, Outcome 05 Pain (6 point scale: $6=$ constant severe pain)

Analysis 07.01. Comparison 07 Intensive physical training versus placebo activities (started post-discharge), Outcome 01 Gait parameters

Analysis 07.02. Comparison 07 Intensive physical training versus placebo activities (started post-discharge), Outcome 02 Tinetti's POMA (Performance orientated mobility assessment)

Analysis 07.03. Comparison 07 Intensive physical training versus placebo activities (started post-discharge), Outcome 03 Loss of social independence

Analysis 07.04. Comparison 07 Intensive physical training versus placebo activities (started post-discharge), Outcome 04 Functional performance measures

Analysis 07.05. Comparison 07 Intensive physical training versus placebo activities (started post-discharge), Outcome 05 Functional performance tests

Analysis 07.06. Comparison 07 Intensive physical training versus placebo activities (started post-discharge), Outcome 06 Strength measures . . . . . . . . . . . . . . . . . . . . . . . . . . . . . . .

Analysis 07.07. Comparison 07 Intensive physical training versus placebo activities (started post-discharge), Outcome 07 Balance .

Analysis 07.08. Comparison 07 Intensive physical training versus placebo activities (started post-discharge), Outcome 08 Subjective/emotional state assessment, falls, balance and general 
Analysis 07.09. Comparison 07 Intensive physical training versus placebo activities (started post-discharge), Outcome

09 Adherence . . . . . . . . . . . . . . . . . . . . . . . . . . . . . . . . . .

Analysis 08.01. Comparison 08 Home-based exercises programme (started at 22 weeks) versus control, Outcome 01 Mobility

Analysis 08.02. Comparison 08 Home-based exercises programme (started at 22 weeks) versus control, Outcome 02 Gait parameters

Analysis 08.03. Comparison 08 Home-based exercises programme (started at 22 weeks) versus control, Outcome 03 Physical Performance and Mobility Examination score (0:failure to 12:top score) . . . . . . . . . . . .

Analysis 08.04. Comparison 08 Home-based exercises programme (started at 22 weeks) versus control, Outcome 04 Functional performance tests

Analysis 08.05. Comparison 08 Home-based exercises programme (started at 22 weeks) versus control, Outcome 05 Strength measures (newtons)

Analysis 08.06. Comparison 08 Home-based exercises programme (started at 22 weeks) versus control, Outcome 06 Balance . . . . . . . . . . . . . . . . . . . . . . . . . . . . . . . . . . . . . . . . . . .

Analysis 08.07. Comparison 08 Home-based exercises programme (started at 22 weeks) versus control, Outcome 07 Subjective rating of pain, fall risk, balance, sleep quality and general health . . . . . . . . . . . . . . .

Analysis 08.08. Comparison 08 Home-based exercises programme (started at 22 weeks) versus control, Outcome 08 Fell at least once during intervention period (4 months) .

Analysis 08.09. Comparison 08 Home-based exercises programme (started at 22 weeks) versus control, Outcome 09 Mortality

Analysis 09.01. Comparison 09 Home-based weight bearing exercises programme (started at 22 weeks) versus control, Outcome 01 Mobility

Analysis 09.02. Comparison 09 Home-based weight bearing exercises programme (started at 22 weeks) versus control, Outcome 02 Gait parameters

Analysis 09.03. Comparison 09 Home-based weight bearing exercises programme (started at 22 weeks) versus control, Outcome 03 Physical Performance and Mobility Examination score (0:failure to 12:top score) . . . . . . . .

Analysis 09.04. Comparison 09 Home-based weight bearing exercises programme (started at 22 weeks) versus control, Outcome 04 Functional performance tests

Analysis 09.05. Comparison 09 Home-based weight bearing exercises programme (started at 22 weeks) versus control, Outcome 05 Strength measures (newtons) . . . . . . . . . . . . . . . . . . . . . . . . . . . . . . . .

Analysis 09.06. Comparison 09 Home-based weight bearing exercises programme (started at 22 weeks) versus control, Outcome 06 Balance

Analysis 09.07. Comparison 09 Home-based weight bearing exercises programme (started at 22 weeks) versus control, Outcome 07 Subjective rating of pain, fall risk, balance, sleep quality and general health . . . . . . . . . .

Analysis 09.08. Comparison 09 Home-based weight bearing exercises programme (started at 22 weeks) versus control, Outcome 08 Fell at least once during intervention period ( 4 months)

Analysis 09.09. Comparison 09 Home-based weight bearing exercises programme (started at 22 weeks) versus control, Outcome 09 Mortality .

Analysis 10.01. Comparison 10 Home-based non-weight bearing exercises programme (started 22 at weeks) control, Outcome 01 Mobility . . . . . . . . . . . . . . . . . . . . . . . . . . . . . . . . . . . . .

Analysis 10.02. Comparison 10 Home-based non-weight bearing exercises programme (started 22 at weeks) versus control, Outcome 02 Gait parameters

Analysis 10.03. Comparison 10 Home-based non-weight bearing exercises programme (started 22 at weeks) versus control, Outcome 03 Physical Performance and Mobility Examination score (0:failure to 12:top score) . . .

Analysis 10.04. Comparison 10 Home-based non-weight bearing exercises programme (started 22 at weeks) versus control, Outcome 04 Functional performance tests . . . . . . . . . . . . . . . . . . . . . . . . . . .

Analysis 10.05. Comparison 10 Home-based non-weight bearing exercises programme (started 22 at weeks) versus control, Outcome 05 Strength measures (newtons)

Analysis 10.06. Comparison 10 Home-based non-weight bearing exercises programme (started 22 at weeks) versus control, Outcome 06 Balance . . . . . . . . . . . . . . . . . . . . . . . . . . . . . . . . .

Analysis 10.07. Comparison 10 Home-based non-weight bearing exercises programme (started 22 at weeks) versus control, Outcome 07 Subjective rating of pain, fall risk, balance, sleep quality and general health . . . . . 
Analysis 10.08. Comparison 10 Home-based non-weight bearing exercises programme (started 22 at weeks) versus control, Outcome 08 Fell at least once during intervention period (4 months) . . . . . . . . . . . . . . .

Analysis 10.09. Comparison 10 Home-based non-weight bearing exercises programme (started 22 at weeks) versus control, Outcome 09 Mortality . . . . . . . . . . . . . . . . . . . . . . . . . . . . . . . . . .

Analysis 11.01. Comparison 11 Home-based weight bearing versus non-weight-bearing exercises programme (started at 22 weeks), Outcome 01 Mobility . . . . . . . . . . . . . . . . . . . . . . . . . . . . . . . .

Analysis 11.02. Comparison 11 Home-based weight bearing versus non-weight-bearing exercises programme (started at 22 weeks), Outcome 02 Gait parameters . . . . . . . . . . . . . . . . . . . . . . . . . . . . .

Analysis 11.03. Comparison 11 Home-based weight bearing versus non-weight-bearing exercises programme (started at 22 weeks), Outcome 03 Physical Performance and Mobility Examination score (0:failure to 12:top score) . .

Analysis 11.04. Comparison 11 Home-based weight bearing versus non-weight-bearing exercises programme (started at 22 weeks), Outcome 04 Functional performance tests . . . . . . . . . . . . . . . . . . . . . . . . .

Analysis 11.05. Comparison 11 Home-based weight bearing versus non-weight-bearing exercises programme (started at 22 weeks), Outcome 05 Strength measures (newtons) . . . . . . . . . . . . . . . . . . . . . . .

Analysis 11.06. Comparison 11 Home-based weight bearing versus non-weight-bearing exercises programme (started at 22 weeks), Outcome 06 Balance . . . . . . . . . . . . . . . . . . . . . . . . . . . . . . . .

Analysis 11.07. Comparison 11 Home-based weight bearing versus non-weight-bearing exercises programme (started at 22 weeks), Outcome 07 Subjective rating of pain, fall risk, balance, sleep quality and general health . . . .

Analysis 11.08. Comparison 11 Home-based weight bearing versus non-weight-bearing exercises programme (started at 22 weeks), Outcome 08 Fell at least once during intervention period (4 months) . . . . . . . . . . . . .

Analysis 11.09. Comparison 11 Home-based weight bearing versus non-weight-bearing exercises programme (started at 22 weeks), Outcome 09 Mortality . . . . . . . . . . . . . . . . . . . . . . . . . . . . . . .

Analysis 11.10. Comparison 11 Home-based weight bearing versus non-weight-bearing exercises programme (started at 22 weeks), Outcome 10 Participant's participation in and perception of exercise programmes . . . . . .

Analysis 12.01. Comparison 12 Home-based exercises programme (started at 7 months), Outcome 01 Inability to perform weight-bearing test without hand support . . . . . . . . . . . . . . . . . . . . . . . . .

Analysis 12.02. Comparison 12 Home-based exercises programme (started at 7 months), Outcome 02 Gait parameters Analysis 12.03. Comparison 12 Home-based exercises programme (started at 7 months), Outcome 03 Strength (kg)

Analysis 12.04. Comparison 12 Home-based exercises programme (started at 7 months), Outcome 04 Balance (postural control) . . . . . . . . . . . . . . . . . . . . . . . . . . . . . . . . . . . . . . . . . . . . .

Analysis 12.05. Comparison 12 Home-based exercises programme (started at 7 months), Outcome 05 Subjective rating of balance and fall risk . . . . . . . . . . . . . . . . . . . . . . . . . . . . . . . . . . . . . . 


\title{
Mobilisation strategies after hip fracture surgery in adults (Review)
}

\author{
Handoll HHG, Sherrington C, Parker MJ
}

\author{
This record should be cited as: \\ Handoll HHG, Sherrington C, Parker MJ. Mobilisation strategies after hip fracture surgery in adults. Cochrane Database of Systematic \\ Reviews 2004, Issue 4. Art. No.: CD001704. DOI: 10.1002/14651858.CD001704.pub2.
}

This version first published online: 18 October 2004 in Issue 4, 2004.

Date of most recent substantive amendment: 23 June 2004

\begin{abstract}
A B S T R A C T
Background

Hip fracture, which happens in predominantly elderly populations, often results in a reduction in mobility. Care programmes after hip fracture surgery include strategies for mobilisation, such as early weight bearing and gait retraining. Other mobilisation strategies, such as exercises and physical training, are used at various stages in rehabilitation including after discharge from hospital.
\end{abstract}

\section{Objectives}

To evaluate the effects of different mobilisation strategies and programmes after hip fracture surgery.

\section{Search strategy}

We searched the Cochrane Musculoskeletal Injuries Group Specialised Register (May 2004), the Cochrane Central Register of Controlled Trials (The Cochrane Library Issue 2, 2004), MEDLINE and other databases, conference proceedings and reference lists of articles.

\section{Selection criteria}

All randomised or quasi-randomised trials comparing different mobilisation strategies/programmes after hip fracture surgery.

\section{Data collection and analysis}

The reviewers independently assessed trial quality and extracted data.

\section{Main results}

Our third update, which extended the review scope to cover the whole rehabilitation period, included four new trials. Most of the 10 included trials were small and all had methodological limitations, including inadequate follow up.

Seven trials evaluated mobilisation strategies started soon after hip fracture surgery. One trial (273 participants) found no statistically significant differences in unfavourable outcomes for weight bearing started at two versus 12 weeks after internal fixation of a displaced intracapsular fracture. Of two trials (188 participants) comparing a more with a less intensive regimen of physiotherapy, one reported a lack of demonstrable difference in recovery of the two patient groups, and the other found a higher level of drop-out in the more intensive group with no difference in length of hospital stay. One trial (80 participants) comparing two-week programmes of weightbearing versus non-weight-bearing exercise found some short-term improvement in mobility and balance in the weight-bearing exercise group. One trial (80 participants) found improved mobility, leg extension power and Barthel score in those given a quadriceps muscle strengthening exercise programme. One trial (40 participants) found no statistically significant difference in recovery of mobility and time to hospital discharge after a treadmill versus conventional gait retraining programme. One trial (27 participants) comparing neuromuscular stimulation of the quadriceps muscle with placebo found a greater recovery of pre-fracture mobility in the stimulation group.

The interventions tested by the three remaining trials started after hospital discharge. One trial (28 participants) found improved outcome after 12 weeks of intensive physical training. One trial (120 participants) found improved outcome after home-based exercises started around 22 weeks from injury. One trial (44 participants) found home-based weight-bearing exercises starting at seven months produced no statistically significant differences aside, perhaps, for greater quadriceps strength. 


\section{Authors' conclusions}

There is insufficient evidence from randomised trials to determine the effectiveness of the various mobilisation strategies examined in this review that start either in the early post-operative period or during the later rehabilitation period. Further research is required to establish the possible benefits of the additional provision of interventions primarily aimed at enhancing mobility.

\section{PLAIN LANGUAGESUMMARY}

Not enough evidence to assess the effects of interventions to get people back on their feet after hip fracture surgery, and to keep them mobile

The aim of care after surgery for hip fracture is to get people safely back on their feet and walking again. People may be asked to rest in bed, restrict weight bearing, or restrict particular activities. Different physiotherapy and exercise programmes may be used. The review found there was not enough evidence from randomised trials to show the effects of these different strategies for helping people walk after hip fracture surgery. The review also found there was not enough evidence from trials testing the effects of exercise programmes to improve and maintain mobility after discharge from hospital.

\section{B A C K G R O U N D}

Hip fractures, which are fractures of the proximal femur, can be subdivided into intracapsular fractures (those occurring proximal to the attachment of the hip joint capsule to the femur) and extracapsular (those occurring distal to the hip joint capsule). Intracapsular fractures can be further subdivided into those which are displaced (the fracture fragments are displaced relative to each other) and those which are essentially undisplaced. Undisplaced fractures include those which are termed impacted or adduction fractures. Numerous subdivisions and classification methods exist for extracapsular fractures and other terms used to describe these fractures include trochanteric, subtrochanteric, pertrochanteric, intertrochanteric, basal and lateral femoral fractures.

The majority of hip fractures occur in older people with an average age of around 80 years. Females predominate over males by about four to one and the injury is usually the result of a simple fall. People sustaining a hip fracture frequently have many other medical and physical problems associated with ageing, including impaired mobility.

Currently, the majority of hip fractures are treated surgically, which enables earlier mobilisation of the patient and avoids some of the complications of prolonged recumbency and immobilisation. Surgery entails either internal fixation where the fracture is fixed using various implants and thereby retaining the femoral head, or by replacing the femoral head with a prosthesis.

A variety of post-operative care programmes following surgery for hip fractures have been employed. Mobilisation is a major component of post-operative care and rehabilitation. Various mobilisation strategies are in use. In the early stages, these include resting the patient in bed ('bed rest'), restricted weight bearing, and restricted activities (such as walking, running). Other strategies for mobilisation relate to the nature of the physiotherapy or exercise regimens used. These include mobilisation interventions such as exercise, training and muscle stimulation which aim to minimise impairments (such as reduced strength) and improve the physical performance of walking.

The original scope of this review was confined to the topic of early weight bearing and mobilisation after internal fixation of intracapsular proximal femoral fractures in adults (Parker 1999). This was then expanded to include interventions that had been used in the mobilisation of all hip fracture patients after surgery and started in the first phase of rehabilitation, generally whilst the patient was in hospital (Handoll 2003). This update extends the scope further to include mobilisation strategies applied in the later stages of rehabilitation, generally in the community. The focus on mobilisation is maintained and thus trials testing interventions, including multi-component interventions, aimed at enhancing activities of daily living and other aspects of functioning rather than specifically mobilisation are not included here. Other aspects of rehabilitation after hip fracture such as the organisation of care programmes (Cameron 2004a) and nutritional supplementation (Avenell 2004) are already considered within separate Cochrane reviews.

The timing and extent of weight bearing form part of any mobilisation strategy after hip fracture surgery. Other components of mobilisation strategies generally involve various forms of exercise regimens; again the extent and timing of these will vary. The aim of these is to improve the patient's walking ability and associated function. The possibility of a refracture and other complications usually affects the decisions as to when to allow restricted or full weight bearing on the injured hip and the subsequent pace and stages of physical rehabilitation. In particular, the patient is at risk of several complications of fracture healing following internal fixation of a hip fracture. For example, the implant may fail to hold 
the fracture or 'cut-out' of the bone (penetration of the implant from the proximal femur either into the hip joint or external to the femur) causing pain and impaired mobility. This may require revision surgery to re-fix the fracture, or replace the femoral head with an arthroplasty. Other complications of fracture healing that may occur are non-union of the fracture (that is failure of the fracture to heal) and avascular necrosis of the femoral head (also termed segmental collapse or aseptic necrosis).

Different considerations feature in the later stages of rehabilitation, which mainly occurs after discharge from hospital and in the community or residential care setting. As before, mobilisation strategies aim to improve the patient's walking ability and associated function. However, there may be a greater emphasis on independent and confident ambulation, with the correct use of ambulatory aids and specific interventions, such as muscle strengthening exercises, aimed at minimising or correcting impairments; for example, various gait problems that often manifest as a limp.

\section{O B J E C T I V E S}

To evaluate, based on evidence from randomised trials, the effects of different mobilisation strategies/programmes after surgery for a hip fracture. As well as testing for all hip fractures, where possible, separate analyses were planned for intracapsular and extracapsular fractures.

We wished to test the following general null hypotheses:

There is no difference in outcome between the provision of any specific mobilisation strategy/programme and non-provision started either as an in-patient or following discharge from in-patient care after surgery for a hip fracture.

There is no difference in outcome between different mobilisation strategies/programmes started either as an in-patient or following discharge from in-patient care after surgery for a hip fracture.

Based on the availability of trials and grouped according to the basic stage in the rehabilitation process when the trial intervention(s) commenced, we tested the following null hypotheses.

\section{Early post-operative rehabilitation started as an in-patient}

- There is no difference in outcome between delayed weight bearing and early weight bearing after internal fixation of an intracapsular fracture.

- There is no difference in outcome between an intensive physiotherapy regimen and conventional treatment.

- There is no difference in outcome between short programmes of weight-bearing exercise and non-weight-bearing exercise.

- There is no difference in outcome when a quadriceps training programme is added to conventional treatment.
- There is no difference in outcome between a treadmill gait retraining programme and conventional treatment.

- There is no difference in outcome between patterned neuromuscular stimulation and placebo stimulation.

Continuation/community rehabilitation started after discharge from in-patient care

- There is no difference in outcome between an intensive physical training regimen and usual care after discharge from in-patient care.

- There is no difference in outcome between a home-based exercise programme of either weight-bearing exercises or nonweight-bearing exercises and no programme after four to five months from injury.

- There is no difference in outcome between a home-based programme of weight-bearing exercise and no programme after four to five months from injury.

- There is no difference in outcome between a home-based programme of non-weight-bearing exercise and no programme after four to five months from injury.

- There is no difference in outcome between home-based programmes of weight-bearing exercise and non-weight-bearing exercise after four to five months from injury.

- There is no difference in outcome between a home-based exercise programme of weight-bearing exercises and usual care after seven months from injury.

Similar null hypotheses will be constructed for other relevant comparisons identified in randomised trials in subsequent updates of this review.

\section{CRITERIA FOR CONSIDERING STUDIES FOR THIS REVIEW}

\section{Types of studies}

All randomised controlled trials comparing different post-operative mobilisation strategies or programmes after surgery to repair an acute hip fracture. Quasi-randomised trials (for example, allocation by alternation or date of birth) and trials in which the treatment allocation was inadequately concealed were considered for inclusion.

\section{Types of participants}

Skeletally mature patients treated for a hip fracture at any stage during rehabilitation.

\section{Types of intervention}

Post-operative care programmes such as immediate or delayed weight bearing after surgery, and any other mobilisation strategies, 
such as exercises, physical training and muscle stimulation, used at various stages in rehabilitation, which aim to improve walking and minimise functional impairments. Excluded were trials testing interventions aimed at improving activities of daily living rather than mobility, and those testing care programmes, management strategies and other multi-component interventions that were not solely aimed at mobilisation.

\section{Types of outcome measures}

While the outcomes sought remain basically unchanged from previous versions (see Table 01 ), this section has been restructured to emphasise the main focus of the interventions, which is to safely restore/enhance mobility, and to apply to the whole rehabilitation period.

(1) Mobility and other related functional outcomes (including impairment)

(a) Mobility/walking ability:

- restoration of pre-fracture mobility/walking ability;

- use of walking aids/need for assistance;

- time to mobilisation/regain of final mobility status.

(b) Gait assessment and objective measures of impairment/function:

- various gait parameters, limp;

- functional performance measures: for example, timed up and go;

- strength, balance, range of motion.

(c) Falls and fear of falling.

(d) General functioning:

- return to living at home;

- other functional outcomes as listed in each study;

- health related quality of life measures: physical domains.

(e) Pain (persistent pain at the final follow-up assessment).

(2) Mortality and complications

(a) Mortality (within the follow-up period of the study).

(b) Fracture healing complications:

- surgical complications of fixation within the follow-up period of the study. This includes non-union of the fracture (the definition of non-union is that used within each individual study, and this outcome includes early re-displacement of the fracture), avascular necrosis and other complications as detailed in each individual study;

- re-operation (within the follow-up period of the study).

(c) Poor anatomical restoration:

- shortening (more than 2 centimetres);
- varus deformity;

- external rotation deformity ( $>20$ degrees).

(d) Post-operative medical complications as detailed in each individual study. These include pneumonia, thromboembolic complications (deep vein thrombosis or pulmonary embolism) and other complications as listed.

(3) Resources

The type of resources considered will depend on the context and stage of rehabilitation. These include length of hospital stay (in days), number of physiotherapy sessions, number of outpatient attendances and need for special care.

(4) Other

These include patient satisfaction and adherence to interventions.

\section{SEARCH METHODSFOR IDENTIFICATIONOFSTUDIES}

See: Cochrane Bone, Joint and Muscle Trauma Group methods used in reviews.

One reviewer $(\mathrm{HH})$ had initially checked the results of a comprehensive search, up to August 1998, for trials on geriatric rehabilitation after fractures in older people for a non-Cochrane review (Cameron 2000). Additional searches of MEDLINE (1998 to August 1999) and EMBASE (January 1999 to September 1999) were undertaken using MeSH headings and text words for hip fracture and rehabilitation. No language restriction was applied.

For this update, we searched the Cochrane Musculoskeletal Injuries Group Specialised Register (to May 2004). The Specialised Register is compiled from multiple databases, including regular searches of the Cochrane Central Register of Controlled Trials in The Cochrane Library, MEDLINE (which combines subject specific terms with the optimal trial search strategy (Alderson 2004)), EMBASE and CINAHL, and handsearch results. For further details see the search strategy in the Group's module in The Cochrane Library.

In addition, we inspected weekly search updates from MEDLINE (April 2002 to week 4 May 2004) and EMBASE (1988 to week 23 2004), and searched the Cochrane Central Register of Controlled Trials (The Cochrane Library Issue 2, 2004), PEDro (http://www.pedro.fhs.usyd.edu.au) to 10 June 2004, the UK National Research Register (Issue 2, 2004), Current Controlled Trials (http://www.controlled-trials.com) to 7 October 2003, various conference proceedings and checked reference lists of articles. No language restrictions were applied.

From April 2002, MEDLINE (OVID WEB) was searched using the following strategy combined with all three levels of the Cochrane optimal trial search strategy (Alderson 2004):

Mobilisation strategies after hip fracture surgery in adults (Review) 
1. exp Hip Fractures/

2. ((hip\$ or ((femur\$ or femoral\$) adj3 (neck or proximal))) adj4

fracture $\$)$.tw.

3. or/1-2

4. Gait/

5. Movement/

6. physical therapy/ or exercise therapy/ or rehabilitation/ or early ambulation/

7. Locomotion/

8. ((early or delayed) adj (weight bearing or mobili\$)).tw.

9. ((quadriceps or muscle or strength or gait) adj (training or retraining)).tw.

10. or/4-9

11. and $/ 3,10$

The generic hip fracture search strategy for EMBASE (1988 to 2004 week 23) is shown in Table 02.

\section{METHODSOF THEREVIEW}

Before this update (Issue 4, 2004), data for the outcomes listed above were independently extracted by all reviewers, and each trial assessed independently, without masking of the study names, for its quality of methodology. Differences were resolved by discussion. For this update, two reviewers independently assessed methodology and extracted data for the four new trials. As Catherine Sherrington is the lead investigator in three newly included trials, the other two named reviewers critically reviewed these trials. Independent data entry into RevMan (RevMan 2003), and presentation and interpretation of these three trials were also performed.

The main assessment of methodology was by the quality of allocation concealment. A further nine aspects of methodology were also scored. Though the scores of the individual items were summed, this was to gain an overall impression rather than for quantitative purposes.

(1) Was there clear concealment of allocation? Score 3 (and code A) if allocation clearly concealed (e.g. numbered sealed opaque envelopes drawn consecutively). Score 2 (and code B) if there was a possible chance of disclosure before allocation. Score 1 (and code B) if the method of allocation concealment or randomisation was not stated or was unclear. Score 0 (and code C) if allocation concealment was clearly not concealed such as those using quasirandomisation (e.g. even or odd date of birth).

(2) Were the inclusion and exclusion criteria clearly defined? Score 1 if text states which patients included and those excluded (including type of fracture). Otherwise score 0.

(3) Were the outcomes of patients who withdrew or were excluded after allocation described and included in an intention to treat analysis? Score 1 if yes or text states that no withdrawals occurred or data are presented clearly showing 'participant flow' which allows this to be inferred. Otherwise score 0 .

(4) Were the treatment and control groups adequately described at entry and if so were the groups well matched, or appropriate co-variate adjustment made? Score 1 if at least four admission details given (e.g. age, sex, pre-injury mobility, function score, mental test score, fracture type, type of surgery) with either no important difference between groups or appropriate adjustment made. Otherwise score 0 .

(5) Were the care programmes other than the trial options identical? Score 1 if text states they were or this can be inferred. Otherwise score 0 .

(6) Was compliance assessed with documentation of patients' actual ambulatory function (specifically weight bearing)? Score 1 if yes. Otherwise score 0 .

(7) Were all the outcome measures clearly defined in the text with a definition of any ambiguous terms encountered? Score 1 if yes. Otherwise score 0 .

(8) Were the outcome assessors blind to assignment status? Score 1 if assessors of anatomical restoration, pain and function at follow up were blinded to treatment outcome. Otherwise score 0 .

(9) Was the timing of outcome measures appropriate? A minimum of 12 months follow up for all surviving patients. Score 1 if yes. Otherwise score 0 .

(10) Was loss to follow up reported and if so were less than $5 \%$ of patients lost to follow up? Score 1 if yes. Otherwise score 0.

Relative risks and 95\% confidence intervals were calculated for dichotomous outcomes, and mean differences and 95\% confidence intervals calculated for continuous outcomes.

\section{DESCRIPTIONOFSTUDIES}

This, the third update of the review, features not only a search update but also an expansion of review scope to cover interventions aimed at initiating and enhancing mobilisation throughout the whole rehabilitation process. Thus, as well as several newly identified studies meeting the revised scope of this review, some of the previously excluded trials that were excluded solely because their interventions started after the early post-operative period are now included.

For this update, six new studies were identified of which one is included (Sherrington 2004), four are excluded (Crotty 2002; Hesse 2003; Lehmann 1961; Tinetti 1999) and one (Magione 2001), found after our search cut-off date, awaits assessment. A full trial report was obtained for one previously ongoing trial, which is now included (Sherrington 2003). Two previously excluded trials (Hauer 2002; Sherrington 1997) evaluating interventions after 
the early post-operative period are also now included. On reconsideration of the inclusion criteria of the review, one other previously ongoing study is now excluded (Allegrante 2001) as is one trial previously awaiting assessment (Johnston 1995). On gaining further information, one trial (Binder 2001) awaiting assessment is now listed as an ongoing study; and another trial (Maltby 2000) was excluded.

In all, 26 studies were considered, 10 of which are included, 10 are excluded for reasons given in the 'Characteristics of excluded studies' table, five are placed in the 'Ongoing studies' section and one in 'Studies awaiting assessment'.

Of the 10 included studies, two were identified from reference lists of trials (Baker 1991; Karumo 1977), one from handsearching (Lamb 2002), two via MEDLINE (Graham 1968; Hauer 2002), one via the National Research Register (Mitchell 2001), two via the Cochrane Musculoskeletal Injuries Group specialised register (Lauridsen 2002; Sherrington 1997) and two were notified by the lead trialist, the contact reviewer of this review (Sherrington 2003; Sherrington 2004). In seven trials, the interventions under test were started in the early post-operative period; some continued after hospital discharge. The other three trials were conducted in a community setting, after in-patient rehabilitation.

Brief details of the trials, ordered by the hypotheses listed in the 'Objectives' are presented below. Aside from Graham 1968, which specified displaced intracapsular fractures, and Karumo 1977, which specified femoral neck fractures, the included trials did not select on type of hip fracture. Further details of the included studies are given in the 'Characteristics of included studies' table.

\section{Early post-operative rehabilitation}

Two trials in this category evaluated the effects of more intensive physiotherapy; each of the other five studies evaluated a different intervention.

Graham 1968 compared weight bearing at two weeks versus 12 weeks after internal fixation of a displaced intracapsular fracture in 273 patients. An interim report for 124 trial participants was available in 1964 (Abrami 1964), with a second report in 1968 (Graham 1968) which presented results for 273 participants at one year and results at three years for the 175 participants who had been followed up by then.

Two trials (Karumo 1977; Lauridsen 2002) tested the effects of intensifying a physiotherapy regimen. Karumo 1977 compared an intensive physiotherapy regime comprising twice daily physiotherapy with a standard regime of once daily physiotherapy in 100 hip fracture patients. Each physiotherapy session lasted an average of 30 minutes and involved training in walking with crutches, sitting, climbing stairs, and flexion and extension exercises of the hip, knee and ankle. Each person in the intervention group was given two physiotherapy sessions each day, each session equivalent to the single session given to the control group. In Lauridsen 2002, intensive physiotherapy, where participants were offered six hours of physiotherapy per week (two hours on Monday, Wednesday and Friday), was compared with standard physiotherapy of 15 to 30 minutes each weekday in 88 women. The contents of the two programmes in Lauridsen 2002 were the same, involving various bench exercises, gait, balance and co-ordination exercises, stair climbing and, occasionally, hydrotherapy.

Sherrington 2003 compared a two-week programme of weightbearing exercise versus a two-week programme of non-weightbearing exercise in 80 patients. Both in-hospital programmes were prescribed by a physiotherapist and adjusted according to the individual patient's capability.

Mitchell 2001 evaluated a quadriceps muscle strengthening regime in additional to conventional physiotherapy in 40 patients. The 40 participants of the control group received conventional physiotherapy alone. The quadriceps exercises, which were undertaken twice weekly for six weeks, comprised three sets of 12 repetitions of knee extension with each leg.

Baker 1991 randomised 20 patients to a treadmill gait retraining programme and another 20 patients to conventional gait retraining. The trial report described the treadmill but did not provide details of the programme involved. Trial participants were only followed up to hospital discharge.

In Lamb 2002, 27 women, aged over 75 years, were randomised to a six week long regime of patterned neuromuscular stimulation versus placebo stimulation for three hours a day, starting one week after surgical fixation.

\section{Continuation/community rehabilitation}

The interventions tested by the three trials in this category all started after hospital discharge.

In Hauer 2002, 57 women aged over 75 years and who had sustained a recent injurious fall were randomised to a 12 week regime of intensive physical training versus placebo motor activity starting on average four to five weeks after surgery upon discharge from in-patient rehabilitation. The results for the sub-group of 28 participants who had had hip surgery are presented in this review. Of these, 25 had surgery for a fall-related hip fracture and three had elective hip surgery. The patient characteristics of the latter three women were confirmed as being essentially similar to those of the 25 women with hip fracture.

In Sherrington 2004, 120 people who had been discharged into the community or an aged-care facility after treatment for a fall-related hip fracture were assessed for study inclusion on average 22 weeks from their injury. Trial participants were randomised to receive one of three interventions: home-based weight-bearing exercises versus home-based non-weight-bearing exercises (performed in the supine position) versus no specific instructions (control group). Exercises in the two intervention groups were prescribed for a minimum of four months. 
Sherrington 1997 compared home-based weight-bearing exercises for one month versus control (no specific instructions) in 44 people, aged 60 years or above, who had been discharged from hospital to home or residential care at an average of seven months from their fall-related hip fracture.

\section{METHODOLOGICAL QUALITY}

The results of the methodological assessment are tabulated below (please see 'Methods' for description of the criteria). Brief accounts of various aspects of trial quality of individual trials are presented in alphabetical order of their study identifier (Trial ID).

\section{Total Trial ID}

00001010002 Baker 1991

11000010104 Graham 1968

311111111011 Hauer 2002

10001010003 Karumo 1977

31011111009 Lamb 1998

31110011019 Lauridsen 2002

31111110009 Mitchell 2001

01000010013 Sherrington 1997

21111110019 Sherrington 2003

31111110009 Sherrington 2004

Baker 1991 was a quasi-randomised trial based on alternate patient allocation at the time of admission (Cochrane code C). Despite the method of randomisation, there was a possibility of allocation concealment in that the patient was allocated "sight unseen". There was lack of information on the type of fractures treated, method of treatment (item 2), baseline patient characteristics (item 4), compliance (item 6) and blinding of outcome assessors (item 8). Follow up was for only the duration of the patient admission with no attempt to determine if the treatment regime had any effect after hospital discharge (item 9). There was insufficient information to determine whether an intention to treat analysis was done (item $3)$.

In Graham 1968, the method of randomisation (item 1) was not stated (Cochrane code B), although there was stratification by age (by decade, 56 to 95 years). There was a lack of information on comparability of baseline characteristics (item 3 ) and care programmes (item 5), and blinding of outcome assessors (item 8). Major methodological flaws of the trial were the incomplete longterm follow up (only 175 of the 273 included patients) and the lack of intention to treat analysis. Trial recruitment and randomisation were at hospital admission, but only those 273 patients who were judged as being suitable, in that they could be expected to walk, at the two weeks clinical assessment were included in the analyses. The number of patients excluded at two weeks was not reported, and though those who were included were continued in the group allocated at randomisation, strictly speaking, intention to treat analyses was not carried out (item 3).
In Hauer 2002, treatment allocation (item 1) was performed by an independent person using a random number system (Cochrane code A). Efforts were made to collect some outcome data (item 3) for the four drop-outs; three of whom did not start the exercises and one who discontinued their exercises. The person performing the outcome assessment was blinded to treatment allocation (item 8). There was a two-year follow up of trial participants (item 9), however separate data for participants who had hip surgery were available only at three months after the end of the trial interventions.

Allocation concealment (item 1) was not reported in Karumo 1977, who used random numbers (Cochrane code B). Though the inclusion criteria were a displaced femoral neck fracture and age over 50 years, the implants used by some of these patients (9 Jewett nails, 1 Rush nail, 1 Kuntscher nail) suggest that some extracapsular fractures were included (item 2). There was a lack of information on baseline characteristics and comparability (item 4), compliance (item 6) and blinding of outcome assessors (item 8). Follow up was only for three months, for mortality (item 9). Intention to treat analysis was not done since the results for 13 patients with inadequate follow up were not presented (item 3).

Concealment of allocation (item 1) was confirmed in Lamb 2002 which used sealed, numbered and opaque envelopes that were opened sequentially (Cochrane code A); there was also stratification by pre-injury mobility. Strictly, intention to treat analyses was not done as the baseline data were not provided for three patients who were excluded (item 3); there was also no indication that these patients were followed up (item 10). Various measures were taken to ensure assessor blinding (item 8). Follow up was for only 13 weeks (item 9).

Randomisation using consecutively drawn numbered sealed opaque envelopes was described by the lead investigator of Lauridsen 2002 on request for further information of trial methods (Cochrane code A). There was a lack of information on care-programme comparability (item 5) and compliance (item 6). Though Lauridsen 2002 scored for assessor blinding (item 8), it is notable that the blinded evaluation was done after non-blinded assessment of whether a patient had reached a threshold level of functional capacity. Follow up was only up to discharge from hospital (item 9).

Trial methodology, patient characteristics and participant flow were well documented in Mitchell 2001. Allocation concealment was very likely in this trial since the sealed envelopes containing the randomly generated group allocation were independently held by a third party who was not otherwise involved in the trial (Cochrane code A). There was however no blinded assessment of outcome (item 8). Only 44 out of the 80 patients entered into the trial completed the final assessment at 16 weeks. Of the 36 patients whose data were missing at 16 weeks, seven had died, 13 had developed a new co-morbidity precluding assessment and 16 had either refused to be assessed or were unavailable. 
The lead trialist of Sherrington 1997 confirmed that the randomisation list, generated using a random numbers table, used for group allocation was not concealed (item 1: Cochrane code C). Though the numbers in the treatment groups at baseline were provided, the post-randomisation exclusion of two participants meant that intention to treat analysis was not done (item 3). Baseline characteristics (item 4) were not comparable: there was a statistically significantly higher number of males in the intervention group (8 versus 1 ). There was a lack of information on care-programme comparability (item 5) and compliance (item 6) was only noted in the intervention group. There was no assessor blinding (item 8). Follow up was for one month only (item 9).

Concealment of allocation (item 1) was likely but not guaranteed in Sherrington 2003, where opaque pieces of paper were used to hide individual's group allocation (Cochrane code B). Intention to treat analyses was done and a participant flow diagram provided (item 3). There was no assessor blinding (item 8). Follow up was for only two weeks (item 9).

Trial methodology, patient characteristics, participant flow and outcomes were well documented in Sherrington 2004. Allocation concealment was considered very likely in this trial (Cochrane code A) where the sealed opaque and numbered envelopes were only opened when the consent form was signed. There was no blinded assessment of outcome (item 8) and trial participants were only followed up for four months; the minimum duration of the exercise programmes (item 9). As well as the loss of data from the seven participants who refused assessment at follow up and the five who died, data were missing for three to six others depending on the functional outcome reported (item 10).

\section{R E S U L T S}

The results of the 10 included trials are presented in the order of the hypotheses listed under 'Objectives'. Where considered appropriate and where data are available, the outcomes of individual trials are presented in the analyses. As well as presenting the results of the four newly included trials (Hauer 2002; Sherrington 1997; Sherrington 2003; Sherrington 2004), the presentation of the results of the six previously included trials has been restructured to conform to the revised categories shown in 'Types of Outcomes'.

\section{Early post-operative rehabilitation}

Weight bearing after internal fixation of an intracapsular bip fracture (Graham 1968) (Graphs 01.01 to 01.04)

Graham 1968 compared weight bearing at two weeks versus 12 weeks after internal fixation of a displaced intracapsular fracture in 273 people. The results for this study were poorly presented and incomplete, both in terms of outcome and the study group. Since three year follow-up data were only available for 175 trial participants, these results are not presented in the summary table.
Data from the interim report (Abrami 1964) are not presented here.

\section{(1) Mobility and function}

There was no report of mobility or other measures of function for this trial.

\section{(2) Mortality and complications}

(a) Mortality

The one-year mortality was $19 / 141$ (13.5\%) in the early weightbearing group versus $24 / 132(18.2 \%$ ) with delayed weight-bearing (relative risk (RR) $0.74,95 \%$ confidence interval (CI) 0.43 to 1.29). The figures for three years were $21 / 85$ (24.7\%) versus $23 / 90$ (25.6\%) (RR 0.97, 95\% CI 0.58 to 1.61). These differences were not statistically significant at both follow-up times.

(b) Fracture healing complications

Non-union was termed failure of fixation and included those fractures in which early re-displacement occurred (early mechanical failure) and those in which the fracture failed to heal. Redisplacement of the fracture occurred in all these cases. At one year from injury, the failure rate for survivors who were followed up was 18/116 $(15.5 \%)$ in the early weight-bearing group versus $14 / 96$ (14.6\%) in the late weight-bearing group (RR $1.06,95 \%$ CI 0.56 to 2.03 ). The failure rates presented for survivors who had been followed up for three years were 13/57 (22.8\%) versus 13/55 (23.6\%) (RR $0.96,95 \%$ CI 0.49 to 1.89 ). None of these differences were statistically significant. These figures exclude trial participants who had died (43/273 at one year, 44/175 at three years), or for whom there was incomplete follow up or who were lost to follow up (13/273 at one year, 16/175 at three years), or those in whom an infection of the hip occurred (5/273 at one year, 3/175 at three years).

Avascular necrosis was termed superior segmental collapse. The incidence at one year in survivors was reported 3/116 (2.6\%) for early weight bearing versus $9 / 96(9.4 \%)$ for the delayed weightbearing group (RR $0.28,95 \%$ CI 0.08 to 0.99 ). The difference was not statistically significant in survivors at three years $(10 / 57$ (17.5\%) versus $14 / 55$ (25.5\%); RR $0.69,95 \%$ CI 0.33 to 1.42 ).

At one year, infections of the hip, reported as septic arthritis, requiring further surgical treatment were reported in two out of 141 people in the early weight-bearing group and three out of 132 people in the delayed weight-bearing group.

(c) Unfavourable outcome

A separate analysis of unfavourable outcome, which includes death, hip infection, non-union and avascular necrosis, shows no statistically significant differences at either one year (42/141 versus 50/132; RR 0.79, 95\% CI 0.56 to 1.10 ) or three years (RR 0.96, $95 \%$ CI 0.73 to 1.25$)$.

(d) Post-operative medical complications

Apart from infection of the hip, reported above, there was no report of post-operative complications aside from the post-randomisation exclusion at two weeks of any person with pulmonary or cardiac complications, deep venous thrombosis and "general feebleness". 


\section{(3) Resources}

These outcomes were not reported.

Intensive physiotherapy regime(Karumo 1977 and Lauridsen 2002) (Graphs 02.01 to 02.05)

Though both trials evaluated an intensification of physiotherapy the interventions were too dissimilar to warrant pooling; there were also no comparable outcome data. These trials are thus presented separately below.

Karumo 1977 compared twice daily physiotherapy (intensive) with once daily physiotherapy (control) in 100 hip fracture patients. The results of Karumo 1977 were generally under-reported; most data being presented either for the overall trial population or split by surgical treatment (prosthesis versus internal fixation) rather than rehabilitation.

In Lauridsen 2002, 88 women with hip fracture were allocated either intensive physiotherapy amounting to six hours maximum per week or standard physiotherapy of approximately two hours per week. In all, 37 trial participants discontinued prematurely for a variety of reasons and thereby failed to complete the stipulated training programme. While Lauridsen 2002 presented "intentionto-treat" and "per protocol" analyses up to discharge from hospital, most of the results were presented as medians and ranges and thus not amenable to statistical examination in this review.

\section{(1) Mobility and function}

Karumo 1977 did not give separate data for the two groups for either walking ability or residence at nine weeks. However, Karumo 1977 reported that there was no "demonstrable" difference in the recovery of the two patient groups in the nine week follow-up period. In this trial, patients were assessed whilst in hospital for their ability to move in bed and sit up in bed on the first postoperative day. Abductor muscle strength and walking ability were assessed at two, four and nine weeks post-operatively. Results at nine weeks for abductor muscle strength showed no statistically significant difference between the two groups (see graph).

While no data were available for analysis, function in Lauridsen 2002 was reported as identical in those of the two groups who completed their training regimen, where $90 \%$ were able to walk with one or two walking sticks at discharge. In contrast only $35 \%$ of people not completing the programme reached this level.

\section{(2) Mortality and complications}

\section{(a) Mortality}

In Karumo 1977, 11 participants, out of a total of 96 (rather than the 100 recruited), died within three months. Some or all of these participants may have been excluded from the analysis as having inadequate follow up. Karumo 1977 reported that there was no difference in mortality between the two groups.

(b) Fracture healing complications

Karumo 1977 reported that 10 participants had mechanical postoperative complications. Ten participants (6 versus 4 ) of Lauridsen 2002 were withdrawn because of "orthopaedic complications" including redisplacement, screw penetration, hip dislocation and femoral head necrosis.

(c) Post-operative medical complications

Nine participants in Karumo 1977 had postoperative wound infection, and one person died of pulmonary embolism; there were no other thromboembolic complications. Karumo 1977 reported that there were no inter-group differences in complications. However, the results for post-operative complications are confounded as antibiotic prophylaxis and antithrombotic prophylaxis were given to only a sub-group of trial participants, 37 and 49 respectively.

\section{(3) Resources}

There was no statistically significant difference in the length of hospital stay between the two groups of Karumo 1977 (see graph). Lauridsen 2002 reported that length of stay (median values 32 versus 34 days) was not statistically different between the two groups when intention-to-treat analysis was undertaken, but was significantly less (median values: 25 versus 32 days; $\mathrm{P}$ ( 1 sided $)=$ 0.03 ) in the intensive group for people completing the training regimen (per protocol analysis).

\section{(4) Other}

Almost twice as many participants in the intensive group of Lauridsen 2002 failed to complete their training regimen (24/44 versus 13/44; relative risk (RR) 1.85, 95\% confidence interval (CI) 1.09 to 3.14 ). Notably more participants in the intensive group voluntarily quit the training programme, mainly because the programme exceeded their "physical or psychical capacity" (6/44 versus 1/44; RR $6.00,95 \%$ CI 0.75 to 47.81 ). Though participants in the intensive group were offered six hours of physiotherapy per week (expected training intensity of 0.86 hours/week), generally the uptake was less, even for the 20 completing the training programme: the median training intensity in the intensive group was 0.5 hours/day in both cases. Nonetheless training intensity was reported as statistically significantly greater in the intensive group (median intensity: 0.5 versus 0.2 hours/day; reported P ( 1 sided) $=0.000005)$.

Weight-bearing exercise programme versus non-weight-bearing exercise programme(Sherrington 2003) (Graphs 03.01 to 03.10) Sherrington 2003 compared a two-week programme of weightbearing exercise versus non-weight-bearing exercise in 80 patients. Outcome was assessed at the end of the two week programmes. The data for three trial participants, one who withdrew consent in the weight-bearing group and two with actual or suspected problems with fracture fixation in the non-weight-bearing group, were generally not provided in Sherrington 2003. Results for outcome measures, such as sway, that were measured only in a subgroup of participants are not presented here.

\section{(1) Mobility and function}

By the end of two weeks, there were marginally significantly fewer participants of the weight-bearing exercise group unable to walk unassisted or using just one walking stick (33/41 versus 39/39; RR 
$0.85,95 \%$ CI 0.72 to 1.00 ), and statistically significantly fewer unable to a lateral step-up on the fractured leg with nil or one hand support (18/40 versus 30/37; RR 0.56 , 95\% CI 0.38 to 0.81 ). None of the differences between the two groups in the other objective measures of mobility and function (gait parameters; an overall physical performance and mobility score; strength; and balance) were statistically significant (see graphs). This finding applied also to subjective ratings of pain, perceived risk of falls, balance, sleep quality and general health (see graph). However, there was some consistent tendency for better balance in the weight-bearing exercise group.

\section{(2) Mortality and complications}

No deaths or medical complications were reported in Sherrington 2003. Two participants in the non-weight-bearing group were unable to complete the trial due to actual or suspected fracture healing complications.

\section{(3) Resources}

There was no difference between the two groups in the length of stay in the in-patient rehabilitation ward (24.1 versus 25.2 days); nor in hospital (36.2 versus 38.5 days: see graph).

\section{(4) Other}

Similar numbers of participants in the two groups found the exercises difficult or very difficult (14/40 versus 12/37), experienced moderate or worse pain while performing the exercises (17/40 versus $18 / 37$ ), and had some doubts on the usefulness of the exercises (12/40 versus $7 / 37)$.

Quadriceps training programme (Mitchell 2001) (Graphs 04.01 to 04.02 )

Mitchell 2001 evaluated the addition to conventional physiotherapy of a quadriceps muscle strengthening programme over a six week period in 80 patients. Outcome was assessed at six weeks in 59 participants and 16 weeks in 44 participants.

\section{(1) Mobility and function}

Leg extensor power was significantly greater in both the fractured and non-fractured legs of intervention group participants compared with control group participants at six weeks (see graph). Functional mobility was reported to be significantly better by six weeks in the intervention group (difference in Elderly Mobility Scale score: reported $\mathrm{P} \leq 0.001$ ). Aside from statistically significant differences in favour of the intervention group in the Barthel index (reported $\mathrm{P} \leq 0.05$ ) and functional reach (reported $\mathrm{P} \leq$ 0.001 ), none of the differences in the other reported outcomes (grip strength, timed up and go, gait speed and select components of the Nottingham Health Profile: emotional reactions, energy, pain, physical mobility, sleep, social isolation) reached statistical significance at six weeks. The significant difference in leg extensor power at six weeks was still evident 10 weeks later (see graph). Functional mobility also remained significantly better in the intervention group at 16 weeks (difference in the Elderly Mobility Scale score: reported $\mathrm{P} \leq 0.05$ ). The statistically significant dif- ference in favour of the intervention group at six weeks in the Barthel index was not evident at 16 weeks but functional reach remained better in the intervention group (reported $\mathrm{P} \leq 0.001$ ). There was an absence of statistically significant differences in the other reported outcomes with the exception of the 'energy' component within the Nottingham Health Profile: the 'energy' scores were better for the intervention group at 16 weeks (reported $\mathrm{P}=$ 0.0185 ), although they had not been at the end of treatment at six weeks.

\section{(2) Mortality and complications}

Four out of 40 participants in each group had died by 16 weeks. Neither fracture healing complications nor post-operative complications were reported in Mitchell 2001.

\section{(3) Resources}

The intervention group participants attended a median of 11 sessions of quadriceps training (range 10 to 12 sessions). There was no difference reported in hospital stay; this was reported to be a median of 39 days in the quadriceps training group and 40 days in the control group.

Treadmill gait retraining programme (Baker 1991) (Graphs 05.01 to 05.02 )

This study compared a treadmill gait retraining programme with conventional gait retraining in 40 elderly women with a hip fracture. Measures of outcome were primarily patient mobility, and gait analysis undertaken during the patient's stay in the rehabilitation hospital, with results being reported for the time of discharge.

\section{(1) Mobility and function}

Though the participants of the treadmill group were reported as having a significantly higher $(\mathrm{P}<0.05)$ level of mobility than those in the control group, the available data do not show the differences to be statistically significant. Fewer treadmill group participants failed to regain their pre-fracture mobility level (7/20 versus 12/20; RR $0.58,95 \%$ CI 0.29 to 1.17 ). There was no difference in the gait parameters (mean difference in gait velocity based on data extracted from a graph was 2.10 metres/minute; $95 \%$ CI -8.94 to 13.14).

Comprehensive gait analysis results were only presented for a subgroup of 12 participants, consisting of six "treadmill-control pairs", who were matched "for number of predictors of poor outcome". The results for this subgroup are not presented here.

Baker 1991 stated that the overall return home rate was " $80.5 \%$ " which may have been a printing error as this does not correspond to a whole number of participants, or may have resulted from an undeclared loss of trial participants from the analyses. There was no report of any other long-term outcomes including those of function and quality of life measures.

\section{(2) Mortality and complications}

No deaths were reported as occurring during hospital stay. Neither fracture healing complications nor post-operative complications were reported in Baker 1991. 


\section{(3) Resources}

Mean length of hospital stay was 54 days for the treadmill group versus 67 days for the control group, a difference that was reported as not being statistically significant.

Patterned neuromuscular stimulation of quadriceps muscle (Lamb 2002) (Graphs 06.01 to 06.05)

This study compared patterned neuromuscular stimulation of the quadriceps muscle with placebo stimulation in 27 elderly women with hip fracture. The results for 24 participants were reported. The three other participants did not complete the trial; two required further hospitalisation due to myasthenia gravis and severe chest infection respectively, and the other withdrew her consent.

\section{(1) Mobility and function}

None of the differences between the two groups at seven weeks after surgery, marking the end of the six week stimulation regimen, in Lamb 2002 reached statistical significance. However, half as many stimulation group participants compared with placebo group participants had not regained their pre-fracture mobility (5/12 versus $10 / 12$; RR $0.50,95 \%$ CI 0.24 to 1.02 ), fewer were unable to 'tandem stand', a measure of postural stability (4/12 versus $9 / 12$; RR 0.44 , 95\% CI 0.19 to 1.05 ) and their leg extensor power in the fractured limb was greater (mean difference $0.17 \mathrm{~W} / \mathrm{kg}, 95 \%-0.10$ to $0.44 \mathrm{~W} / \mathrm{kg}$ ) The two participant groups had very similar mean walking speeds (gait velocity) and identical mean pain scores at seven weeks.

At final follow up, 13 weeks after surgery and six weeks post intervention, the difference between the two groups in the numbers of participants who had regained their former mobility was statistically significantly in favour of the stimulation group (failure to regain mobility: $3 / 12$ versus $9 / 12$; RR 0.33 , 95\% CI 0.12 to $0.94)$. Though consistently favouring the stimulation group, none of the differences in the other outcomes measured were statistically significant. There was some indication of a continued improvement between seven and 13 weeks in leg extensor power in the injured limb and associated improvement in walking speed in the stimulation group compared with the placebo group.

\section{(2) Mortality and complications}

These outcomes were not reported in Lamb 2002.

\section{(3) Resources}

These outcomes were not reported in Lamb 2002.

\section{(4) Other}

Compliance was reported to be over $75 \%$, with no difference between the two groups.

\section{Continuation/community rehabilitation}

Twelve-week intensive physical training versus placebo activities after discharge from in-patient rehabilitation (Hauer 2002) (Graphs 07.01 to 07.09 )

In Hauer 2002, 28 women, aged over 75 years and home-dwelling prior to hospital admission, were randomised to 12 weeks of inten- sive physical training versus placebo motor activity starting about four to five weeks after surgery upon discharge from in-patient rehabilitation. Aside from loss of social independence, outcome data at six-months follow up were not available for four trial participants; three of these (two in the intervention group versus one in the control group) did not start with the group sessions after randomisation, and the fourth participant dropped out of training "because of motivational reasons". Follow-up data were also collected at the end of the 12-week training period. The results presented here generally apply to the six-month follow up, taking place three months after the termination of the training.

\section{(1) Mobility and function}

Participants of the intensive physical training group had faster walking velocity (mean difference $0.23 \mathrm{~m} / \mathrm{sec}, 95 \%$ CI 0.05 to 0.41 ) and tended to have larger box step values than those participating in placebo activities (see graph). Though the results of the performance oriented mobility assessment also favoured the intensive training group, none of the differences were statistically significant (see graph). At the end of follow up, three intervention group participants had moved to relatives or a nursing home compared with four in the control group. Nonetheless, the Barthel's activities of daily living (ADL) and Lawton's instrumental ADL results indicated high levels of independence and functional competence in both groups at six-months follow up. Self-reported physical activity which was low at baseline in both groups, though slightly higher in the intensive group, increased during the training period in the intensive group but was diminishing back to the baseline values by six-months follow up. The statistically significantly difference for self-reported total activity at six months between the two groups has to be set into the context of the already low readings for the trial participants. Intensive group participants did better in the functional performance tests, in particular in stair climbing performance (time for stair rise; mean difference -7.80 seconds, $95 \%$ CI -15.14 to -0.46 seconds). Strength measures were consistency higher in the intensive training group and differences between the two groups were statistically significantly different for leg extensor muscle strength (see graph). There were no statistically significant differences in the objective measures of balance. However, participants in the intensive group had significantly better Fall Handicap Inventory scores, were less fearful of falling, and felt steadier (see graph). There was no difference between the two groups in overall feeling of depression, nor in morale.

\section{(2) Mortality and complications}

No deaths were reported in Hauer 2002 by six-months follow up. Eleven of the 57 participants in Hauer 2002 had died by twoyears follow up but separate mortality data for the 28 hip surgery patients were not available. Hauer 2002 reported that no major health problems occurred during training or testing and that all the minor problems, including knee pain and wound/scar aching, were resolved by adjustment of training and physiotherapy.

\section{(3) Resources}


There was no mention of costs in Hauer 2002. It should be noted that the group sessions provided in Hauer 2002 to both groups were on top of twice weekly sessions of physiotherapy provided to all trial participants.

(4) Other

As stated above, two intensive group participants and one control group participant did not start their allocated group sessions, and a further intensive group participant gave up after starting. Adherence to the group activities was high in both groups (see graph). The provision of transport to training locations may have helped in this regard. Hauer 2002 estimated that the training intervention more than doubled the total physical activity in the intensive therapy group; however, as reported above, the physical activity level of this group returned to almost baseline levels after training had ceased.

Four-month long home-based exercise programmes started 22 weeks after hip fracture (Sherrington 2004)

The 120 participants in Sherrington 2004 were randomised to receive one of three interventions: home-based weight-bearing exercises versus home-based non-weight-bearing exercises (performed in the supine position) versus no specific instructions (control group). Exercises in the two intervention groups were prescribed for a minimum of four months. The results from this trial are presented for four comparisons: (1) a home-based exercise programme (either weight or non-weight-bearing exercises) versus control; (2) weight-bearing exercise programme versus control; (3) non-weight-bearing exercise programme versus control; (4) weight-bearing versus non-weight-bearing exercise programmes. Trial participants were assessed at one and four months; the results from four months are presented here.

A bome-based exercise programme (either weight or nonweight-bearing exercises) versus control (Graphs 08.01 to 08.09)

\section{(1) Mobility and function}

There were no statistically significant differences between participants allocated home-based exercises and those in the control group in various measures of mobility, in gait parameters, or in measures of physical or functional performance (see graphs). There were also no statistically significant differences between those allocated exercises and those in the control group for various objective measures of strength or balance (see graphs). This finding applied also to subjective ratings of pain, perceived risk of falls, sleep quality and general health; there were, however, statistically significantly fewer people in the exercise groups reporting unsteady balance (53/72 versus 32/36; RR $0.83,95 \%$ CI 0.69 to 0.99$)$. There was no statistically significant difference in the numbers who fell at least once during the intervention period. Despite these statistically non-significant findings for individual outcomes, there is a consistent picture of better mobility, balance and strength in the combined exercises groups.

(2) Mortality and complications
Five deaths (four in the exercises groups and one in the control group) were reported in Sherrington 2004. Four people were reported as being unable to complete the physical assessment at four months because of ill health. It should be noted that Sherrington 2004 already had excluded people with medical conditions and complications from the fracture resulting in delayed healing and associated weight-bearing restrictions.

\section{(3) Resources}

There was no mention of costs in Sherrington 2004.

\section{(4) Other}

At the end of the trial period, $29 \%$ of those assessed in the exercises groups were doing the exercises less than three times weekly. This includes 19\% who had given up completely. There was no monitoring of the use of home-based exercises in the control group.

A home-based weight-bearing exercise programme versus control (Graphs 09.01 to 09.09)

\section{(1) Mobility and function}

There were no statistically significant differences between participants allocated home-based weight-bearing exercises and those in the control group in various measures of mobility, in gait parameters, or in measures of physical or functional performance (see graphs). Though the six measures of muscle strength were consistently better in the weight-bearing group, only difference in the values for knee extension of the fractured leg reached statistically significance (mean difference 40 newtons; 95\% CI 4.50 to 75.50 newtons). Objective measures of balance also favoured the exercise group but none were statistically significant. There were no statistically significant differences in subjective ratings of pain, perceived risk of falls, balance, sleep quality and general health; nor in the numbers who fell at least once during the intervention period.

\section{(2) Mortality and complications}

Four deaths (three in the exercises group and one in the control group) were reported in Sherrington 2004.

\section{(3) Resources}

There was no mention of costs in Sherrington 2004.

\section{(4) Other}

At the end of the trial period, $31 \%$ of those assessed in the exercises group were doing the exercises less than three times weekly. This includes $20 \%$ who had given up completely. There was no monitoring of the use of home-based exercises in the control group.

\section{A home-based non-weight-bearing exercise programme versus control (Graphs 10.01 to 10.09 )}

\section{(1) Mobility and function}

There were no statistically significant differences between participants allocated home-based non-weight-bearing exercises and those in the control group in various measures of mobility, in gait parameters, or in measures of physical or functional performance 
(see graphs). There were also no statistically significant differences between those allocated exercises and those in the control group for various objective measures of strength or balance (see graphs). This finding applied also to subjective ratings of pain, perceived risk of falls, balance, sleep quality and general health (see graph). There was no statistically significant difference in the numbers who fell at least once during the intervention period.

\section{(2) Mortality and complications}

Two deaths (one in the exercises group and one in the control group) were reported in Sherrington 2004.

(3) Resources

There was no mention of costs in Sherrington 2004.

\section{(4) Other}

At the end of the trial period, $27 \%$ of those assessed in the exercises group were doing the exercises less than three times weekly. This includes $19 \%$ who had given up completely. There was no monitoring of the use of home-based exercises in the control group.

Home-based weight-bearing versus non-weight-bearing exercise programmes (Graphs 11.01 to 11.10 )

\section{(1) Mobility and function}

There were no statistically significant differences between participants allocated home-based weight-bearing exercises and those allocated weight-bearing exercises in various measures of mobility, in gait parameters, or in measures of physical or functional performance (see graphs). There were also no statistically significant differences between those allocated exercises and those in the control group for various objective measures of strength or balance; with the exception of functional reach which was better in the weightbearing group (mean difference $4.90 \mathrm{~cm}$; $95 \%$ CI 0.87 to 8.93 $\mathrm{cm}$ ) (see graphs). The lack of statistically significant differences applied also to subjective ratings of pain, perceived risk of falls, balance, sleep quality and general health (see graph). There was no statistically significant difference in the numbers who fell at least once during the intervention period.

\section{(2) Mortality and complications}

Four deaths (three in the weight-bearing exercises group and one in the non-weight-bearing exercises group) were reported in Sherrington 2004 .

\section{(3) Resources}

There was no mention of costs in Sherrington 2004.

\section{(4) Other}

Though the differences did not reach statistical significance, more participants of the weight-bearing exercises group compared with the non-weight-bearing exercises group reported difficulty doing the exercises $(6 / 35$ versus $0 / 37)$ and experienced pain during these $(10 / 35$ versus $5 / 37)$ at the end of the trial period. Similar numbers in the two groups considered the exercises were not useful (10/35 versus 9/37); this is perhaps reflected in the similar numbers that were doing the exercises less than three times weekly (11/35 versus $10 / 37)$, including those not doing them at all (7/35 versus $7 / 37)$.

One month of home-based weight-bearing exercises started seven months after hip fracture(Sherrington 1997) (Graphs 12.01 to 12.05 )

Sherrington 1997 compared a one-month programme of homebased weight-bearing exercises versus usual care (no specific instructions) in 44 people, aged 60 years or above, who had been discharged from hospital to home or residential care at an average of seven months after their hip fracture. The data for four participants, two of whom withdrew consent and two others who were excluded because of poor mental or physical health respectively, were not provided. Trial participants were assessed at one month, on completion of the trial intervention.

\section{(1) Mobility and function}

At follow up, there were no statistically significant differences between the two groups in the ability to weight bear unassisted nor in two measures of gait (velocity and cadence); see graphs. Quadriceps strength was significantly greater in the intervention group (mean difference fractured leg $3.10 \mathrm{~kg} ; 95 \%$ CI 0.41 to 5.79 ). There were no statistically significant differences between the two groups in objective measures of postural control nor in subjective ratings of balance and fall risk (see graphs). Fall data were not collected by Sherrington 1997.

\section{(2) Mortality and complications}

No deaths were reported in Sherrington 1997. One person in the control group was unable to complete all the physical tests at follow up because of pain due to a fall, later diagnosed as a further fracture.

\section{(3) Resources}

There was no mention of costs in Sherrington 1997. However, the stepping blocks, comprising telephone books wrapped in packing tape, used in the intervention group were inexpensive and all intervention participants chose to keep these after the completion of the trial.

\section{(4) Other}

The mean number of days of exercise was 24.7 days (range 18 to 30 days) in the intervention group. The control group participants were not asked whether they performed similar exercises. Two people in the intervention group participated in gentle exercise class/ activities and one in the control group attended a hydrotherapy class.

\section{DISCUSSION}

Our review now covers mobilisation strategies implemented at any stage during rehabilitation after hip fracture surgery. The evidence from randomised and quasi-randomised trials comprises 10 trials involving 880 participants. Only two trials tested comparable 
interventions; even so, no pooling of data from these was possible. In effect, our review is a critical appraisal and summary of 10 usually small and, in some cases, flawed trials and thus a cautious interpretation of the findings is necessary.

Our search for trials was comprehensive but it is likely that we have missed some. The recent discovery of Magione 2001, presently awaiting assessment, with preliminary results published in a conference abstract demonstrates a potential source of trials; others (e.g. Maltby 2000) may not have even got this far. There are also five ongoing trials, including up to 600 participants, that are likely to be included in subsequent review updates.

Our focus on mobilisation strategies after hip fracture surgery has resulted in the exclusion of trials such as Allegrante 2001 and Tinetti 1999 that tested multifactorial intervention and other trials that primarily focussed on elective hip surgery. The reason for excluding the first category is that it is not possible to separate out the effects of the mobilisation component of multifactorial interventions. Although the aim of these trials is to restore/augment function, we have kept our focus on mobilisation and mobility. These latter remain key objectives for people after hip fracture surgery. The exclusion of trials focussing on elective hip replacement surgery reflects that these populations differ in important ways to the generally older and frailer populations sustaining a hip fracture.

One key reason for the scarcity of trials may be because the evaluation of rehabilitation interventions is difficult to do well. These are generally complex interventions with considerable variation in practice including the often adaptive nature of rehabilitation, where treatment is varied according to the perceived needs and progress of individual patients. Some aspects of trial methodology, notably concealment of allocation, are always possible but others, such as blinding and avoiding confounders are more of a challenge for these trials. In the following accounts of the 10 included trials, one frequent comment is on the short-term nature of the outcome assessment. (Follow up was less than one year in eight trials.) In particular, the follow up of patients only up to the end of the intervention, while administratively convenient, could give misleading results; and the question of whether the effect of the intervention persists in the longer term remains.

Various choices have arisen in the compilation of the analyses of this review. Generally, the results at final follow up rather than 'change scores' (change from baseline) have been presented. This can result in a disparity between the results presented here for individual trials and their trial reports. Though disconcerting, we opted for a consistent approach in the review and these disparities perhaps more underline that these are small trials where randomisation is unlikely to achieve populations that are comparable in all key characteristics.

This review also presented another dilemma resulting from one of the reviewers (Catherine Sherrington) being the lead investiga- tor of three newly included trials (Sherrington 1997; Sherrington 2003; Sherrington 2004). We considered it was important that not only quality assessment and data extraction of these three trials were carried out independently by the other two reviewers but that this also applied to the decisions regarding the presentation of the results and their interpretation. While this avoided conflict of interest, it had the disadvantage that we downplayed the potential advantages of Sherrington's insights on the results of her three trials.

\section{Weight bearing after internal fixation of an intracapsular hip fracture}

We have not identified any randomised trial that adequately addresses this issue. The one identified study included in this review (Graham 1968) used a method of internal fixation (sliding nail plate) that is generally no longer used to treat this fracture. In addition, the trial used a two-week period of bed/chair rest prior to mobilisation for all participants. Current practice is to mobilise patients immediately after surgery. Because of these factors it is difficult to see how the results of this study could be translated to current practice.

In the limited results presented by Graham 1968, there was only a statistically significant difference in the incidence of avascular necrosis at one year. The results for non-union, infection and mortality, and overall unfavourable outcome all suggest there is no difference between a policy of early weight bearing (at two weeks) and later weight bearing (at 12 weeks). The poor trial methodology, limited number of participants and incomplete ascertainment of outcome mean that clinically important difference cannot be excluded.

\section{Intensive physiotherapy regimen}

In practice, routine or standard physiotherapy is not a fixed item and there is considerably variety, for instance in the timing, extent and nature of the physiotherapy. This is illustrated by the differences between the two trials in this category, both of which aimed to investigate an intensification of physiotherapy. It is noteworthy that the routine regimen of 30 minutes physiotherapy each day for the control group of Karumo 1977 would be considered by some to be more than the standard for many patients after a hip fracture. The control group of Lauridsen 2002 were scheduled for 15 to 30 minutes physiotherapy each week day and had a median of 12 minutes per day.

Karumo 1977 was a small trial that may have been seriously compromised by poor methodology. One concern is the exclusion of the results of 13 out of the 100 trial participants on the basis of incomplete follow up. It is certain that some of these people died and others may have had other adverse outcomes. Another concern is that the care programmes post-randomisation were not equivalent; most importantly a variety of surgical operations were undertaken but also only some of the trial population were given antibiotic and antithrombotic prophylaxis. Though it was claimed in the trial report that there was "no difference" in the general 
clinical data between the two groups, the differences in the perioperative care programmes may have meant that the two groups of participants were not matched. Data were not available to confirm or refute this. Karumo 1977 also had inadequate follow up and failed to present comprehensive quantitative results to enable confirmation of their conclusions, namely of the similarity in outcome of the two groups and thus the lack of evidence to show a benefit from a more intensive physiotherapy regimen.

Lauridsen 2002 also was a small trial with an inadequate duration of follow up. Nearly half of the participants withdrew from the trial and did not complete the training programme; significantly more drop-outs were in the intensive group. As well as more participants opting out because they could not cope with the intensification of training, participants in the intensive group generally did not take up the offer of six hours (as opposed to 2 hours) of physical therapy per week. Dropouts/those not completing the training regimen in both groups were worse off than those completing the training programme in terms of ambulation at hospital discharge. While those completing the programme in the intensive group attained comparable functional levels earlier, in terms of a reduction in length of stay, there was no indication that this applied for the overall group. The main message from this trial is that the particular intensification regimen on offer in Lauridsen 2002, comprising two hours of physiotherapy on Monday, Wednesday and Friday, was beyond the capacity of some patients and rarely taken up to the full amount even in those patients who had completed training.

\section{Weight-bearing exercise programme versus non-weight-bear- ing exercise programme}

The main outcome assessment of Sherrington 2003 took place at the end of the two-week exercises programmes. It cannot be assumed that the improvement in mobility, reflected by a potential improvement in the ability to walk unassisted or with just one stick as well as the improved ability to perform a lateral step-up on the fractured leg found in the weight-bearing exercise group at two weeks, was maintained over time. The possible tendency for improved balance in the weight-bearing group at two weeks also may not have persisted subsequently. The insufficient follow up in this trial precludes a conclusion on the relative effectiveness of the two programmes under test. As suggested in Sherrington 2003, a programme comprising a combination of weight-bearing and non-weight-bearing exercises is also not ruled out.

\section{Quadriceps training programme}

The length of follow up was too short and number of participants in the study of Mitchell 2001 too few to draw any definite conclusions. In addition, the absence of data from $45 \%$ of the randomised participants at final follow up means that any findings of enhanced muscle strength and better mobility scores must be considered provisional. The failure to blind study assessors may also lead to potentially biased results. The clinical implications of the higher values of leg extensor power achieved after quadriceps training, the better mobility and Barthel scores are also not established.

\section{Treadmill gait retraining programme}

Baker 1991 was a small trial with flawed methodology, an incomplete description of the interventions under test, and a limited assessment of outcome together with inadequate follow up. Thus it not possible to draw any conclusions on overall effect of treadmill gait training compared with conventional gait training. However, more participants of the training group recovered their pre-fracture mobility and there was a tendency to a reduced length of hospital stay in this group. Thus there remains a potential for treadmill training to enhance the recovery of mobility of hip fracture patients, and given this, further research seems merited.

\section{Patterned neuromuscular stimulation of quadriceps muscle}

Lamb 2002 was a small study with a length of follow up too short to allow conclusions on the effectiveness of this treatment method. The limited results presented indicated that the neuromuscular stimulation was fairly well tolerated by the women. The stimulator was designed for home use, being portable and independent of an electric supply. Quantitative data provided in the full trial report supported claims that neuromuscular stimulation improved mobility after surgical fixation of a hip fracture; there was some indication that the effect persisted after the end of the six weeks regimen. As the study authors recognised, larger pragmatic studies with longer term follow up are needed to establish whether the potential short term gains in mobility "translate into long-term benefits".

Twelve-week intensive physical training versus placebo activities after discharge from in-patient care

Participants who adhered to the intensive training programme in Hauer 2002 had superior mobility and functional motor performance, muscle strength, and fewer fall-related behavioural problems. Though the level of physical activity in the intensive training group dropped to almost baseline levels three months after the cessation of training, there was some persistence in the improvements in muscle strength and some other variables in this group. Only minor adverse effects were reported and there were none that could not be resolved. Thus, this well-conducted trial provides some reasonable evidence of the potential benefits of intensive physical training after hospital discharge. There are, however, some aspects of the trial that caution against drawing these conclusions. Firstly, the trial is small and the effect on the favourable finding of an intention to treat analysis where the results of four participants ( $14 \%$ of the trial population) are included may potentially diminish the differences between the two groups. Secondly, the control group received no strength and balance training at all; this was excluded from the routine physiotherapy provided to both groups. Thus, the question tested by the trial could be interpreted as whether strength and balance training is effective rather than whether intensive physical training is effective. Furthermore, though the choice by Hauer 2002 to remove the strength and bal- 
ance training from the routine physiotherapy is an understandable one, it does give problems regarding applicability to other settings where strength and balance training are part of the routinely-provided physiotherapy for such patients. The provision of transport to attend training sessions seemed to have paid dividends in terms of adherence in this trial and perhaps should be taken on board as a general principle.

Persistence or otherwise of training effects is a question that hangs over some of the other trials included in this review. Hauer 2002 gave some evidence of an often diminished but still persisting effect after three months. The real implications of this, in terms of actually mobility, quality of life and sustained functional independence in people aged 75 years or older who are already fairly frail and mainly sedentary, cannot be assessed here from the small sample available. The finding that the increased level of physical activity during the intensive training period did not persist after training ended supports Hauer 2002's call for a continuing intervention but the nature of this is not established by this trial.

Four-month long home-based exercise programmes started 22 weeks after hip fracture

Based on measures of improvement from baseline assessment rather than final outcome measures, Sherrington 2004 concluded that "a weight-bearing home exercise program can improve balance and functional ability to a greater extent than a non-weight bearing program or no intervention among older people who have completed usual care after a fall-related hip fracture." These conclusions are not supported by the analyses of the evidence as presented in this review. Though the majority of both objective and subjective outcome measures show no statistically significant differences for either of the four comparisons, the consistency of the results for mobility, functional, strength and balance outcomes gives some indication of possible benefit of an home-based exercise programme, whether weight-bearing or non-weight-bearing. However, the loss to follow up, the short-term follow up and the lack of assessor blinding could distort these findings and it is notable that over a quarter of those in the two exercise groups who were assessed considered that the exercises were not even of moderate usefulness.

Differences between weight-bearing and non-weight-bearing exercise groups were also not statistically significant. It is noteworthy that the weight-bearing exercises, which involve exercises that are more relevant to activities of daily life, did not appear to enhance physical performance and, while not evidently associated with a greater risk of falling, were judged as more difficult and painful to do by participants. However, this comparison, like the others, is underpowered and more evidence is required to establish the benefits or otherwise of home-based exercises and whether an emphasis on weight-bearing exercises is appropriate.

A comparison of weight-bearing exercises versus either nonweight-bearing exercises or no exercises was considered, based on the clinical impression of the lead investigator (Sherrington 2004a) of this trial that non-weight-bearing exercises were relatively ineffectual. Due to the aforementioned concern of bias arising from a potential conflict of interest, this comparison has been placed in reserve until the inclusion of another trial testing a similar comparison.

One month of home-based weight-bearing exercises started seven months after hip fracture

Sherrington 1997 was another too small study, further compromised by a lack of masking of allocation and of outcome assessment, and a short follow up. The only statistically significant finding was in the greater quadriceps strength of the intervention group; this may have reflected the higher proportion of males in this group. Though compliance in the intervention group was good, there was insufficient monitoring, especially of falls, to confirm that the intervention was safe.

\section{AUTHORS' CONCLUSIONS}

\section{Implications for practice}

There is insufficient evidence from randomised trials to determine the effects of early weight bearing, in particular after the internal fixation of an intracapsular proximal femoral fracture.

There is insufficient evidence from randomised trials to determine the effects of any particular mobilisation strategy or programme started either in the early or later rehabilitation period after hip fracture surgery.

Clearly, intervention is required to restore and enhance mobilisation in older people after surgery for hip fracture. The interventions chosen should match the needs of individual patients and be based on agreed local practice guidelines. Such guidelines, which should acknowledge and allow for the insufficiency of the underlying evidence to inform practice, should also include consideration of the continued risk of further falls and fractures and potential for functional decline in this often frail patient population.

\section{Implications for research}

The presence of five ongoing trials points to the importance of maintaining this review, but further primary research is also required. Such research should focus on interventions that may have a beneficial overall, long-term impact.

An important question is whether the potential benefit of early weight bearing after fixation with contemporary implants is offset by late fixation failure or aseptic necrosis.

Trials investigating the timing, duration, intensity and form (in particular the use of weight-bearing exercises) of interventions are also warranted. Such studies could also investigate whether differing responses to interventions occur among different subgroups of 
hip fracture patients: for instance, the more frail versus more physically able. Lessons from the literature on fall prevention (Gillespie 2004) and strength training (Latham 2004) in older people may be applicable to rehabilitation after hip fracture surgery.

Different post-operative and later rehabilitation mobilisation strategies would be best assessed within good quality randomised trials that have long-term (one year or more) and comprehensive follow up, including resource consumption.

Development of a standard portfolio of validated and patientorientated outcome measures for trials would enable meta-analysis of the results of future trials.

\section{NOTES}

This review is an expansion of the scope of the review described in the title of the protocol 'Early weight bearing and mobilisation after internal fixation of intracapsular proximal femoral fractures in adults'.

The main changes for the first update of this review, published Issue 2, 2002, were:

(1) Date of search for trials was extended to February 2002

(2) One new study (Mitchell 2001) of quadriceps muscle training was included

(3) Of the other seven newly identified studies, one was excluded, two were placed in 'Ongoing Studies' and four were placed in 'Studies Awaiting Assessment'

(4) There was no substantive change to the conclusions of the review

The main changes for the second update of this review, published Issue 1, 2003, were:

(1) Date of search for trials was extended to October 2002.

(2) One new study (Lauridsen 2002) evaluating intensive physiotherapy was included.

(3) Two newly identified studies were excluded (Barber 2002; Hauer 2002).

(4) Additional details/results were added from the full publication of Lamb 2002, formerly Lamb 1998.

(5) Availability of the full publication of Kuisma 2002, formerly Johnstone 1999, resulted in its exclusion.

(6) The identification of 3 more ongoing trials (Cameron 2004; Crotty 2003; Sherrington 2002).

(7) There was no substantive change to the conclusions of the review.

The main changes for the third update of this review, published Issue 4, 2004, are listed under 'Most recent changes'. As planned, the scope of the review has been expanded to cover interventions aimed at initiating and enhancing mobilisation throughout the whole rehabilitation process. Due to a potential conflict of interest resulting from the inclusion in this update of three trials for which Catherine Sherrington was the lead investigator, Helen Handoll has taken over the role of contact reviewer.

\section{POTENTIAL CONFLICTOF I N T E R E S T}

None known.

\section{ACKNOWLEDGEMENTS}

We thank the following for their comments and help at editorial review of the first version: Prof William Gillespie, Prof Harley Gray (external referee: review only), Mr Peter Herbison (review only), Prof James Hutchison (external referee: protocol only), Prof Rajan Madhok, Ms Leeann Morton, Prof Gordon Murray (protocol only), Mr Anthony Pohl (external referee: review only) and Prof Marc Swiontkowski. We also thank Ms Hilda Bastian for her help with the Synopsis.

For the first update, we thank Mrs Lesley Gillespie for her help with the search strategy and trial retrieval, and Ms Leeann Morton and Prof William Gillespie for their help at editorial review.

We thank Dr Yvonne Dynan for her contribution to the first two versions of the review and Ms Pernille Jensen for checking over a study report in Danish.

Helen Handoll's work on the first two versions of the review was supported by the Chief Scientist Office, Department of Health, The Scottish Office, UK.

For the second update, we thank Mrs Lesley Gillespie for her help with the search strategy and trial retrieval, Ms Judy Sherrington for proof reading, Prof William Gillespie, Mr Peter Herbison, Ms Janet Wale and Meghan Donaldson (external referee) for their feedback and help at editorial review.

\section{SOURCES OF SUPPORT}

\section{External sources of support}

- National Health and Medical Research Council, Prevention of Older Peoples' Injuries Health Research Partnership Program AUSTRALIA

\section{Internal sources of support}

- University of Teesside, Middlesbrough UK

- Peterborough and Stamford Hospitals NHS Foundation Trust, Peterborough UK

- Prince of Wales Medical Research Institute, Sydney AUSTRALIA

Mobilisation strategies after hip fracture surgery in adults (Review) 


\section{R E F E R E N C E S}

\section{References to studies included in this review \\ Baker 1991 \{published data only\}}

Baker PA, Evans OM, Lee C. Treadmill gait retraining following fractured neck-of-femur. Archives of Physical Medicine and Rehabilitation 1991;72(9):649-52.

Graham 1968 \{published data only\}

Abrami G, Stevens J. Early weight bearing after internal fixation of transcervical fracture of the femur. Preliminary report of a clinical trial. Journal of Bone and Joint Surgery. British Volume 1964;46(2): 204-5.

* Graham J. Early or delayed weight-bearing after internal fixation of transcervical fracture of the femur. A clinical trial. Journal of Bone and Joint Surgery. British Volume 1968;50(3):562-9.

Hauer 2002 \{published and unpublished data\}

Hauer K. personal communication March 52004.

Hauer K, Pfisterer M, Schuler M, Bartsch P, Oster P. Two years later: A prospective long-term follow-up of a training intervention in geriatric patients with a history of severe falls. Archives of Physical Medicine and Rehabilitation 2003;84(10):1426-32.

Hauer K, Rost B, Rutschle K, Opitz H, Specht N, Bartsch P, et al. Exercise training for rehabilitation and secondary prevention of falls in geriatric patients with a history of injurious falls. Journal of the American Geriatrics Society 2001;49(1):10-20.

* Hauer K, Specht N, Schuler M, Bartsch P, Oster P. Intensive physical training in geriatric patients after severe falls and hip surgery. Age and Ageing 2002;31(1):49-57.

Oster P, Hauer K, Specht N, Rost B, Baertsch P, Schlierft G. Muscle strength and coordination training for prevention of falls in elderly patients [Kraft- and Koordinationstraining zur Sturzpravention in Alter]. Zeitschrift Fur Gerontologie Und Geriatrie 1997;30:289-92.

Karumo 1977 \{published data only\}

Karumo I. A randomized trial of postoperative physiotherapy after meniscectomy and fractures of the femoral neck and shaft [thesis]. Helsinki: University of Helsinki, 1978.

* Karumo I. Recovery and rehabilitation of elderly subjects with femoral neck fractures. Annales Chirurgiae et Gynaecologiae 1977;66 (3):170-6.

Lamb 2002 \{published data only\}

Lamb SE, Grimley Evans J, Morse RE, Trundle H. A randomised placebo controlled and double blind study of neuromuscular stimulation to improve mobility in the first three months after surgical fixation for proximal femoral fracture [abstract]. Journal of Bone and Joint Surgery. British Volume 1998;80 Suppl II:172.

* Lamb SE, Oldham JA, Morse RE, Evans JG. Neuromuscular stimulation of the quadriceps muscle after hip fracture: a randomized controlled trial. Archives of Physical Medicine and Rehabilitation 2002;83 (8):1087-92.

Lauridsen 2002 \{published data only\}

* Lauridsen UB, de la Cour BB, Gottschalck L, Svensson BH. Intensive physical therapy after hip fracture. Danish Medical Bulletin 2002;49(1):70-2.
Lauridsen UB, de la Cour BB, Gottschalck L, Svensson BH. Intensive physical therapy after trochanteric femoral fracture. A randomized clinical trial [Intensiv fysisk traening efter hoftenaer femurfraktur. En randomiseret klinisk undersogelse]. Ugeskrift for Laeger 2002;164 (8):1040-4

Mitchell 2001 \{published and unpublished data\}

Martin BJ. Randomised, controlled trial of additional quadriceps strength training in patients rehabilitating after a proximal femoral fracture. The National Research Register Issue 2, 2001. Oxford: Update Software.

* Mitchell SL, Stott DJ, Martin BJ, Grant SJ. Randomised controlled trial of quadriceps training after proximal femoral fracture. Clinical Rehabilitation 2001;15(3):282-90.

Mitchell SL, Stott DJ, Martin BJ, Grant SJ. Randomised controlled trial of quadriceps training after proximal femoral fracture [abstract]. Age and Ageing 1999;28(Suppl 2):81.

Sherrington 1997 \{published and unpublished data\}

Sherrington C. personal communication January 152004.

Sherrington C. personal communication March 242004.

* Sherrington C, Lord SR. Home exercise to improve strength and walking velocity after hip fracture: a randomised controlled trial. Archives of Physical Medicine and Rehabilitation 1997;78(2):208-12.

Sherrington 2003 \{published and unpublished data\}

Sherrington C. personal communication January 152004.

* Sherrington C, Lord SR, Herbert RD. A randomised trial of weightbearing versus non-weight-bearing exercise for improving physical ability in inpatients after hip fracture. Australian Journal of Physiotherapy 2003; Vol. 49, issue 1:15-22.

Sherrington C, Lord SR, Herbert RD. The effects of exercise on physical ability following fall-related hip fracture: two randomised controlled trials. Proceedings of the Australian Physiotherapy Association 7th International Physiotherapy Congress, Sydney, May 2528 2002. 2002.

Sherrington 2004 \{published and unpublished data\} Sherrington C. personal communication February 92004.

Sherrington C, Lord SR, Herbert RD. A randomised controlled trial of weight-bearing versus non-weight-bearing exercise for improving physical ability after hip fracture and completion of usual care [Abstract]. XVIth conference of the International Society for Postural and Gait Research; 2003 March 23-27;Sydney (Australia). http:// www.powmri.unsw.edu.au/ispg2003/ (accessed 24/07/03).

* Sherrington C, Lord SR, Herbert RD. A randomized controlled trial of weight-bearing versus non-weight-bearing exercise for improving physical ability after usual care for hip fracture. Archives of Physical Medicine and Rehabilitation 2004;85(5):710-6.

Sherrington C, Lord SR, Herbert RD. The effects of exercise on physical ability following fall-related hip fracture: two randomised controlled trials. Proceedings of the Australian Physiotherapy Association 7th International Physiotherapy Congress; 2002 May 25-28; Sydney. 2002. 


\section{References to studies excluded from this review Allegrante 2001}

Allegrante JP. Improving functional recovery after hip fracture. National Library of Medicine 2001; website: http://ClinicalTrials.gov/.

* Ruchlin HS, Elkin EB, Allegrante JP. The economic impact of a multifactorial intervention to improve postoperative rehabilitation of hip fracture patients. Arthritis Care \& Research 2001;45(5):446-52.

Barber 2002

Barber M, Braid V, Mitchell SL, Martin BJ, Grant SJ, Granat M, et al. Electrical stimulation of quadriceps during rehabilitation following proximal femoral fracture [Abstract]. Age and Ageing 2001;30 Suppl 2:19.

* Barber M, Braid V, Mitchell SL, Martin BJ, Grant SJ, Scott DJ. Electrical stimulation of quadriceps during rehabilitation following proximal femoral fracture. International Journal of Rehabilitation Research 2002;25(1):61-3.

Crotty 2002

Crotty M, Whitehead C, Finucane P, Gray S. Rehabilitation in the home for patients with fractured neck of the femur [Project No: 0130]. http://www.cas.flinders.edu.au/sanra/research/proj0130. html [accessed 6 December 2001].

Crotty M, Whitehead C, Miller M, Gray S. Patient and caregiver outcomes 12 months after home-based therapy for hip fracture: a randomized controlled trial. Archives of Physical Medicine \& Rehabilitation 2003;84(8):1237-9.

* Crotty M, Whitehead CH, Gray S, Finucane PM. Early discharge and home rehabilitation after hip fracture achieves functional improvements: A randomized controlled trial. Clinical Rehabilitation 2002;16(4):406-13.

\section{Hesse 2003}

Hesse S, Werner C, Seibel H, von Frankenberg S, Kappel E-M, Kirker $S$, et al. Treadmill training with partial body-weight support after total hip arthroplasty: A randomized controlled trial. Archives of Physical Medicine and Rehabilitation 2003;84:1767-73.

\section{Johnston 1995}

Johnston J. Evaluation of early home rehabilitation program for geriatric patients with hip fractures. Hong Kong Health Services Research Fund (archived register); website: http://www.controlled-trials.com/ (accessed: 12 July 2001).

Kishida 2001

Kishida Y, Sugano N, Sakai T, Nishij T, Haraguchi K, Ohzeno K, et al. Full weight-bearing after cementless total hip arthroplasty. International Orthopaedics 2001;25(1):25-8.

\section{Kuisma 2002}

Johnston J. Study of the outcomes of three types of physiotherapy services in Hong Kong. Hong Kong Health Services Research Fund register; website: http://www.controlled-trials.com/ (accessed: 12 July 2001).

* Kuisma R. A randomised, controlled comparison of home versus institutional rehabilitation of patients with hip fracture. Clinical Rehabilitation 2002;16(5):553-61.

\section{Lehmann 1961}

Lehmann JF, Fordyce WE, Rathbun LA, Larson RE, Wood DH. Clinical evaluation of a new approach in the treatment of contracture associated with hip fracture after internal fixation. Archives of Physical Medicine \& Rehabilitation 1961;42:95-100.

Maltby 2000

Harper WM. personal communication March 22004.

Maltby SJ. personal communication July 212000.

* Maltby SJ. Can biofeedback influence standing asymmetry, perceived confidence and gait following hip fracture?. The National Research Register Issue 2, 2001. Oxford: Update Software.

\section{Tinetti 1999}

Tinetti ME, Baker DI, Gottschalk M, Williams CS, Pollack D, Garrett $\mathrm{P}$, et al. Home-based multicomponent rehabilitation program for older persons after hip fracture: a randomized trial. Archives of Physical Medicine \& Rehabilitation 1999;80(8):916-22.

\section{References to studies awaiting assessment}

\section{Magione 2001}

Mangione KK, Tomlinson S, Craik RL. Physical therapist interventions to optimize physical performance in patients after hip fracture. Journal of Geriatric Physical Therapy 2001;24(3):17.

\section{References to ongoing studies}

Binder 2001

Binder E. personal correspondence March 12004.

Binder EF. Effects of exercise on markers of inflammation in skeletal muscle in elderly hip fracture patients. National Library of Medicine 2001; website: http://ClinicalTrials.gov/.

* Binder EF, Sinacore DR, Schechtman KB, Brown M. Effects of intensive exercise after hip fracture: results from a randomised, controlled trial [Abstract]. Journal of the American Geriatrics Society 2003; 51(Suppl 4):S232.

\section{Braid 2001}

Braid V. personal correspondence March 32004.

* Braid V, Barber M, Mitchell SL, Martin BJ, Grant SJ, Granat M, et al. Proximal femoral fracture: A randomised controlled trial of electrical stimulation [abstract]. Extending the boundaries. Congress and Exhibition of The Chartered Society of Physiotherapy. Proceedings Book; 2001 Oct 19-21; Birmingham (UK). London: The Chartered Society of Physiotherapy, 2001:15.

Braid V, Barber M, Mitchell SL, Martin BJ, Grant SJ, Granat M, et al. Proximal femoral fracture rehabilitation: A randomised controlled trial of electrical stimulation of the quadriceps [abstract]. Age and Ageing 2002;28 Suppl 1:28.

Mitchell S. A randomised, controlled trial of electrical stimulation of the quadriceps in patients rehabilitating after a proximal femoral fracture. In: The National Research Register Issue 2, 2001. Oxford: Update Software.

Cameron 2004

Cameron IC. personnal communication March 12002.

Crotty 2003

Miller M. personnal communication May 242002.

Resnick 2002

Resnick B. personal communication February 92004. 
Resnick B. Testing the Exercise Plus Program following hip fracture. http://www1.od.nih.gov/behaviorchange/projects/maryland.htm (accessed 10/01/04).

* Resnick B, Magaziner J, Orwig, D, Zimmerman S. Evaluating the components of the Exercise Plus Program: rationale, theory and implementation. Health Education Research 2002;17(5):648-58.

\section{Additional references}

\section{Abrami 1964}

Abrami G, Stevens J. Early weight bearing after internal fixation of transcervical fracture of the femur. Preliminary report of a clinical trial. Journal of Bone and Joint Surgery. British Volume 1964;46(2): $204-5$.

\section{Alderson 2004}

Alderson P, Green S, Higgins JPT, editors. MEDLINE highly sensitive search strategies for identifying reports of randomized controlled trials in MEDLINE. Cochrane Reviewers' Handbook 4.2.2 [updated March 2004]; Appendix 5b. In: The Cochrane Library, Issue 1, 2004. Chichester, UK: John Wiley \& Sons, Ltd.

\section{Avenell 2004}

Avenell A, Handoll HHG. Nutritional supplementation for hip fracture aftercare in the elderly (Cochrane Review). In: The Cochrane Library, 2, 2004. Chichester, UK: John Wiley \& Sons, Ltd.

\section{Cameron 2000}

Cameron I, Crotty M, Currie C, Finnegan T, Gillespie L, Gillespie W, et al. Geriatric rehabilitation following fractures in older people: a systematic review. Health Technology Assessment 2000;4(2):i-iii, 1102.

\section{Cameron 2004a}

Cameron ID, Handoll HHG, Finnegan TP, Madhok R, Langhorne P. Co-ordinated multidisciplinary approaches for inpatient rehabilitation of older patients with proximal femoral fractures (Cochrane Review). In: The Cochrane Library, 2, 2004. Chichester, UK: John Wiley \& Sons, Ltd.

\section{Gillespie 2004}

Gillespie LD, Gillespie WJ, Robertson MC, Lamb SE, Cumming $\mathrm{RG}$, Rowe BH. Interventions for preventing falls in elderly people (Cochrane Review). In: The Cochrane Library, 2, 2004. Chichester, UK: John Wiley \& Sons, Ltd.

\section{Lamb 1998}

Lamb SE, Grimley Evans J, Morse RE, Trundle H. A randomised placebo controlled and double blind study of neuromuscular stimulation to improve mobility in the first three months after surgical fixation for proximal femoral fracture [abstract]. Journal of Bone and Joint Surgery. British Volume 1998;80 Suppl II:172.

\section{Latham 2004}

Latham N, Anderson C, Bennett D, Stretton C. Progressive resistance strength training for physical disability in older people (Cochrane Review). In: The Cochrane Library, 2, 2004. Chichester, UK: John Wiley \& Sons, Ltd.

\section{RevMan 2003}

The Cochrane Collaboration. Review Manager (RevMan). Version 4.2 for Windows. Oxford, England: The Cochrane Collaboration, 2003.

\section{Sherrington 2004a}

Sherrington C. personal communication June 212004.

\section{References to other published versions of this review}

Handoll 2003

Handoll HHG, Parker MJ, Sherrington C. Mobilisation strategies after hip fracture surgery in adults (Cochrane Review). In: The Cochrane Library, 1, 2003. Oxford: Update Software.

\section{Parker 1999}

Parker MJ. Early weight bearing and mobilisation after internal fixation of intracapsular proximal femoral fractures in adults (Protocol for a Cochrane Review). In: The Cochrane Library, 3, 1999. Oxford: Update Software.

* Indicates the major publication for the study

TA B LE S

\section{Characteristics of included studies}

\begin{tabular}{ll} 
Study & Baker $\mathbf{1 9 9 1}$ \\
\hline Methods & Quasi-randomised trial, by alternation; patients were allocated "sight unseen" \\
\hline Participants & Caulfield Hospital, Victoria, Australia \\
& 40 women with a hip fracture \\
& Age: mean 83.5 years (range 69-97 years) \\
\% male: none & Number lost to follow-up: not stated \\
\hline Interventions & Treadmill gait retraining programme \\
\hline
\end{tabular}




\section{Characteristics of included studies (Continued)}

\begin{tabular}{|c|c|}
\hline \multirow[t]{7}{*}{ Outcomes } & Length of follow up: until discharge from rehabilitation hospital \\
\hline & Mobility level at discharge \\
\hline & Walking velocity \\
\hline & Stride length \\
\hline & Gait analysis \\
\hline & Return to living at home \\
\hline & Length of hospital stay \\
\hline Notes & A subgroup of 6 'matched pairs' were studied in greater detail by gait analysis \\
\hline \multicolumn{2}{|l|}{ Allocation concealment } \\
\hline Study & Graham 1968 \\
\hline Methods & Randomised trial, stratified by age of patient, method of randomisation not stated \\
\hline \multirow[t]{6}{*}{ Participants } & Western Infirmary, Glasgow, UK \\
\hline & 273 people with a displaced intracapsular proximal femoral fracture treated by closed reduction and internal \\
\hline & fixation with a sliding nail plate. \\
\hline & Age: not stated \\
\hline & $\%$ male: not stated \\
\hline & Number lost to follow-up: 8 /175 (participants with 3 years since operation) \\
\hline \multirow[t]{2}{*}{ Interventions } & $\begin{array}{l}\text { Early weight bearing at } 2 \text { weeks after surgery } \\
\text { versus }\end{array}$ \\
\hline & delayed weight bearing at 12 weeks after surgery \\
\hline \multirow[t]{5}{*}{ Outcomes } & Length of follow up: 1 year for all, 3 years for subgroup \\
\hline & Mortality \\
\hline & Non-union of the fracture (failure) \\
\hline & Avascular necrosis (segmental collapse) \\
\hline & Infection of the hip \\
\hline \multirow[t]{3}{*}{ Notes } & The paper of 1964 was a preliminary report of 3 months results for 124 people thus far included in the trial. \\
\hline & Results for the 273 people included at 2 weeks past randomisation/hospital admission were available at one \\
\hline & $\begin{array}{l}\text { year. The numbers of trial participants assessed at one and three years are different as for } 98 \text { participants } \\
\text { insufficient time had elapsed from time of operation to complete the three year review. }\end{array}$ \\
\hline Allocation concealment & B - Unclear \\
\hline
\end{tabular}

\section{Study}

Methods

Participants

\section{Hauer 2002}

Randomised trial: randomisation was "performed by an external person who did not participate in the study using a protected random number system”. Stratified by hip fracture and non-hip fracture patients (see Notes)

\section{Heidelberg, Germany}

28 women aged $75+$ years: 25 with a fall-related hip fracture and 3 with elective hip surgery who had experienced a recent injurious fall. Discharged from hospital.

Age: mean 81 years

$\%$ male: $0 \%$

Number lost to follow-up: 4 (3 didn't start exercises and 1 dropped out)

Interventions

functional and balance training) versus

placebo motor activity 


\section{Characteristics of included studies (Continued)}

Both regimes, taking place 3 times a week, started on average 4-5 weeks after surgery upon discharge from inpatient rehabilitation. Both groups received identical additional physiotherapy, twice weekly for 25 minutes: strength and balance training was excluded from these sessions.

\begin{tabular}{|c|c|}
\hline Outcomes & $\begin{array}{l}\text { Length of follow up: } 6 \text { months (12 weeks }+3 \text { months) } \\
\text { Walking velocity and cadence } \\
\text { Independent weight bearing } \\
\text { Performance orientated motor assessment } \\
\text { Box step } \\
\text { Functional reach } \\
\text { Timed up-and-go } \\
\text { Chair and stair rises } \\
\text { Activities of daily living; sports and household activities } \\
\text { Muscle strength: leg-press, leg-extensor, leg flexor, ankle-plantar flexion, hand grip strength (non-trained } \\
\text { muscle group) } \\
\text { Loss of independence } \\
\text { Subjective fear of falling } \\
\text { Subjective walking steadiness } \\
\text { Emotional state: depression, moral and handicap scales } \\
\text { Adherence }\end{array}$ \\
\hline Notes & $\begin{array}{l}\text { This trial was excluded in the versions of the review up to Issue } 3,2004 \text { because the intervention began } \\
\text { after the early post-operative period covered by this review, which then focused on early post-operative } \\
\text { rehabilitation. } \\
\text { Trial actually included } 57 \text { people who had sustained an injurious fall. A later report of the trial gave the } \\
\text { results for the sub-group of } 28 \text { participants who had had hip surgery; these are included here. } \\
\text { Further information, including method of randomisation, received from lead trialist on } 05 / 03 / 2004 \text { and } \\
24 / 06 / 04\end{array}$ \\
\hline Allocation concealment & A - Adequate \\
\hline Study & Karumo 1977 \\
\hline Methods & Randomised trial, using random numbers \\
\hline Participants & $\begin{array}{l}\text { University Central Hospital, Helsinki, Finland } \\
100 \text { people with a femoral neck fracture } \\
\text { Age: mean } 73 \text { years (range not stated; all over } 50 \text { years) } \\
\% \text { male: } 25 \% \\
\text { Number lost to follow-up: } 13\end{array}$ \\
\hline Interventions & $\begin{array}{l}\text { Intensive (performed twice daily) physiotherapy regime } \\
\text { versus } \\
\text { same regime performed once daily (conventional care) } \\
\text { Physiotherapy was on average } 30 \text { minutes per day. For the intensive group, the physiotherapy time was double } \\
\text { this. }\end{array}$ \\
\hline Outcomes & $\begin{array}{l}\text { Length of follow up: } 3 \text { months (for mortality) } \\
\text { Walking ability } \\
\text { Ability to move and sit up in bed on first post-operative day } \\
\text { Abductor muscle strength } \\
\text { Residence at } 9 \text { weeks } \\
\text { Mortality } \\
\text { "Mechanical" post-operative complications } \\
\text { Medical complications including thromboembolism and post-operative infection }\end{array}$ \\
\hline
\end{tabular}




\section{Characteristics of included studies (Continued)}

\begin{tabular}{|c|c|}
\hline & Length of hospital stay \\
\hline \multirow[t]{3}{*}{ Notes } & $\begin{array}{l}\text { Of the } 100 \text { people recruited for the trial, } 13 \text { had inadequate follow-up and the results of these participants } \\
\text { are not presented. }\end{array}$ \\
\hline & $\begin{array}{l}\text { Most of the results for the trial were presented split according to whether the participant had a prosthesis or } \\
\text { internal fixation; rather than by the trial interventions. }\end{array}$ \\
\hline & $\begin{array}{l}\text { A thesis (1978, University of Helsinki) was located by Lesley Gillespie (10/06/2004). Request for a copy has } \\
\text { been sent. }\end{array}$ \\
\hline Allocation concealment & B - Unclear \\
\hline Study & Lamb 2002 \\
\hline Methods & $\begin{array}{l}\text { Randomised trial, using sequential opened numbered sealed opaque envelopes; } \\
\text { stratified by pre-injury mobility }\end{array}$ \\
\hline Participants & $\begin{array}{l}\text { John Radcliffe Nuffield Orthopaedic Hospital, Oxford, UK } \\
27 \text { women, aged } 75+\text { years, treated surgically (not total hip replacement) for hip fracture } \\
\text { Age: mean } 83.7 \text { years (range } 79-87 \text { years) } \\
\% \text { male: none } \\
\text { Number lost to follow-up: } 3 \text { excluded. One had myasthenia gravis, one a severe chest infection and the third } \\
\text { patient withdrew consent }\end{array}$ \\
\hline \multirow[t]{2}{*}{ Interventions } & $\begin{array}{l}\text { Patterned neuromuscular stimulation of the quadriceps muscle for three hours a day for } 6 \text { weeks } \\
\text { versus } \\
\text { placebo stimulation }\end{array}$ \\
\hline & $\begin{array}{l}\text { Interventions started in hospital one week post-surgery and continued at home after hospital discharge at } \\
10-14 \text { days. }\end{array}$ \\
\hline \multirow[t]{7}{*}{ Outcomes } & Length of follow up: 13 weeks \\
\hline & Recovery of mobility \\
\hline & Walking velocity \\
\hline & Leg extensor power \\
\hline & Compliance \\
\hline & Pain \\
\hline & Side effects (none) \\
\hline \multicolumn{2}{|l|}{ Notes } \\
\hline Allocation concealment & A - Adequate \\
\hline
\end{tabular}

\begin{tabular}{ll} 
Study & Lauridsen $\mathbf{2 0 0 2}$ \\
\hline Methods & Randomised trial, using consecutively drawn numbered sealed opaque envelopes \\
\hline Participants & Rehabilitation Unit, Hvidovre Hospital, Copenhagen, Denmark \\
& 88 women transferred to a rehabilitation unit within 3 weeks after surgical treatment of a hip fracture. \\
& Age: median 80 years (range 61-89 years) \\
& $\%$ male: none \\
& Number lost to follow-up: none \\
\hline Interventions & Intensive physiotherapy where patients were offered 6 hours per week, comprising 2 hours on Monday, \\
& Wednesday and Friday \\
& versus \\
& standard physiotherapy of 15-30 minutes per weekday
\end{tabular}

Training was stopped when the planned functional capacity was attained unaided (walk 50+ metres without resting in 2 minutes or less, using walking stick or quadraped if necessary; climb one flight of stairs; manage 


\section{Characteristics of included studies (Continued)}

sit-to-stand transfer; move in and out of bed; manage bathing, dressing and lavatory visits) or when patients withdrew from study.

\begin{tabular}{ll}
\hline Outcomes & Length of follow up: until discharge from hospital \\
& Use of walking aids \\
& Orthopaedic complication \\
& Length of hospital stay \\
& Duration of training \& length of training period \\
& Drop-outs from training \\
\hline Notes & Details of the method of randomisation provided on contact with lead trialist, but no other useful information \\
& gained. \\
& The current account of the trial is based on the report in the Danish Medical Bulletin. A colleague, Pernille \\
& Jensen, based in Denmark checked through the paper written in Danish (in Ugeskr Laeger) and confirmed \\
& that with the exception of a few small details, the English paper was a straight translation. \\
\hline Allocation concealment & A - Adequate
\end{tabular}

\begin{tabular}{|c|c|}
\hline Study & Mitchell 2001 \\
\hline Methods & $\begin{array}{l}\text { Randomised trial, using computer generated random numbers; allocation concealed in sealed envelopes held } \\
\text { by a third party not involved in the study }\end{array}$ \\
\hline Participants & $\begin{array}{l}\text { Geriatric Orthopaedic Unit connected with Glasgow Royal Infirmary, UK } \\
80 \text { people with a hip fracture who had been transferred to a rehabilitation unit at about } 15 \text { days after surgery } \\
\text { for a hip fracture } \\
\text { Age: mean } 80 \text { years (range not stated) } \\
\% \text { male: } 16 \% \\
\text { Number lost to follow-up: } 16 \text { (refused or unavailable); also } 7 \text { died and } 13 \text { with new comorbidity precluding } \\
\text { assessment not included in final analyses }\end{array}$ \\
\hline Interventions & $\begin{array}{l}\text { Twice weekly quadriceps strengthening exercises in both legs for } 6 \text { weeks whilst a hospital in-patient on a } \\
\text { rehabilitation ward } \\
\text { versus } \\
\text { no quadriceps strengthening exercises } \\
\text { All trial participants received conventional physiotherapy for approximately } 20 \text { minutes per day ( } 5 \text { days a } \\
\text { week). }\end{array}$ \\
\hline Outcomes & $\begin{array}{l}\text { Length of follow up: } 16 \text { weeks } \\
\text { Elderly mobility scale } \\
\text { Leg extension power } \\
\text { Hand grip strength } \\
\text { 'Get up and go' test } \\
\text { Barthel index } \\
\text { Nottingham Health Profile (gait speed, emotional reactions, energy, pain, physical mobility, sleep, social } \\
\text { isolation) } \\
\text { Functional reach } \\
\text { Walking velocity } \\
\text { Length of hospital stay } \\
\text { Mortality }\end{array}$ \\
\hline Notes & \\
\hline Allocation concealment & A - Adequate \\
\hline
\end{tabular}




\section{Characteristics of included studies (Continued)}

\begin{tabular}{|c|c|}
\hline Study & Sherrington 1997 \\
\hline Methods & $\begin{array}{l}\text { Randomised trial, using random numbers, balanced within blocks of } 10 \text { participants. The list of "subject } \\
\text { numbers" was not concealed. }\end{array}$ \\
\hline Participants & $\begin{array}{l}\text { Sydney, Australia } \\
44 \text { people aged } 60+\text { years with a fall-related hip fracture who had lived in the community beforehand. } \\
\text { Discharged from } 1 \text { of } 4 \text { acute hospitals to home or residential care within } 9 \text { months of their fracture } \\
\text { Age: mean } 78.5 \text { years (range } 64-94 \text { years) } \\
\% \text { male: } 21 \% \\
\text { Number lost to follow-up: } 2 \text { (withdrew consent); also } 2 \text { excluded at initial assessment }\end{array}$ \\
\hline \multirow[t]{3}{*}{ Interventions } & $\begin{array}{l}\text { Home-based weight-bearing exercises for } 1 \text { month } \\
\text { versus } \\
\text { control (no specific instructions: usual care) }\end{array}$ \\
\hline & $\begin{array}{l}\text { Individuals in the intervention group were provided with stepping block }(s) \text { made of old telephone directories } \\
\text { and shown the exercises. They were advised on how many stepping blocks and repetitions to do at least once } \\
\text { daily at the start and told to increase the repetitions gradually. A photograph was taken to help remind the } \\
\text { participant of the correct method and they were checked at } 1 \text { week (4-16 days). Participants also kept a diary. }\end{array}$ \\
\hline & $\begin{array}{l}\text { All participants had an preliminary interview and physical assessment lasting about } 1 \text { hour. This took place } \\
\text { on average } 7 \text { months ( } 5-9 \text { months) after their injury. }\end{array}$ \\
\hline \multirow[t]{9}{*}{ Outcomes } & Length of follow up: 1 month (range 27-43 days) \\
\hline & Quadriceps strength \\
\hline & Sway and balance \\
\hline & Functional reach \\
\hline & Walking velocity and cadence \\
\hline & Independent weight bearing \\
\hline & Compliance and participation in other general exercise \\
\hline & Subjectively assessed risk of falling \\
\hline & Subjectively assessed balance \\
\hline \multirow[t]{3}{*}{ Notes } & This trial was excluded in the versions of the review up to Issue 3, 2004 because participants were recruited \\
\hline & $\begin{array}{l}7 \text { months after a hip fracture; this was previously outside the time period covered by this review, which then } \\
\text { focused on early post-operative rehabilitation. }\end{array}$ \\
\hline & Additional information obtained from Cathie Sherrington 09/02/2004 and 24/03/2004 \\
\hline Allocation concealment & $\mathrm{C}$ - Inadequate \\
\hline
\end{tabular}

\begin{tabular}{ll} 
Study & Sherrington $\mathbf{2 0 0 3}$ \\
\hline Methods & Randomised trial, using random numbers, balanced within blocks of 6 participants. The allocation for each \\
person was concealed by a separate piece of opaque paper - this was removed to reveal the allocation for the \\
trial participant, without revealing the allocation for subsequent participants.
\end{tabular}




\section{Characteristics of included studies (Continued)}

For both groups, the treating physiotherapist chose several initial exercises, then added extra exercises in keeping with the participant's capability. Participants were encouraged to take prescribed pain relief before exercising.

\begin{tabular}{ll}
\hline Outcomes & Length of follow up: 2 weeks \\
& Walking ability: use of supports \\
& Gait: walking velocity, step length, force plate weight-bearing \\
& Strength: hip abduction and flexion and knee extension \\
& Balance: step test, sway and functional reach \\
& Functional performance measures \\
& Compliance and assessment of exercises \\
& Subjectively assessed: risk of falling, balance, pain, sleep quality, health \\
& Fracture fixation problems \\
& Length of hospital stay \\
& Trial, previously listed in Ongoing studies under Sherrington 2002, was performed as part of Cathie Sher- \\
& rington's PhD work. \\
& Additional information provided $15 / 01 / 2004$ by Cathie Sherrington included further details of method of \\
Notes & Bandomisation and data for self-assessed outcomes. \\
\hline Allocation concealment & \\
\hline
\end{tabular}

\begin{tabular}{ll} 
Study & Sherrington 2004 \\
\hline Methods & $\begin{array}{l}\text { Randomised trial, using random numbers, balanced within blocks of } 6 \text { participants. Use of sealed opaque } \\
\text { numbered envelopes. }\end{array}$ \\
\hline Participants & Community dwellers and residents of aged-care facilities discharged from 6 hospitals in Sydney, Australia \\
& 120 consenting adults who had completed usual care after a fall-related hip fracture: able to complete \\
& assessments and participate in exercise programmes. (Excluded if severely cognitively impaired, had relevant \\
medical conditions, had complications from fracture resulting in delayed healing and associated weight- \\
bearing restrictions.) \\
Age: mean 79 years (range 57-95 years) \\
\% male: $20 \%$ \\
Number lost to follow-up: 12 (7 withdrew consent - refused assessment; 5 died)
\end{tabular}

Interventions Home-based weight-bearing exercises (weight-bearing position with support as required) versus home-based non-weight-bearing exercises (performed in the supine position) versus control (no specific instructions)

For both exercise groups, the prescribing physiotherapist chose several initial exercises and number of repetitions in keeping with the participant's capability. Individuals in the weight-bearing group were provided with stepping block(s). Participants were advised on progression. Line drawings of the exercises were provided and they were checked at 1 week. Further assessment and prescription at 1 and 4 months. Participants also asked to keep a record of their exercises.

All participants had an preliminary assessment which took place on average 22 weeks after their injury. Exercises were prescribed for 4 months minimum.

Outcomes Length of follow up: 4 months

Walking ability/mobility

Gait: walking velocity, step length

Strength: hip abduction and flexion and knee extension

Balance: step test, sway and functional reach

Functional performance measures: timed sit-to-stand, supine-to-sit and Physical Performance and Mobility

Examination 
Mortality

Subjectively assessed: risk of falling, balance, pain, sleep quality, health

Compliance and assessment of exercises (intervention groups only)

Falls

Notes Trial was performed as part of Cathie Sherrington's PhD work.

Additional information, including binary data for mobility and subjective outcomes, received 09/02/2004.

Allocation concealment A-Adequate

ADL: activities of daily living

\section{Characteristics of excluded studies}

\begin{tabular}{|c|c|}
\hline Study & Reason for exclusion \\
\hline Allegrante 2001 & $\begin{array}{l}\text { This trial involving } 152 \text { participants with primary unilateral hip fracture, age } 65+\text { years, compared a multifactorial } \\
\text { intervention (patient instruction protocol; hospital-based } 8 \text {-week programme of high-intensity isokinetic strength } \\
\text { training; and at-home walking programme and supportive phone calls including contact with peer advocate) with } \\
\text { standard medical care. It was excluded because the effects of the mobilisation part of the multifactorial intervention } \\
\text { could not be determined. }\end{array}$ \\
\hline Barber 2002 & $\begin{array}{l}\text { This was a small case-control, and thereby excluded, study of electrical stimulation during rehabilitation following } \\
\text { proximal femoral fracture. The historic control group was derived from participants of Mitchell } 2001 \text {. }\end{array}$ \\
\hline Crotty 2002 & Early discharge trial comparing home rehabilitation with conventional care in hospital. Not in scope of review. \\
\hline Hesse 2003 & $\begin{array}{l}\text { Treadmill training plus physical therapy versus physical therapy was compared in } 80 \text { patients receiving a first time } \\
\text { unilateral hip replacement, five of whom had had a hip fracture. The number of hip fracture patients was too few } \\
\text { for inclusion in the review. }\end{array}$ \\
\hline Johnston 1995 & $\begin{array}{l}\text { Trial, only identified in a trial register, comparing early home rehabilitation program versus traditional rehabilitation } \\
\text { programme in patients with hip fractures. Not in scope of review. }\end{array}$ \\
\hline Kishida 2001 & $\begin{array}{l}\text { Immediate weight bearing versus weight bearing at six weeks was compared in } 33 \text { patients with } 37 \text { hips who received } \\
\text { an uncemented total hip arthroplasty; there is no indication in the trial report that these were hip fracture patients. }\end{array}$ \\
\hline Kuisma 2002 & $\begin{array}{l}\text { This trial compared discharge from an acute ward to home with visits by a physiotherapist versus usual care in a } \\
\text { rehabilitation centre in } 81 \text { hip fracture patients. The trial is primarily a home versus hospital comparison and thus } \\
\text { was excluded. }\end{array}$ \\
\hline Lehmann 1961 & $\begin{array}{l}\text { This quasi-randomised and dated trial compared ultrasound with infrared for the treatment of joint contracture after } \\
\text { internal fixation of hip fracture in } 30 \text { people. This trial was excluded as most of the implants used and, in particular, } \\
\text { the } 10 \text { day delay to physiotherapy, which may have exacerbated the complication the trial set out to treat, are not } \\
\text { consistent with current practice. }\end{array}$ \\
\hline Maltby 2000 & $\begin{array}{l}\text { There were } 22 \text { fairly frail patients in this randomised controlled trial comparing visual biofeedback training and } \\
\text { physiotherapy versus physiotherapy alone in the treatment of proximal femoral fracture patients. The patients were } \\
\text { followed up for } 2 \text { weeks. Though a draft report of the trial was received (July 2000), it was insufficiently complete } \\
\text { to include in the review. Simon Maltby left the hospital soon afterwards. Contact with Prof WM Harper in March } \\
2004 \text { revealed that no further progress had been made with the study or its write up and that it is now shelved. }\end{array}$ \\
\hline Tinetti 1999 & $\begin{array}{l}\text { This trial compared systematic multicomponent home based rehabilitation involving physical therapy and functional } \\
\text { therapy (for activities of daily living) versus usual care in } 304 \text { non-demented patients aged } 65+\text { years post hospital/ } \\
\text { subacute facility discharge for surgically repaired hip fracture. It was excluded because the effects of the mobilisation } \\
\text { part of the multicomponent intervention could not be determined. }\end{array}$ \\
\hline
\end{tabular}

\section{Characteristics of ongoing studies}

\begin{tabular}{ll} 
Study & Binder $\mathbf{2 0 0 1}$ \\
\hline Trial name or title $\quad$ Effects of intensive exercise after hip fracture \\
\hline $\begin{array}{l}\text { Mobilisation strategies after hip fracture surgery in adults (Review) } \\
\text { Copyright } \odot 2006 \text { The Cochrane Collaboration. Published by John Wiley \& Sons, Ltd }\end{array}$
\end{tabular}




\section{Characteristics of ongoing studies (Continued)}

Participants 90 participants within 16 weeks of hip fracture. Community-dwelling, independent in ambulation and with persistent mobility and activity of daily living defects.

Interventions $\quad$ Post completion of standard physical therapy.

(a) Graduated physical therapy and weight training program. Supervised exercise sessions: thrice weekly for 6 months.

(b) Exercises at home focused on flexibility and balance.

Outcomes

Follow-up: 6 months post-discharge

Physical Performance Test score

Functional Status questionnaire (FSQ) score

Strength

Gait

Balance

Knee extension

\begin{tabular}{ll}
\hline Starting date & Start date: 01/08/1998 \\
& Completed: 31/05/2003
\end{tabular}

Contact information Ellen F Binder

Washington University

St Louis

Missouri 63110

United States

Email: ebinder@im.wustl.edu

Notes Conference abstract provides interim results.

Ellen Binder on 01/03/2004 indicated that the trial report was under review and should be published sometime in 2004 .

\begin{tabular}{|c|c|}
\hline Study & Braid 2001 \\
\hline Trial name or title & Proximal femoral fracture: A randomised controlled trial of electrical stimulation \\
\hline Participants & 26 participants with proximal femoral fracture \\
\hline Interventions & $\begin{array}{l}\text { (a) Six weeks of electrical stimulation of the quadriceps + standard physiotherapy } \\
\text { (b) Standard physiotherapy alone }\end{array}$ \\
\hline Outcomes & $\begin{array}{l}\text { Follow-up: } 14 \text { weeks } \\
\text { Leg extensor power } \\
\text { Functional mobility (Elderly mobility scale) } \\
\text { Isometric quadriceps strength } \\
\text { Disability } \\
\text { Quality of life }\end{array}$ \\
\hline Starting date & $\begin{array}{l}\text { Start date: } 01 / 10 / 1999 \\
\text { End date: } 01 / 11 / 2000 \\
\text { Study completed and being written-up (December 2001) }\end{array}$ \\
\hline Contact information & $\begin{array}{l}\text { Ms Virginia Braid } \\
\text { Physiotherapy Department } \\
\text { Glasgow Royal Infirmary } \\
\text { Queen Elizabeth Building } \\
\text { 10 Alexandra Parade } \\
\text { Glasgow } \\
\text { G31 2ER } \\
\text { UK } \\
\text { Tel: +44 } 1412114459\end{array}$ \\
\hline
\end{tabular}




\section{Characteristics of ongoing studies (Continued)}

Notes Contact made with Sara Mitchell (3/10/02) who indicated that the trial was randomised using computer generated random numbers; allocation concealed in sealed envelopes held by a third party not involved in the study. Also that the trial is written up and sent out for publication.

Contact with Virginia Braid (03/03/04) confirmed a continued intention for publication of trial report.

\begin{tabular}{|c|c|}
\hline Study & Cameron 2004 \\
\hline Trial name or title & Enhancing mobility after hip fracture \\
\hline Participants & 160 older men and women admitted to a rehabilitation ward after hip fracture \\
\hline Interventions & $\begin{array}{l}\text { (a) Intensive weight bearing exercise } \\
\text { (b) Non weight bearing exercise }\end{array}$ \\
\hline Outcomes & $\begin{array}{l}\text { Follow-up: } 4 \text { months } \\
\text { Gait, balance and mobility }\end{array}$ \\
\hline Starting date & $\begin{array}{l}\text { Started March } 2002 . \\
\text { Proposed end date: August } 2004\end{array}$ \\
\hline Contact information & $\begin{array}{l}\text { Prof Ian Cameron } \\
\text { Rehabilitation Studies Unit } \\
\text { University of Sydney } \\
\text { PO Box } 6 \\
\text { Ryde } \\
\text { New South Wales AUSTRALIA } \\
\text { NSW } 1680 \\
\text { Telephone: +61 } 298089236 \\
\text { Facsimile: +61 } 298099037 \\
\text { E-mail: } \\
\text { ianc@mail.usyd.edu.au }\end{array}$ \\
\hline Notes & $\begin{array}{l}\text { Stratified randomisation based on a computer generated sequence, with details of allocation held in sealed } \\
\text { opaque and sequentially numbered envelopes }\end{array}$ \\
\hline Study & Crotty 2003 \\
\hline Trial name or title & Evaluation of nutrition and exercise as geriatric injury interventions (the ENERGII trial) \\
\hline Participants & $\begin{array}{l}112 \text { participants, aged } 70 \text { years and above, admitted to hospital for treatment of a fall related fracture of the } \\
\text { hip or lower limb. Local residence, previously independently mobile, able to weight bear following surgery, no } \\
\text { metastatic cancer or major gastrointestinal disorders, no renal failure and able to follow simple commands. Mid- } \\
\text { arm circumference below the } 25 \text { th percentile ('nutritionally at-risk) of a representative sample of community } \\
\text { dwelling older adults in South Australia. }\end{array}$ \\
\hline
\end{tabular}

\begin{tabular}{lll}
\hline Interventions & (a) Exercise intervention: participants receive an individually prescribed program of high intensity resistance
\end{tabular} training using resistive bands. Participants are supervised by a physiotherapist for the first six weeks and educated to complete unsupervised for six weeks; physiotherapist visits weekly.

(b) Nutrition intervention: participants receive an individually prescribed (determined by nutritional status) volume of a high protein, high calorie nutritional supplement $(1.5 \mathrm{cal} / \mathrm{ml} ; 16 \%$ protein, $49 \%$ carbohydrate, $35 \% \mathrm{fat})$. This is administered and documented by nursing staff in hospital and residential care. Participants are visited three times a week for 6 weeks and then weekly for 6 weeks where the research assistant encourages consumption of the nutritional supplement and discusses general health and recovery.

(c) Nutrition and exercise intervention: combination of the interventions detailed in a. and b.

(d) Usual care: This consists of ad hoc nutritional assessment and interventions in addition to routine physiotherapy usually focussed on encouragement of mobility. Participants are visited three times a week for six weeks and then weekly for six weeks where the research assistant discusses general health and recovery. 


\section{Characteristics of ongoing studies (Continued)}

Outcomes Follow-up: 6 and 12 weeks and 12 months. Outcomes include: length of stay, complication rate, costs, walking speed and use of mobility aids, activities of daily living, falls, quadricep strength, grip strength, upper arm anthropometry, body weight change, prealbumin, balance, confidence, quality of life and mortality.

\begin{tabular}{|c|c|}
\hline Starting date & $\begin{array}{l}\text { Started September } 2000 . \\
\text { Proposed end date: July } 2003\end{array}$ \\
\hline Contact information & $\begin{array}{l}\text { Prof Maria Crotty } \\
\text { Dept of Rehabilitation and Aged Care } \\
\text { Repatriation General Hospital } \\
\text { Daws Road } \\
\text { Daw Park South } \\
\text { AUSTRALIA 5041 } \\
\text { Telephone: +61882751103 } \\
\text { Facsimile: +61882751130 } \\
\text { Email: maria.crotty@rgh.sa.gov.au }\end{array}$ \\
\hline Notes & $\begin{array}{l}\text { Details of study from Michelle Miller in May 2002; when } 73 \text { patients had been recruited. Further details } \\
\text { received from Maria Crotty in July } 2003 \text { (nutrition review); when } 100 \text { patients had been recruited. } \\
\text { Randomised using a computer generated table of random numbers and allocation sealed in envelopes. Inde- } \\
\text { pendent allocation of treatment by an individual in hospital pharmacy department. }\end{array}$ \\
\hline Study & Resnick 2002 \\
\hline Trial name or title & Exercise Plus Program following hip surgery \\
\hline Participants & 210 older women with hip fracture from five acute care facilities participating in the Baltimore Hip Study \\
\hline Interventions & $\begin{array}{l}\text { (a) An Exercise Trainer component which includes regular home visits by an exercise trainer to implement an } \\
\text { exercise program with patients } \\
\text { (b) A Plus component only which includes motivational interventions but without an exercise trainer with } \\
\text { exercise } \\
\text { (c) The full Exercise Plus program, which includes the Plus Component (motivational } \\
\text { intervention) and the Exercise Trainer component } \\
\text { (d) Routine care }\end{array}$ \\
\hline Outcomes & $\begin{array}{l}\text { Follow-up: } 2,6 \text { and } 12 \text { months. } \\
\text { Outcomes include: measures of function, muscle strength, physical activity, fear of falling, falls, fall-related } \\
\text { injuries, psychological well-being, overall health status, exercise behaviour, adherence, self-efficacy expectations, } \\
\text { outcome expectations. }\end{array}$ \\
\hline Starting date & $\begin{array}{l}\text { Started: } 2000 \\
\text { Proposed end date: } 2004 \text { (revised target of } 210 \text { patients reached early 2004) }\end{array}$ \\
\hline Contact information & $\begin{array}{l}\text { Assistant Professor Barbara Resnick } \\
\text { School of Nursing and Medicine } \\
\text { University of Maryland } \\
\text { Baltimore } \\
\text { MD } 21201 \\
\text { USA } \\
\text { Email: bresnick@umaryland.edu }\end{array}$ \\
\hline Notes & $\begin{array}{l}\text { Extensive account of rationale already published (2002). Trial funded by the National Institute on Aging and } \\
\text { National Institutes of Health. } \\
\text { Information of trial status received from Barbara Resnick 9/2/2004 }\end{array}$ \\
\hline
\end{tabular}


A D D I T I O NAL TABLES

Table 01. Types of outcome measures sought in versions of the review before Issue 4, 2004

\section{Outcomes sought}

(1) Fracture healing complications.

(a) Surgical complications of fixation within the follow-up period of the study. This includes non-union of the fracture (the definition of non-union is that used within each individual study, and this outcome includes early re-displacement of the fracture), avascular necrosis and other complications as detailed in each individual study.

(b) Re-operation (within the follow-up period of the study).

(2) Post-operative course and complications.

(a) Any medical complication as detailed in each individual study. This includes pneumonia, thromboembolic complications (deep vein thrombosis or pulmonary embolism) and other complications as listed.

(b) Length of hospital stay (in days).

(c) Time until mobilisation and regain of muscle power.

(d) Post-operative walking ability and gait assessment.

(3) Anatomical restoration.

(a) Shortening (more than 2 centimetres).

(b) Varus deformity.

(c) External rotation deformity (more than 20 degrees).

(4) Final outcome measures.

(a) Mortality (within the follow-up period of the study).

(b) Pain (persistent pain at the final follow-up assessment).

(c) Return to living at home.

(d) Return of mobility, use of walking aids.

(e) Other functional outcomes as listed in each study.

(f) Health related quality of life measures.

\section{Table 02. Search strategy for EMBASE (OVID-WEB)}

\section{EMBASE}

1. exp Hip Fracture/

2. ((hip\$ or ((femur\$ or femoral\$) adj3 (neck or proximal))) fracture $\$)$.tw.

3. or/1-2

4. exp Randomized Controlled trial/

5. exp Double Blind Procedure/

6. exp Single Blind Procedure/

7. exp Crossover Procedure/

8. Controlled Study/

9. or/4-8

10. ((clinical or controlled or comparative or placebo or prospective\$ or randomi\#ed) adj3 (trial or study)).tw.

11. (random $\$$ adj7 (allocat $\$$ or allot $\$$ or assign $\$$ or basis $\$$ or divid $\$$ or order $\$$ )).tw.

12. ((singl\$ or doubl\$ or trebl\$ or tripl\$) adj7 (blind\$ or mask\$)).tw.

13. (cross?over $\$$ or (cross adj1 over $\$))$.tw.

14. ( (allocat\$ or allot\$ or assign\$ or divid\$) adj3 (condition\$ or experiment\$ or intervention\$ or treatment $\$$ or therap\$ or control\$ or group $\$)$ ).tw.

15. or/ $10-14$

16. or $/ 9,15$

17. limit 16 to human

18. and $/ 3,17$

Mobilisation strategies after hip fracture surgery in adults (Review) 
Table 02. Search strategy for EMBASE (OVID-WEB) (Continued)

EMBASE

A N A L Y S E

Comparison 01. Early versus delayed weight bearing

\begin{tabular}{|c|c|c|c|}
\hline Outcome title & $\begin{array}{lc}\text { No. of } & \text { No. of } \\
\text { studies } & \text { participants }\end{array}$ & Statistical method & Effect size \\
\hline 01 Mortality & & Relative Risk (Fixed) 95\% CI & Totals not selected \\
\hline 02 Non-union (fixation failure) & & Relative Risk (Fixed) 95\% CI & Totals not selected \\
\hline 03 Avascular necrosis & & Relative Risk (Fixed) 95\% CI & Totals not selected \\
\hline $\begin{array}{l}04 \text { Unfavourable outcome (death, } \\
\text { failure or infection) }\end{array}$ & & Relative Risk (Fixed) 95\% CI & Totals not selected \\
\hline
\end{tabular}

Comparison 02. Intensive versus usual physiotherapy

\begin{tabular}{|c|c|c|c|c|}
\hline Outcome title & $\begin{array}{l}\text { No. of } \\
\text { studies }\end{array}$ & $\begin{array}{c}\text { No. of } \\
\text { participants }\end{array}$ & Statistical method & Effect size \\
\hline $\begin{array}{l}01 \text { Adductor muscle strength }(\mathrm{kp}) \\
\text { at } 9 \text { weeks }\end{array}$ & 2 & 87 & Weighted Mean Difference (Fixed) 95\% CI & $1.20[-0.79,3.19]$ \\
\hline $\begin{array}{l}02 \text { Orthopaedic complication (as } \\
\text { reason for withdrawal from } \\
\text { trial) }\end{array}$ & & & Relative Risk (Fixed) 95\% CI & Totals not selected \\
\hline 03 Length of hospital stay (days) & 2 & 87 & Weighted Mean Difference (Fixed) 95\% CI & $-2.76[-11.92,6.40]$ \\
\hline $\begin{array}{l}04 \text { Withdrawal from trial by } \\
\text { patient }\end{array}$ & & & Relative Risk (Fixed) 95\% CI & Totals not selected \\
\hline $\begin{array}{l}05 \text { Non-completion of training } \\
\text { programme }\end{array}$ & & & Relative Risk (Fixed) 95\% CI & Totals not selected \\
\hline
\end{tabular}

\section{Comparison 03. Weight-bearing exercises versus non-weight-bearing exercises}

\begin{tabular}{|c|c|c|c|c|}
\hline Outcome title & $\begin{array}{l}\text { No. of } \\
\text { studies }\end{array}$ & $\begin{array}{c}\text { No. of } \\
\text { participants }\end{array}$ & Statistical method & Effect size \\
\hline $\begin{array}{l}01 \text { Unable to walk at all or without } \\
\text { two sticks or a frame }\end{array}$ & & & Relative Risk (Fixed) 95\% CI & Totals not selected \\
\hline $\begin{array}{l}02 \text { Unable to do a lateral step-up } \\
\text { unsupported or with one hand } \\
\text { alone }\end{array}$ & & & Relative Risk (Fixed) 95\% CI & Totals not selected \\
\hline 03 Gait parameters & & & Weighted Mean Difference (Fixed) 95\% CI & Totals not selected \\
\hline $\begin{array}{l}04 \text { Physical Performance and } \\
\text { Mobility Examination score } \\
\text { (0:failure to } 12 \text { :top score) }\end{array}$ & & & Weighted Mean Difference (Fixed) 95\% CI & Totals not selected \\
\hline 05 Strength measures (newtons) & & & Weighted Mean Difference (Fixed) 95\% CI & Totals not selected \\
\hline 06 Balance & & & Weighted Mean Difference (Fixed) 95\% CI & Totals not selected \\
\hline $\begin{array}{l}07 \text { Subjective rating of pain, fall } \\
\text { risk, balance, sleep quality and } \\
\text { general health }\end{array}$ & & & Relative Risk (Fixed) 95\% CI & Totals not selected \\
\hline 08 Fracture fixation problems & & & Relative Risk (Fixed) 95\% CI & Totals not selected \\
\hline $\begin{array}{l}09 \text { Total length of stay in hospital } \\
\text { (days) }\end{array}$ & & & Weighted Mean Difference (Fixed) 95\% CI & Totals not selected \\
\hline
\end{tabular}




\section{Comparison 04. Quadriceps training programme}

\begin{tabular}{|c|c|c|c|c|}
\hline Outcome title & $\begin{array}{l}\text { No. of } \\
\text { studies }\end{array}$ & $\begin{array}{c}\text { No. of } \\
\text { participants }\end{array}$ & Statistical method & Effect size \\
\hline 01 Leg extensor power (watts) & & & Weighted Mean Difference (Fixed) 95\% CI & Totals not selected \\
\hline 02 Mortality & & & Relative Risk (Fixed) 95\% CI & Totals not selected \\
\hline
\end{tabular}

\section{Comparison 05. Treadmill gait training versus conventional gait training}

\begin{tabular}{|c|c|c|c|c|}
\hline Outcome title & $\begin{array}{l}\text { No. of } \\
\text { studies }\end{array}$ & $\begin{array}{c}\text { No. of } \\
\text { participants }\end{array}$ & Statistical method & Effect size \\
\hline $\begin{array}{l}01 \text { Failure to regain pre-fracture } \\
\text { mobility }\end{array}$ & & & Relative Risk (Fixed) 95\% CI & Totals not selected \\
\hline 02 Gait velocity (metres/minute) & & & Weighted Mean Difference (Fixed) 95\% CI & Totals not selected \\
\hline
\end{tabular}

\section{Comparison 06. Neuromuscular stimulation versus placebo}

\begin{tabular}{|c|c|c|c|c|}
\hline Outcome title & $\begin{array}{l}\text { No. of } \\
\text { studies }\end{array}$ & $\begin{array}{c}\text { No. of } \\
\text { participants }\end{array}$ & Statistical method & Effect size \\
\hline $\begin{array}{l}01 \text { Failure to regain pre-fracture } \\
\text { mobility }\end{array}$ & & & Relative Risk (Fixed) 95\% CI & Totals not selected \\
\hline $\begin{array}{l}02 \text { Unable to 'tandem stand' } \\
\text { (postural instability) }\end{array}$ & & & Relative Risk (Fixed) 95\% CI & Totals not selected \\
\hline $\begin{array}{l}03 \text { Gait velocity (walking speed } \\
\text { over } 15.25 \text { metres) (metres/ } \\
\text { second) }\end{array}$ & & & Weighted Mean Difference (Fixed) 95\% CI & Totals not selected \\
\hline $\begin{array}{l}04 \text { Leg extensor power (watts/ } \\
\text { kilogram) }\end{array}$ & & & Weighted Mean Difference (Fixed) 95\% CI & Totals not selected \\
\hline $\begin{array}{l}05 \text { Pain }(6 \text { point scale: } 6=\text { constant } \\
\text { severe pain) }\end{array}$ & & & Weighted Mean Difference (Fixed) 95\% CI & Totals not selected \\
\hline
\end{tabular}

\section{Comparison 07. Intensive physical training versus placebo activities (started post-discharge)}

\begin{tabular}{|c|c|c|c|c|}
\hline Outcome title & $\begin{array}{l}\text { No. of } \\
\text { studies }\end{array}$ & $\begin{array}{c}\text { No. of } \\
\text { participants }\end{array}$ & Statistical method & Effect size \\
\hline 01 Gait parameters & & & Weighted Mean Difference (Fixed) 95\% CI & Totals not selected \\
\hline $\begin{array}{l}02 \text { Tinetti's POMA (Performance } \\
\text { orientated mobility assessment) }\end{array}$ & & & Weighted Mean Difference (Fixed) 95\% CI & Totals not selected \\
\hline 03 Loss of social independence & & & Relative Risk (Fixed) 95\% CI & Totals not selected \\
\hline $\begin{array}{l}04 \text { Functional performance } \\
\text { measures }\end{array}$ & & & Weighted Mean Difference (Fixed) 95\% CI & Totals not selected \\
\hline 05 Functional performance tests & & & Weighted Mean Difference (Fixed) 95\% CI & Totals not selected \\
\hline 06 Strength measures & & & Weighted Mean Difference (Fixed) 95\% CI & Totals not selected \\
\hline 07 Balance & & & Weighted Mean Difference (Fixed) 95\% CI & Totals not selected \\
\hline $\begin{array}{l}08 \text { Subjective/emotional state } \\
\text { assessment, falls, balance and } \\
\text { general }\end{array}$ & & & Weighted Mean Difference (Fixed) 95\% CI & Totals not selected \\
\hline 09 Adherence & & & Weighted Mean Difference (Fixed) 95\% CI & Totals not selected \\
\hline
\end{tabular}

Mobilisation strategies after hip fracture surgery in adults (Review)

Copyright (c) 2006 The Cochrane Collaboration. Published by John Wiley \& Sons, Ltd 


\section{Comparison 08. Home-based exercises programme (started at 22 weeks) versus control}

\begin{tabular}{|c|c|c|c|}
\hline Outcome title & $\begin{array}{lc}\text { No. of } & \text { No. of } \\
\text { studies } & \text { participants }\end{array}$ & Statistical method & Effect size \\
\hline 01 Mobility & & Relative Risk (Fixed) 95\% CI & Totals not selected \\
\hline 02 Gait parameters & & Weighted Mean Difference (Fixed) 95\% CI & Totals not selected \\
\hline $\begin{array}{l}03 \text { Physical Performance and } \\
\text { Mobility Examination score } \\
\text { (0:failure to } 12 \text { :top score) }\end{array}$ & & Weighted Mean Difference (Fixed) 95\% CI & Totals not selected \\
\hline 04 Functional performance tests & & Weighted Mean Difference (Fixed) 95\% CI & Totals not selected \\
\hline 05 Strength measures (newtons) & & Weighted Mean Difference (Fixed) 95\% CI & Totals not selected \\
\hline 06 Balance & & Weighted Mean Difference (Fixed) 95\% CI & Totals not selected \\
\hline $\begin{array}{l}07 \text { Subjective rating of pain, fall } \\
\text { risk, balance, sleep quality and } \\
\text { general health }\end{array}$ & & Relative Risk (Fixed) 95\% CI & Totals not selected \\
\hline $\begin{array}{l}08 \text { Fell at least once during } \\
\text { intervention period ( } 4 \text { months) }\end{array}$ & & Relative Risk (Fixed) 95\% CI & Totals not selected \\
\hline 09 Mortality & & Relative Risk (Fixed) 95\% CI & Totals not selected \\
\hline
\end{tabular}

\section{Comparison 09. Home-based weight bearing exercises programme (started at 22 weeks) versus control}

\begin{tabular}{|c|c|c|c|}
\hline Outcome title & $\begin{array}{lc}\begin{array}{l}\text { No. of } \\
\text { studies }\end{array} & \begin{array}{c}\text { No. of } \\
\text { participants }\end{array} \\
\end{array}$ & Statistical method & Effect size \\
\hline 01 Mobility & & Relative Risk (Fixed) 95\% CI & Totals not selected \\
\hline 02 Gait parameters & & Weighted Mean Difference (Fixed) 95\% CI & Totals not selected \\
\hline $\begin{array}{l}03 \text { Physical Performance and } \\
\text { Mobility Examination score } \\
\text { (0:failure to } 12 \text { :top score) }\end{array}$ & & Weighted Mean Difference (Fixed) 95\% CI & Totals not selected \\
\hline 04 Functional performance tests & & Weighted Mean Difference (Fixed) 95\% CI & Totals not selected \\
\hline 05 Strength measures (newtons) & & Weighted Mean Difference (Fixed) 95\% CI & Totals not selected \\
\hline 06 Balance & & Weighted Mean Difference (Fixed) 95\% CI & Totals not selected \\
\hline $\begin{array}{l}07 \text { Subjective rating of pain, fall } \\
\text { risk, balance, sleep quality and } \\
\text { general health }\end{array}$ & & Relative Risk (Fixed) 95\% CI & Totals not selected \\
\hline $\begin{array}{l}08 \text { Fell at least once during } \\
\text { intervention period ( } 4 \text { months) }\end{array}$ & & Relative Risk (Fixed) 95\% CI & Totals not selected \\
\hline 09 Mortality & & Relative Risk (Fixed) 95\% CI & Totals not selected \\
\hline
\end{tabular}

Comparison 10. Home-based non-weight bearing exercises programme (started 22 at weeks) versus control

\begin{tabular}{|c|c|c|c|}
\hline Outcome title & $\begin{array}{lc}\text { No. of } & \text { No. of } \\
\text { studies } & \text { participants }\end{array}$ & Statistical method & Effect size \\
\hline 01 Mobility & & Relative Risk (Fixed) 95\% CI & Totals not selected \\
\hline 02 Gait parameters & & Weighted Mean Difference (Fixed) 95\% CI & Totals not selected \\
\hline $\begin{array}{l}03 \text { Physical Performance and } \\
\text { Mobility Examination score } \\
\text { (0:failure to 12:top score) }\end{array}$ & & Weighted Mean Difference (Fixed) 95\% CI & Totals not selected \\
\hline 04 Functional performance tests & & Weighted Mean Difference (Fixed) 95\% CI & Totals not selected \\
\hline 05 Strength measures (newtons) & & Weighted Mean Difference (Fixed) 95\% CI & Totals not selected \\
\hline 06 Balance & & Weighted Mean Difference (Fixed) 95\% CI & Totals not selected \\
\hline $\begin{array}{l}07 \text { Subjective rating of pain, fall } \\
\text { risk, balance, sleep quality and } \\
\text { general health }\end{array}$ & & Relative Risk (Fixed) 95\% CI & Totals not selected \\
\hline
\end{tabular}

Mobilisation strategies after hip fracture surgery in adults (Review) 
08 Fell at least once during intervention period ( 4 months)

09 Mortality
Relative Risk (Fixed) 95\% CI

Relative Risk (Fixed) 95\% CI
Totals not selected

Totals not selected

Comparison 11. Home-based weight bearing versus non-weight-bearing exercises programme (started at 22 weeks)

\begin{tabular}{|c|c|c|c|}
\hline Outcome title & $\begin{array}{lc}\begin{array}{l}\text { No. of } \\
\text { studies }\end{array} & \begin{array}{c}\text { No. of } \\
\text { participants }\end{array} \\
\end{array}$ & Statistical method & Effect size \\
\hline 01 Mobility & & Relative Risk (Fixed) 95\% CI & Totals not selected \\
\hline 02 Gait parameters & & Weighted Mean Difference (Fixed) 95\% CI & Totals not selected \\
\hline $\begin{array}{l}03 \text { Physical Performance and } \\
\text { Mobility Examination score } \\
\text { (0:failure to 12:top score) }\end{array}$ & & Weighted Mean Difference (Fixed) 95\% CI & Totals not selected \\
\hline 04 Functional performance tests & & Weighted Mean Difference (Fixed) 95\% CI & Totals not selected \\
\hline 05 Strength measures (newtons) & & Weighted Mean Difference (Fixed) 95\% CI & Totals not selected \\
\hline 06 Balance & & Weighted Mean Difference (Fixed) 95\% CI & Totals not selected \\
\hline $\begin{array}{l}07 \text { Subjective rating of pain, fall } \\
\text { risk, balance, sleep quality and } \\
\text { general health }\end{array}$ & & Relative Risk (Fixed) 95\% CI & Totals not selected \\
\hline $\begin{array}{l}08 \text { Fell at least once during } \\
\text { intervention period ( } 4 \text { months) }\end{array}$ & & Relative Risk (Fixed) 95\% CI & Totals not selected \\
\hline 09 Mortality & & Relative Risk (Fixed) 95\% CI & Totals not selected \\
\hline $\begin{array}{l}10 \text { Participant's participation in } \\
\text { and perception of exercise } \\
\text { programmes }\end{array}$ & & Relative Risk (Fixed) 95\% CI & Totals not selected \\
\hline
\end{tabular}

\section{Comparison 12. Home-based exercises programme (started at 7 months)}

\begin{tabular}{|c|c|c|c|c|}
\hline Outcome title & $\begin{array}{l}\text { No. of } \\
\text { studies }\end{array}$ & $\begin{array}{c}\text { No. of } \\
\text { participants }\end{array}$ & Statistical method & Effect size \\
\hline $\begin{array}{l}01 \text { Inability to perform weight- } \\
\text { bearing test without hand } \\
\text { support }\end{array}$ & & & Relative Risk (Fixed) 95\% CI & Totals not selected \\
\hline 02 Gait parameters & & & Weighted Mean Difference (Fixed) 95\% CI & Totals not selected \\
\hline 03 Strength $(\mathrm{kg})$ & & & Weighted Mean Difference (Fixed) 95\% CI & Totals not selected \\
\hline 04 Balance (postural control) & & & Weighted Mean Difference (Fixed) 95\% CI & Totals not selected \\
\hline $\begin{array}{l}05 \text { Subjective rating of balance and } \\
\text { fall risk }\end{array}$ & & & Relative Risk (Fixed) 95\% CI & Totals not selected \\
\hline
\end{tabular}

\section{NDEX TERMS}

\section{Medical Subject Headings (MeSH)}

Gait; Hip Fractures [*rehabilitation; surgery]; Locomotion; Movement; *Physical Therapy Modalities; Program Evaluation; Randomized Controlled Trials; Weight-Bearing

\section{MeSH check words}

Adult; Humans

\section{COVER SHEET}




\section{Authors}

\section{Contribution of author(s)}

Issue protocol first published

Review first published

Date of most recent amendment

Date of most recent

SUBSTANTIVE amendment

\section{What's New}

Handoll HHG, Sherrington C, Parker MJ

Martyn Parker initiated and designed the review and compiled the first draft of the review. Helen Handoll located the review studies, checked data entry and critically rewrote and completed the first draft. Three reviewers, Yvonne Dynan, Helen Handoll and Martyn Parker performed independent quality assessment and data extraction of the included trials. The first update was initiated and drafted by Martyn Parker. Helen Handoll located the review studies, checked data entry, contacted some of the trialists and critically rewrote and completed the first draft. All three reviewers named above performed independent quality assessment and data extraction of newly included trial materials.

The second update was initiated by Martyn Parker (MP). Helen Handoll (HH) and MP located the review studies and contacted some of the trialists. HH, MP and Catherine Sherrington (CS) performed independent study selection, and quality assessment and data extraction of newly included trial materials. HH completed the first draft, which was checked and corrected by the other two reviewers.

The third update was initiated by HH. CS and $\mathrm{HH}$ located the review studies and contacted trialists. HH, MP and CS performed independent study selection. HH and either MP or CS performed independent quality assessment and data extraction of newly included trial materials. HH completed the first draft, which was checked and corrected by the other two reviewers.

All three named reviewers are guarantors of the review.

$1999 / 3$

$2000 / 3$

19 August 2004

23 June 2004

The main changes for the third update of this review, published Issue 4, 2004, were:

(1) Expansion of the scope of the review to cover interventions aimed at initiating and enhancing mobilisation throughout the whole rehabilitation process.

(2) Types of outcome measures and the order of presentation of the trials were revised upon reconsideration of the new scope of the review.

(3) Date of search for trials was extended to May 2004.

(4) Four studies were newly included. One (Sherrington 1993) applied to the early postoperative period; the other three (Hauer 2002; Sherrington 2004; Sherrington 1997) took place after hospital discharge.

(5) Four newly identified studies were excluded (Crotty 2002; Hesse 2003; Lehmann 1961; Tinetti 1999).

(6) Two previously ongoing studies are now excluded (Allegrante 2001; Maltby 2000) as is one trial previously awaiting assessment (Johnston 1995).

(7) One trial (Binder 2001) previously awaiting assessment is now listed as an ongoing study.

(8) One newly identifed study (Mangione 2001) awaits assessment.

(9) Various changes were made to comply with the Cochrane Style Guide.

(10) The conclusions of the review were revised to accommodate the new scope of the review.

For details of previous updates, please see 'Published Notes'.

31 May 2004

Information not supplied by author 
Date new studies found and included/excluded

Date authors' conclusions section amended

\section{Contact address}

DOI

Cochrane Library number

Editorial group

Editorial group code
15 May 2004

23 June 2004

Dr Helen Handoll

University of Teesside

c/o University Department of Orthopaedic Surgery

Royal Infirmary of Edinburgh

Little France

Old Dalkeith Road

Edinburgh

EH16 4SU

UK

E-mail: h.handoll@ed.ac.uk

Tel: +441312423499

Fax: +441312426467

10.1002/14651858.CD001704.pub2

CD001704

Cochrane Bone, Joint and Muscle Trauma Group (formerly the Musculoskeletal Injuries Group)

HM-MUSKINJ

Analysis 01.0I. Comparison 0 I Early versus delayed weight bearing, Outcome 0 I Mortality

Review: Mobilisation strategies after hip fracture surgery in adults

Comparison: 0 I Early versus delayed weight bearing

Outcome: 01 Mortality

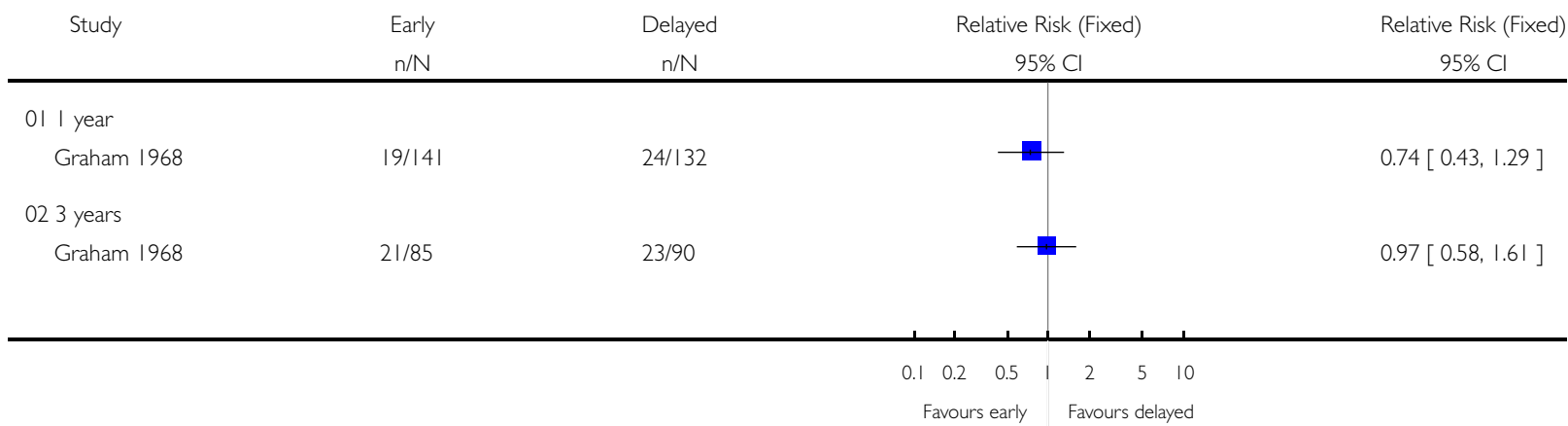


Analysis 01.02 . Comparison 01 Early versus delayed weight bearing, Outcome 02 Non-union (fixation failure)

\begin{tabular}{|c|c|c|c|c|}
\hline \multicolumn{5}{|c|}{$\begin{array}{l}\text { Comparison: } 01 \text { Early versus delayed weight bearing } \\
\text { Outcome: } 02 \text { Non-union (fixation failure) }\end{array}$} \\
\hline \multirow[t]{2}{*}{ Study } & Early & Delayed & Relative Risk (Fixed) & Relative Risk (Fixed) \\
\hline & $n / N$ & $n / N$ & $95 \% \mathrm{Cl}$ & $95 \% \mathrm{Cl}$ \\
\hline \multicolumn{5}{|l|}{011 year } \\
\hline Graham 1968 & $18 / 116$ & $14 / 96$ & & $1.06[0.56,2.03]$ \\
\hline \multicolumn{5}{|l|}{023 years } \\
\hline Graham 1968 & $13 / 57$ & $13 / 55$ & $\square$ & $0.96[0.49,1.89]$ \\
\hline
\end{tabular}

Analysis 01.03. Comparison 01 Early versus delayed weight bearing, Outcome 03 Avascular necrosis

Review: Mobilisation strategies after hip fracture surgery in adults

Comparison: 0 I Early versus delayed weight bearing

Outcome: 03 Avascular necrosis

\begin{tabular}{|c|c|c|c|c|}
\hline Study & Early & Delayed & Relative Risk (Fixed) & Relative Risk (Fixed) \\
\hline \multicolumn{5}{|l|}{$0 \mid$ I year } \\
\hline Graham 1968 & $3 / 116$ & 9/96 & 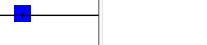 & $0.28[0.08,0.99]$ \\
\hline \multicolumn{5}{|l|}{023 years } \\
\hline Graham 1968 & $10 / 57$ & $14 / 55$ & $-\mathbf{n}$ & $0.69[0.33,1.42]$ \\
\hline
\end{tabular}




\section{Analysis 01.04. Comparison 01 Early versus delayed weight bearing, Outcome 04 Unfavourable outcome}

(death, failure or infection)

Review: Mobilisation strategies after hip fracture surgery in adults

Comparison: 01 Early versus delayed weight bearing

Outcome: 04 Unfavourable outcome (death, failure or infection)

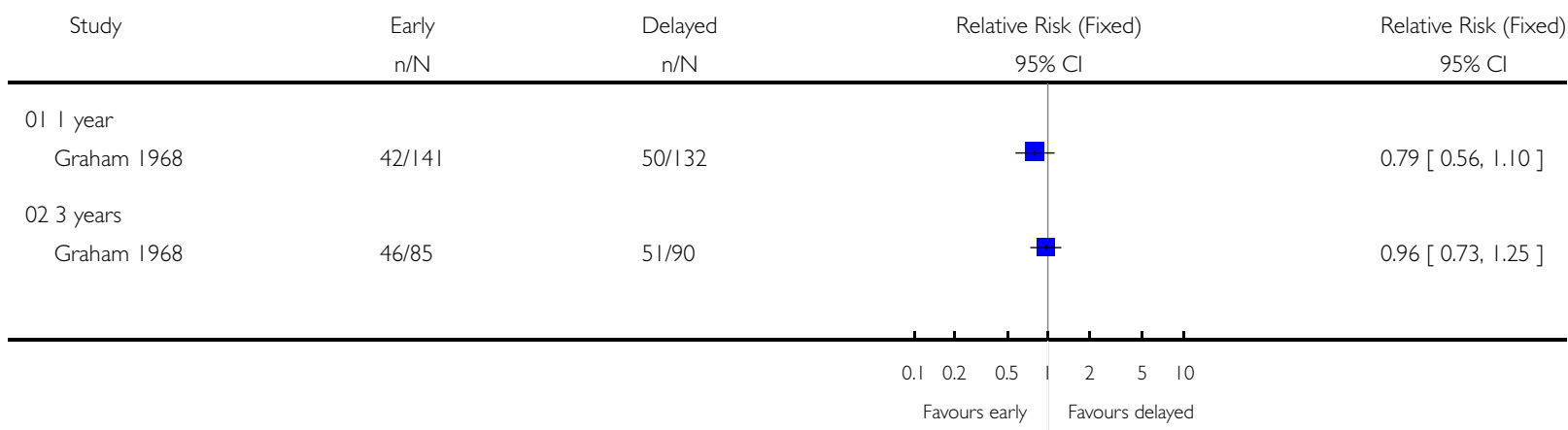

Analysis 02.01. Comparison 02 Intensive versus usual physiotherapy, Outcome 01 Adductor muscle strength (kp) at 9 weeks

Review: Mobilisation strategies after hip fracture surgery in adults

Comparison: 02 Intensive versus usual physiotherapy

Outcome: 0 I Adductor muscle strength $(\mathrm{kp})$ at 9 weeks

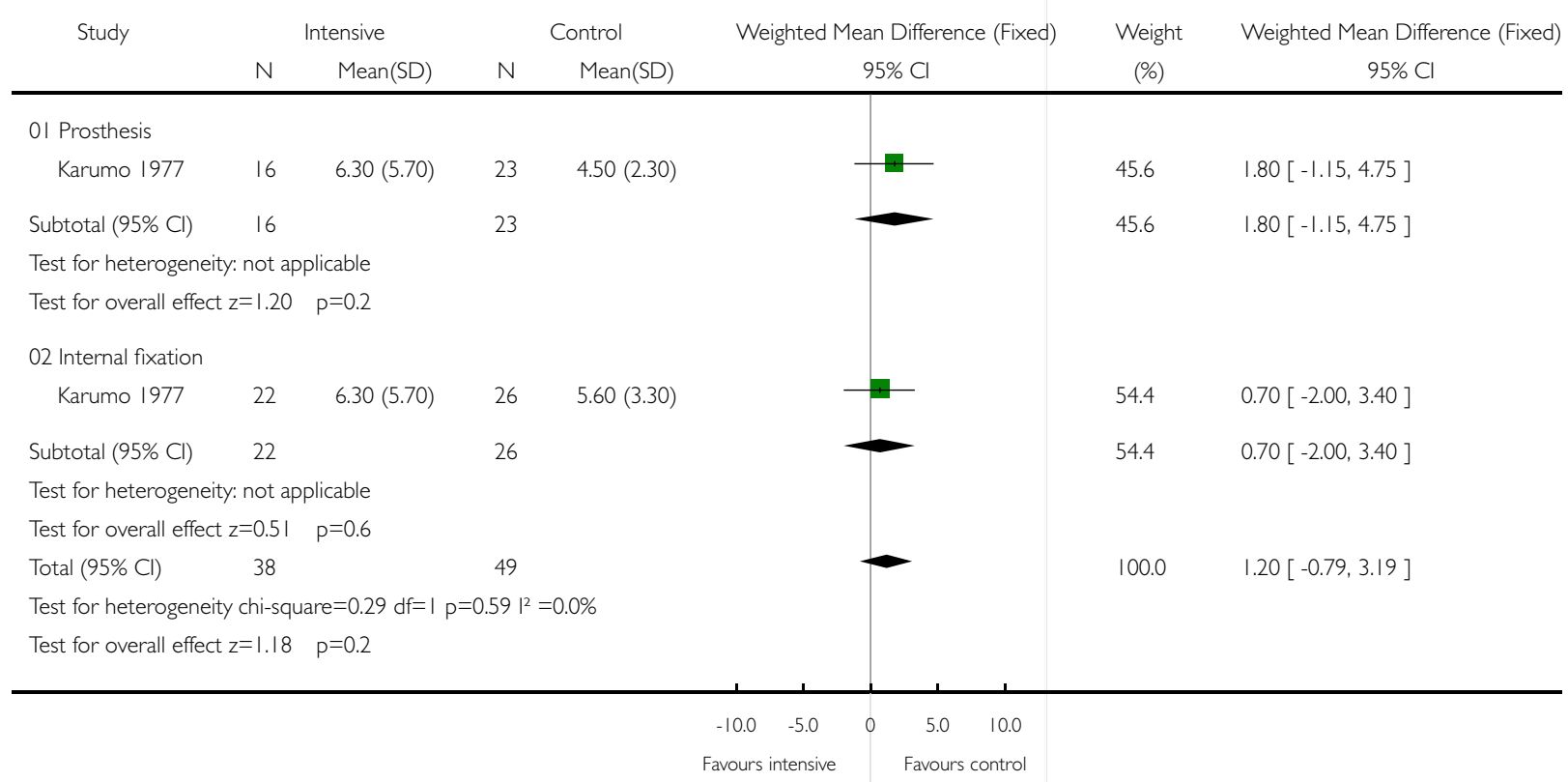


Analysis 02.02. Comparison 02 Intensive versus usual physiotherapy, Outcome 02 Orthopaedic complication (as reason for withdrawal from trial)

Review: Mobilisation strategies after hip fracture surgery in adults

Comparison: 02 Intensive versus usual physiotherapy

Outcome: 02 Orthopaedic complication (as reason for withdrawal from trial)

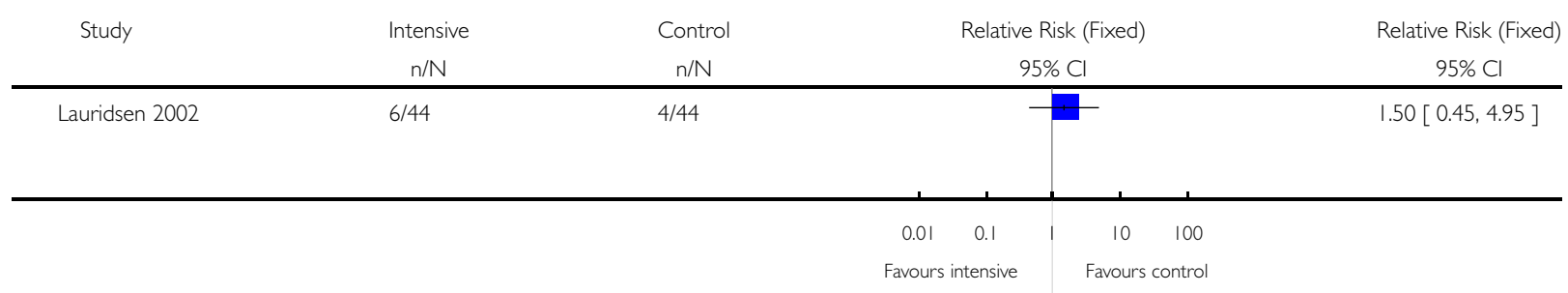

Analysis 02.03. Comparison 02 Intensive versus usual physiotherapy, Outcome 03 Length of hospital stay (days)

Review: Mobilisation strategies after hip fracture surgery in adults

Comparison: 02 Intensive versus usual physiotherapy

Outcome: 03 Length of hospital stay (days)

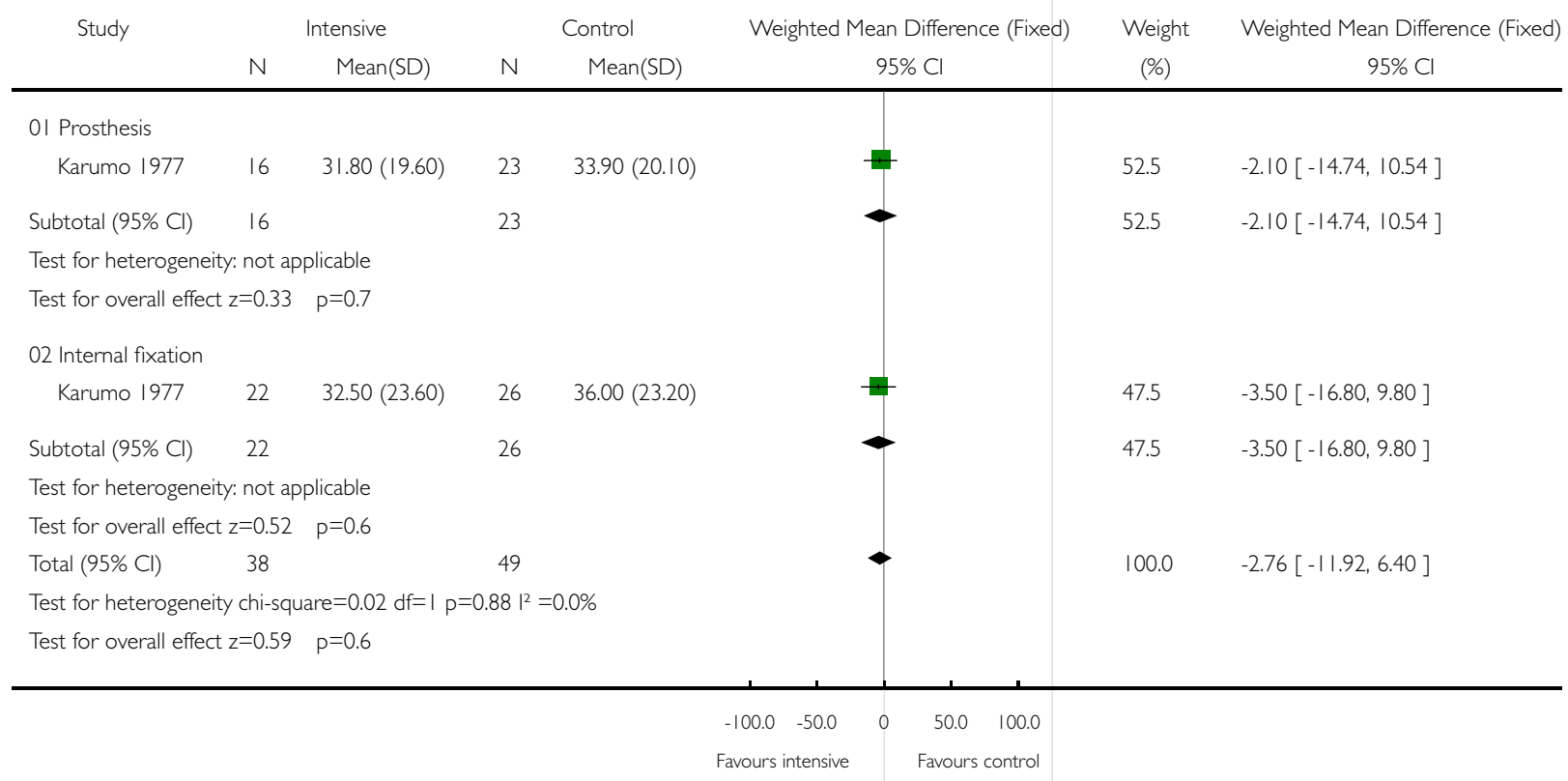


Analysis 02.04. Comparison 02 Intensive versus usual physiotherapy, Outcome 04 Withdrawal from trial by patient

Review: Mobilisation strategies after hip fracture surgery in adults

Comparison: 02 Intensive versus usual physiotherapy

Outcome: 04 Withdrawal from trial by patient

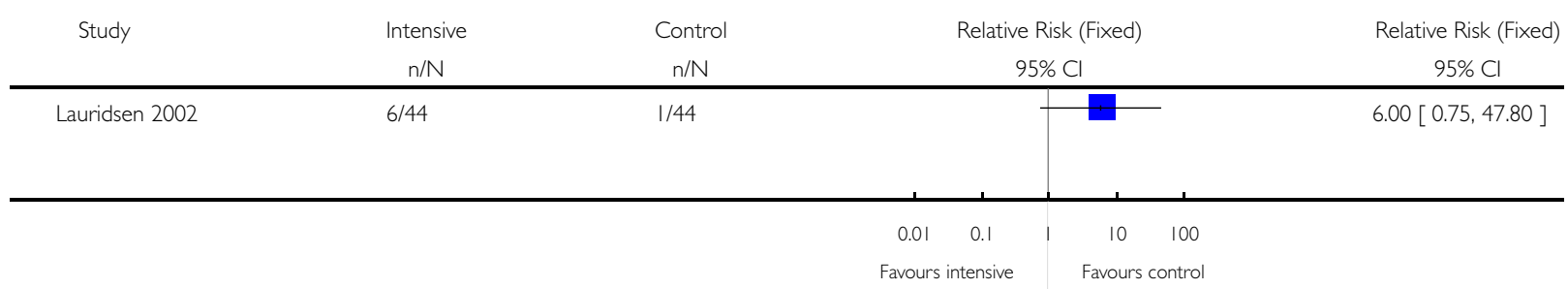

Analysis 02.05. Comparison 02 Intensive versus usual physiotherapy, Outcome 05 Non-completion of training programme

\begin{tabular}{|c|c|c|c|c|}
\hline \multicolumn{5}{|c|}{ Comparison: 02 Intensive versus usual physiotherapy } \\
\hline Study & Intensive & Control & Relative Risk (Fixed) & Relative Risk (Fixed) \\
\hline & $\mathrm{n} / \mathrm{N}$ & $n / N$ & $95 \% \mathrm{Cl}$ & $95 \% \mathrm{Cl}$ \\
\hline Lauridsen 2002 & $24 / 44$ & $13 / 44$ & - & $1.85[1.09,3.14]$ \\
\hline
\end{tabular}

Analysis 03.01. Comparison 03 Weight-bearing exercises versus non-weight-bearing exercises, Outcome 01 Unable to walk at all or without two sticks or a frame

Review: Mobilisation strategies after hip fracture surgery in adults

Comparison: 03 Weight-bearing exercises versus non-weight-bearing exercises

Outcome: 0 I Unable to walk at all or without two sticks or a frame

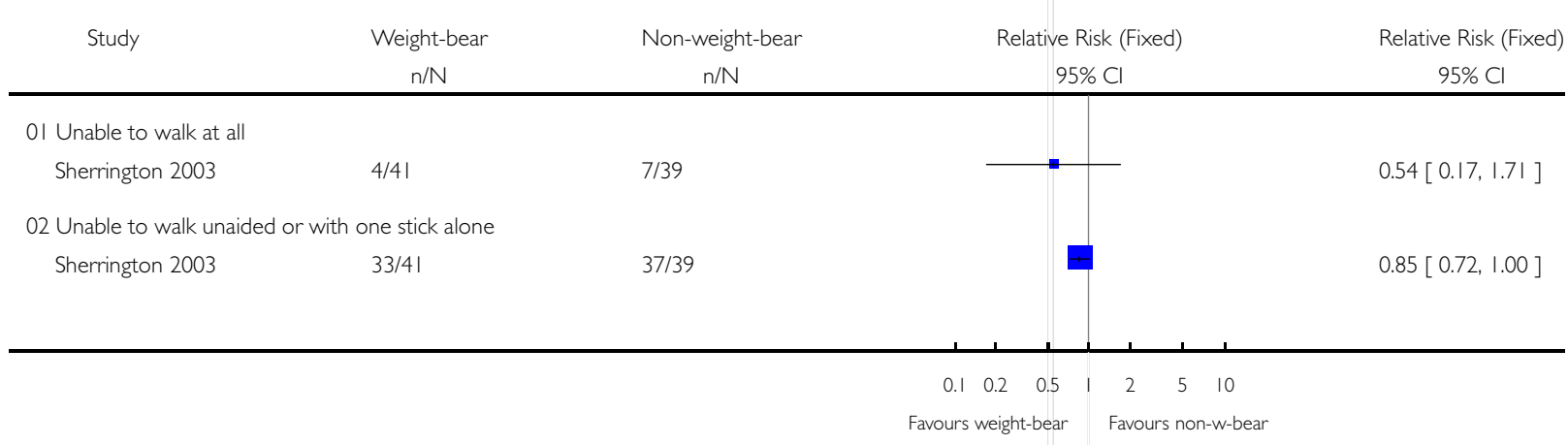


Analysis 03.02. Comparison 03 Weight-bearing exercises versus non-weight-bearing exercises, Outcome 02 Unable to do a lateral step-up unsupported or with one hand alone

Review: Mobilisation strategies after hip fracture surgery in adults

Comparison: 03 Weight-bearing exercises versus non-weight-bearing exercises

Outcome: 02 Unable to do a lateral step-up unsupported or with one hand alone

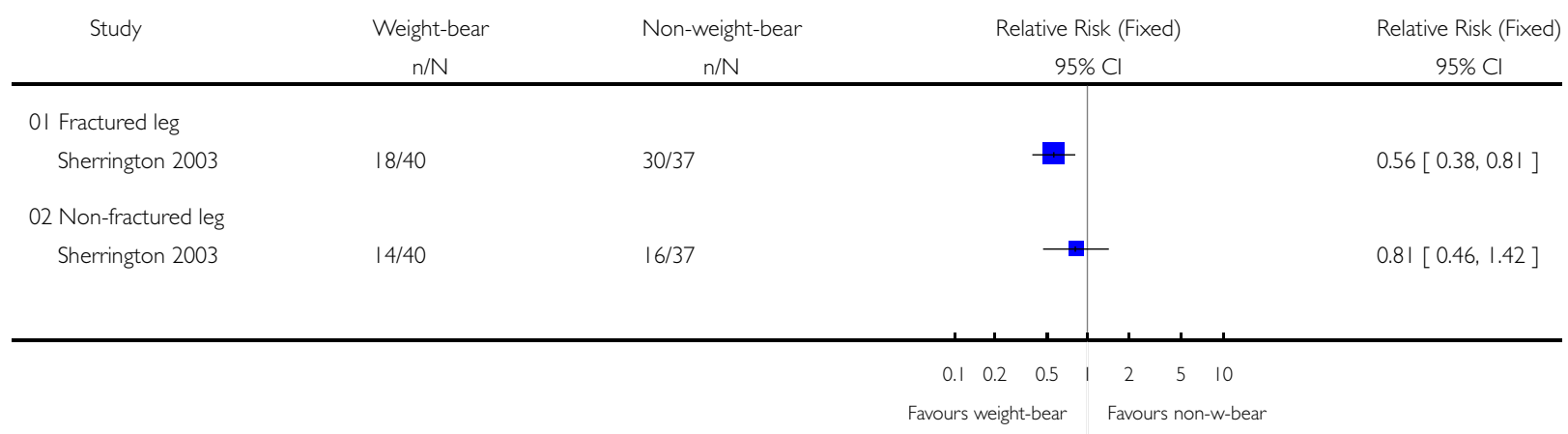

Analysis 03.03. Comparison 03 Weight-bearing exercises versus non-weight-bearing exercises, Outcome 03 Gait parameters

Review: Mobilisation strategies after hip fracture surgery in adults

Comparison: 03 Weight-bearing exercises versus non-weight-bearing exercises

Outcome: 03 Gait parameters

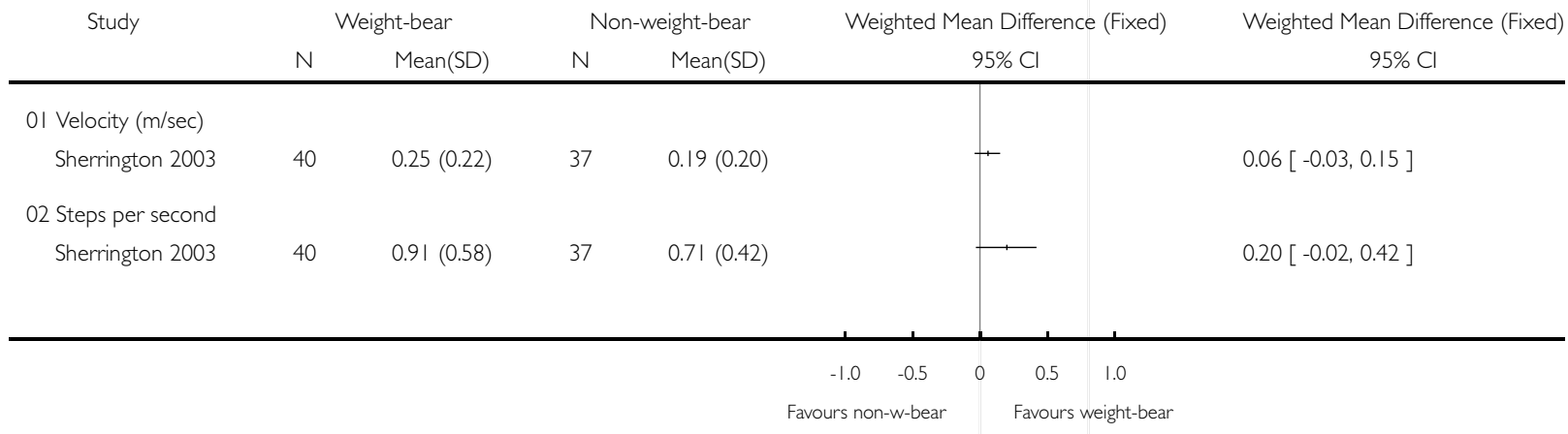

Analysis 03.04. Comparison 03 Weight-bearing exercises versus non-weight-bearing exercises, Outcome 04 Physical Performance and Mobility Examination score (0:failure to I 2:top score)

Review: Mobilisation strategies after hip fracture surgery in adults

Comparison: 03 Weight-bearing exercises versus non-weight-bearing exercises

Outcome: 04 Physical Performance and Mobility Examination score (0:failure to 12:top score)

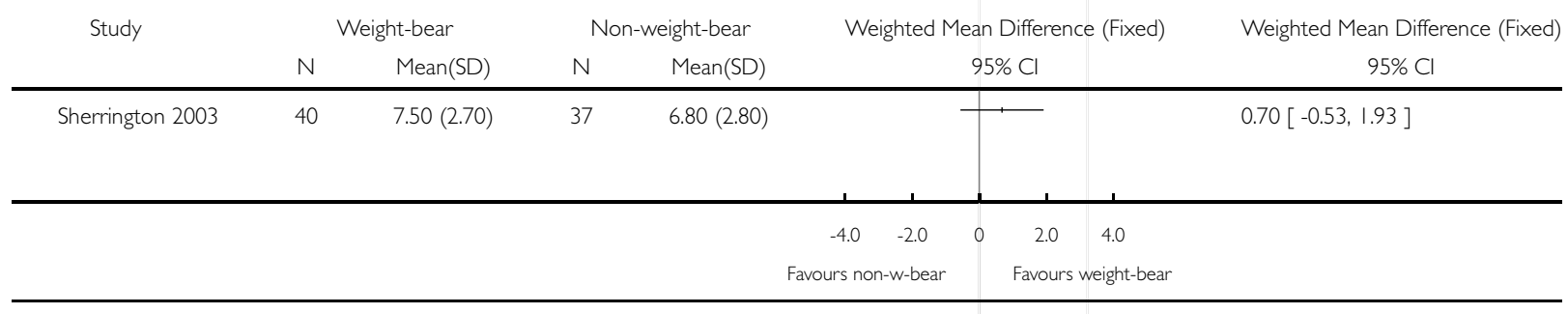

Mobilisation strategies after hip fracture surgery in adults (Review) 
Analysis 03.05. Comparison 03 Weight-bearing exercises versus non-weight-bearing exercises, Outcome 05 Strength measures (newtons)

Review: Mobilisation strategies after hip fracture surgery in adults

Comparison: 03 Weight-bearing exercises versus non-weight-bearing exercises

Outcome: 05 Strength measures (newtons)

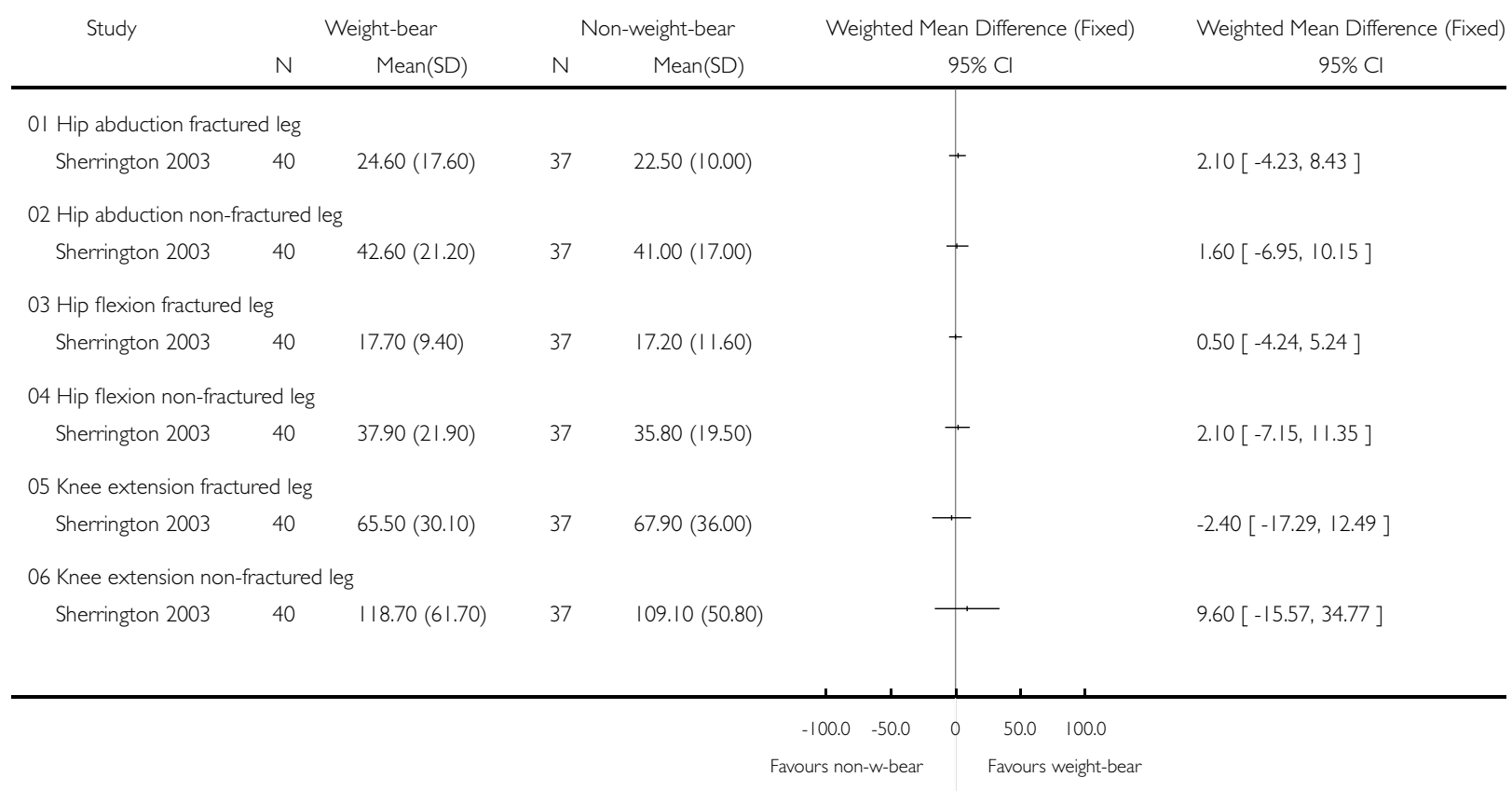

\section{Analysis 03.06. Comparison 03 Weight-bearing exercises versus non-weight-bearing exercises, Outcome 06}

\section{Balance}

Review: Mobilisation strategies after hip fracture surgery in adults

Comparison: 03 Weight-bearing exercises versus non-weight-bearing exercises

Outcome: 06 Balance

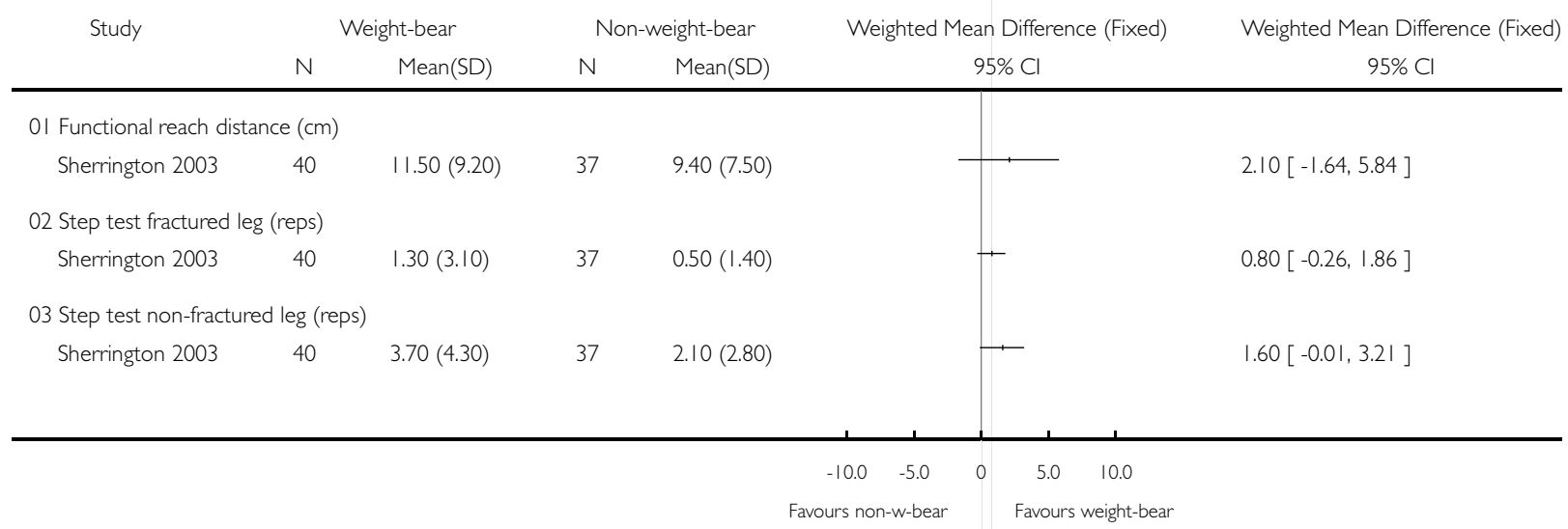

Mobilisation strategies after hip fracture surgery in adults (Review) 
Analysis 03.07. Comparison 03 Weight-bearing exercises versus non-weight-bearing exercises, Outcome 07 Subjective rating of pain, fall risk, balance, sleep quality and general health

Review: Mobilisation strategies after hip fracture surgery in adults

Comparison: 03 Weight-bearing exercises versus non-weight-bearing exercises

Outcome: 07 Subjective rating of pain, fall risk, balance, sleep quality and general health

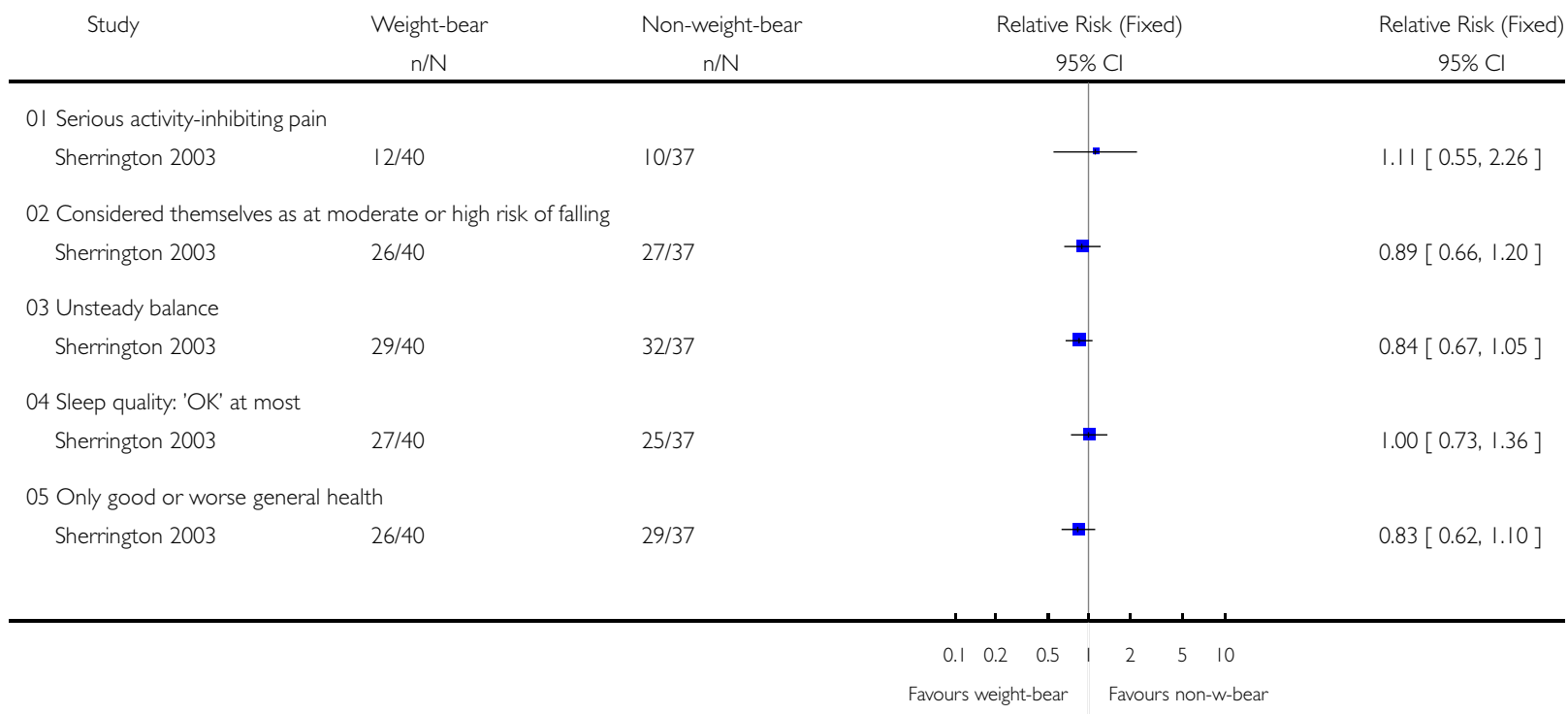

Analysis 03.08. Comparison 03 Weight-bearing exercises versus non-weight-bearing exercises, Outcome 08 Fracture fixation problems

Review: Mobilisation strategies after hip fracture surgery in adults

Comparison: 03 Weight-bearing exercises versus non-weight-bearing exercises

Outcome: 08 Fracture fixation problems

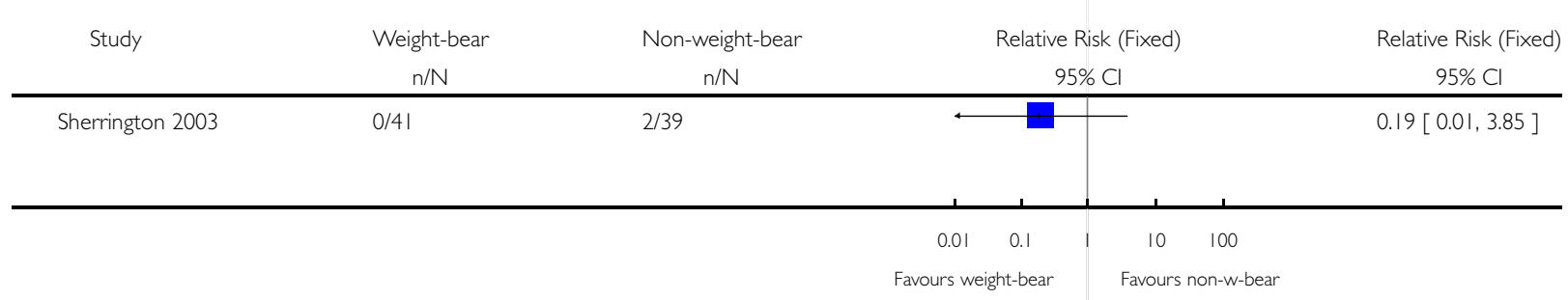


Analysis 03.09. Comparison 03 Weight-bearing exercises versus non-weight-bearing exercises, Outcome 09 Total length of stay in hospital (days)

Review: Mobilisation strategies after hip fracture surgery in adults

Comparison: 03 Weight-bearing exercises versus non-weight-bearing exercises

Outcome: 09 Total length of stay in hospital (days)

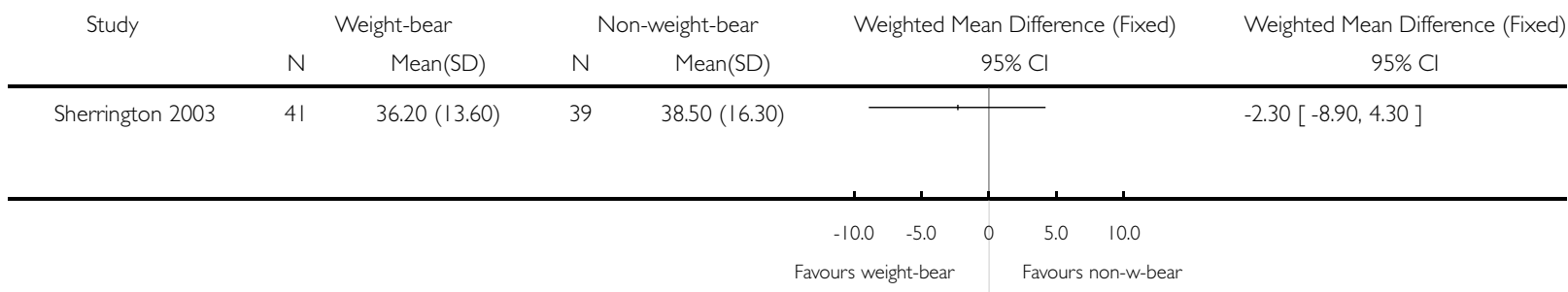

Analysis 03.10. Comparison 03 Weight-bearing exercises versus non-weight-bearing exercises, Outcome 10 Participant's perception of exercise programmes

Review: Mobilisation strategies after hip fracture surgery in adults

Comparison: 03 Weight-bearing exercises versus non-weight-bearing exercises

Outcome: 10 Participant's perception of exercise programmes

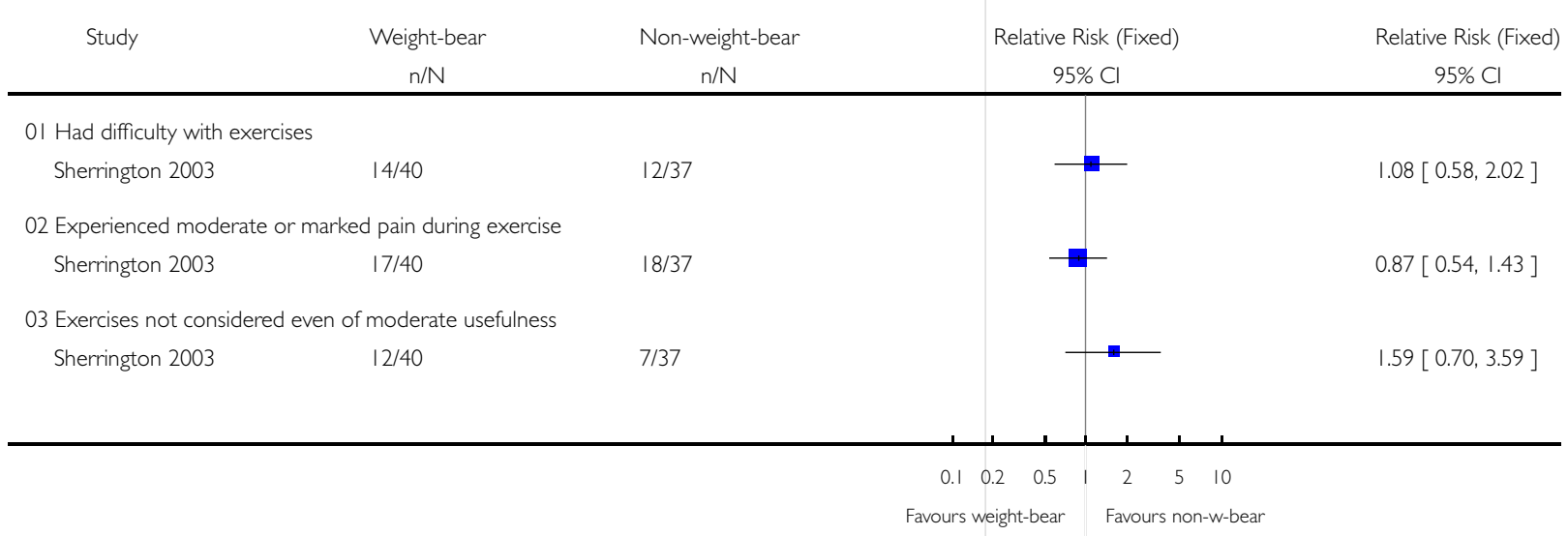


Analysis 04.01. Comparison 04 Quadriceps training programme, Outcome 01 Leg extensor power (watts) Review: Mobilisation strategies after hip fracture surgery in adults

Comparison: 04 Quadriceps training programme

Outcome: 01 Leg extensor power (watts)

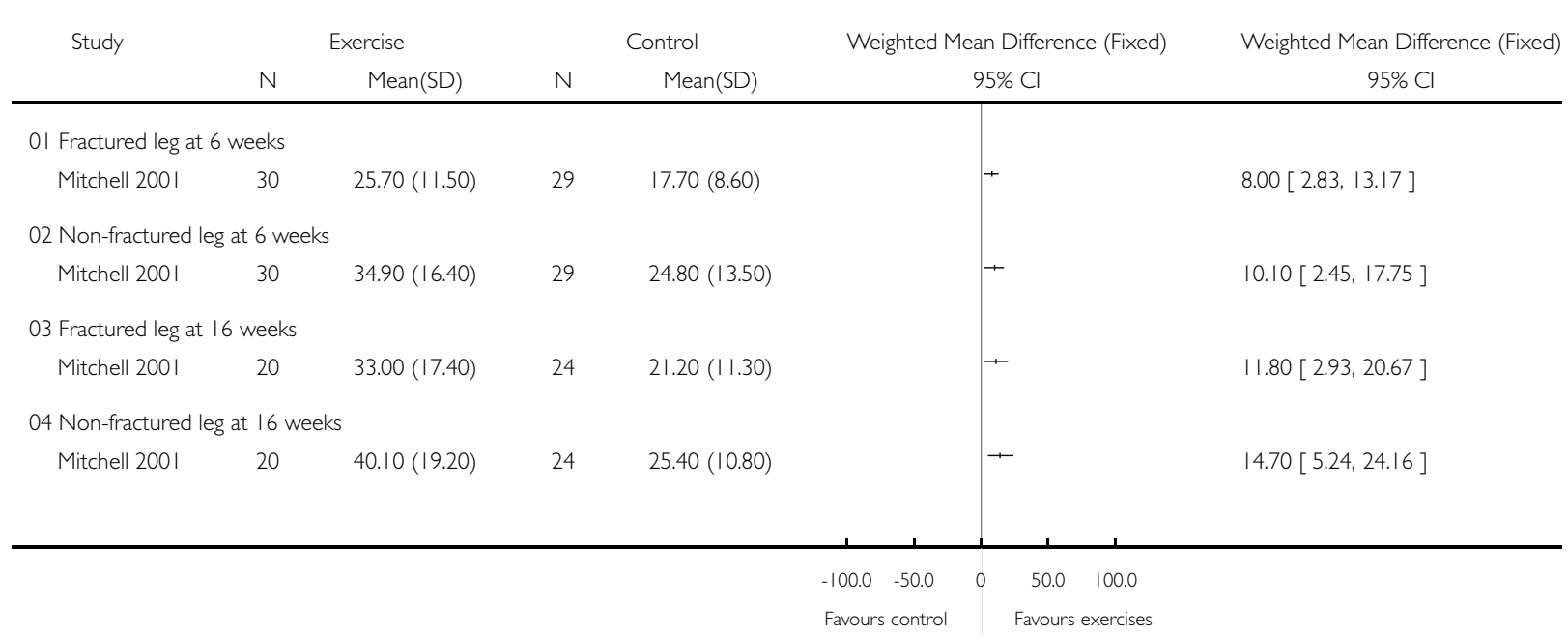

Analysis 04.02. Comparison 04 Quadriceps training programme, Outcome 02 Mortality

Review: Mobilisation strategies after hip fracture surgery in adults

Comparison: 04 Quadriceps training programme

Outcome: 02 Mortality

\begin{tabular}{|c|c|c|c|c|}
\hline Study & $\begin{array}{c}\text { Exercise } \\
n / N\end{array}$ & $\begin{array}{c}\text { Control } \\
\mathrm{n} / \mathrm{N}\end{array}$ & $\begin{array}{c}\text { Relative Risk (Fixed) } \\
\qquad 95 \% \mathrm{Cl}\end{array}$ & $\begin{array}{c}\text { Relative Risk (Fixed) } \\
\qquad 95 \% \mathrm{Cl}\end{array}$ \\
\hline Mitchell 200। & $4 / 40$ & $4 / 40$ & 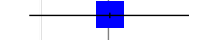 & $1.00[0.27,3.72]$ \\
\hline
\end{tabular}

Analysis 05.0I. Comparison 05 Treadmill gait training versus conventional gait training, Outcome 0 I Failure to regain pre-fracture mobility

Review: Mobilisation strategies after hip fracture surgery in adults

Comparison: 05 Treadmill gait training versus conventional gait training

Outcome: 0 I Failure to regain pre-fracture mobility

\begin{tabular}{|c|c|c|c|c|}
\hline Study & $\begin{array}{c}\text { Treadmill } \\
\mathrm{n} / \mathrm{N}\end{array}$ & $\begin{array}{c}\text { Control } \\
n / N\end{array}$ & $\begin{array}{c}\text { Relative Risk (Fixed) } \\
95 \% \mathrm{Cl}\end{array}$ & $\begin{array}{c}\text { Relative Risk (Fixed) } \\
95 \% \mathrm{Cl}\end{array}$ \\
\hline Baker |99| & 7/20 & $12 / 20$ & - & $0.58[0.29,1.17]$ \\
\hline & & & $\begin{array}{ccccccc}0.1 & 0.2 & 0.5 & 1 & 2 & 5 & 10 \\
\text { Eayours treadmill } & & \text { Eavours control }\end{array}$ & \\
\hline
\end{tabular}

Mobilisation strategies after hip fracture surgery in adults (Review)

Copyright ( 2006 The Cochrane Collaboration. Published by John Wiley \& Sons, Ltd 
Analysis 05.02. Comparison 05 Treadmill gait training versus conventional gait training, Outcome 02 Gait velocity (metres/minute)

Review: Mobilisation strategies after hip fracture surgery in adults

Comparison: 05 Treadmill gait training versus conventional gait training

Outcome: 02 Gait velocity (metres/minute)

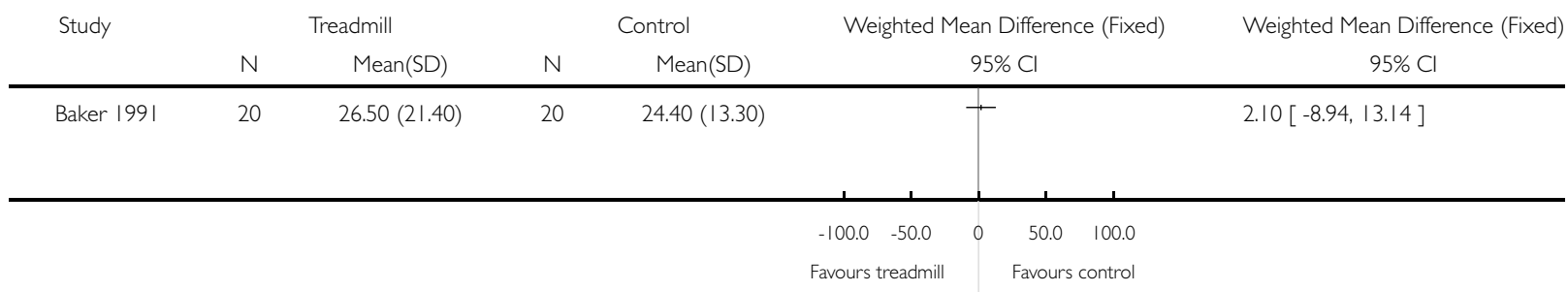

Analysis 06.01. Comparison 06 Neuromuscular stimulation versus placebo, Outcome 01 Failure to regain pre-fracture mobility

Review: Mobilisation strategies after hip fracture surgery in adults

Comparison: 06 Neuromuscular stimulation versus placebo

Outcome: 0 I Failure to regain pre-fracture mobility

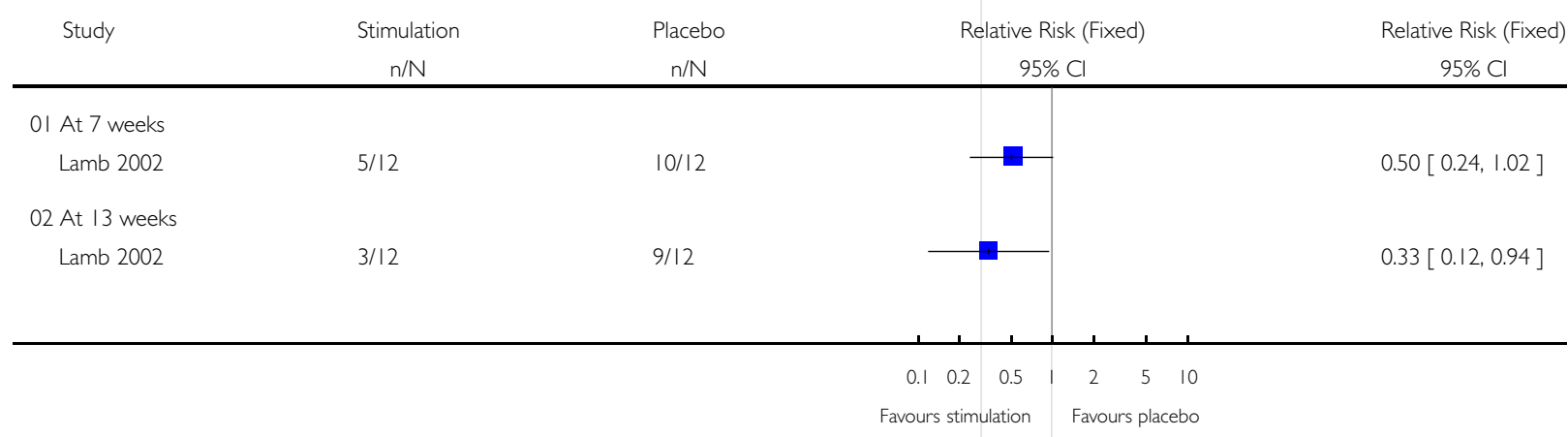

Analysis 06.02. Comparison 06 Neuromuscular stimulation versus placebo, Outcome 02 Unable to 'tandem stand' (postural instability)

Review: Mobilisation strategies after hip fracture surgery in adults

Comparison: 06 Neuromuscular stimulation versus placebo

Outcome: 02 Unable to 'tandem stand' (postural instability)

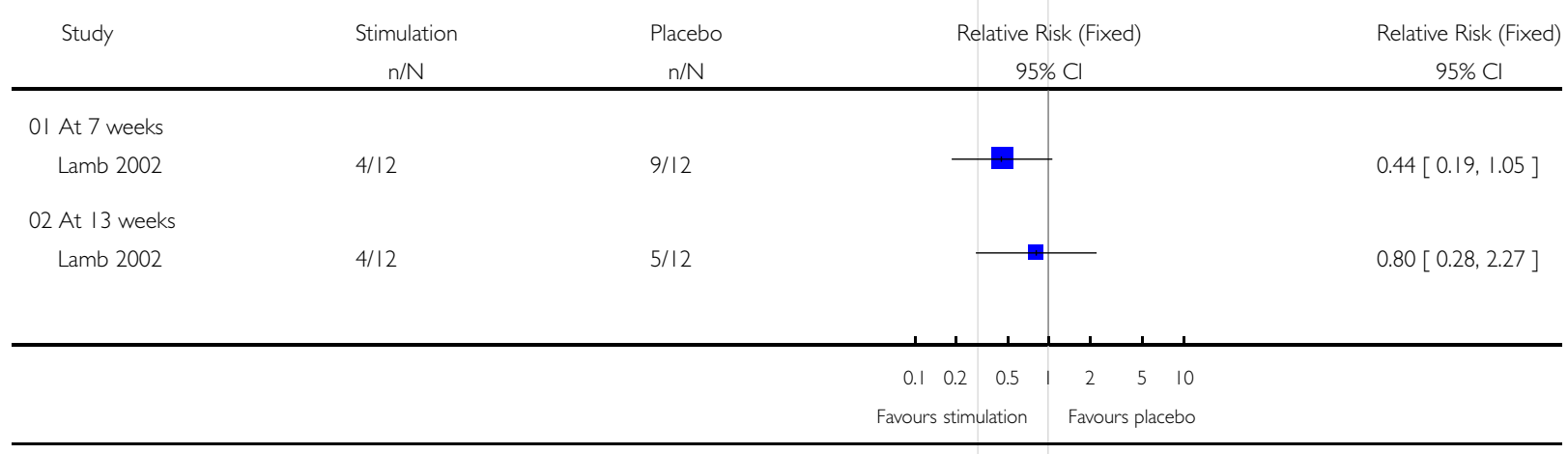

Mobilisation strategies after hip fracture surgery in adults (Review) 
Analysis 06.03. Comparison 06 Neuromuscular stimulation versus placebo, Outcome 03 Gait velocity (walking speed over 15.25 metres) (metres/second)

Review: Mobilisation strategies after hip fracture surgery in adults

Comparison: 06 Neuromuscular stimulation versus placebo

Outcome: 03 Gait velocity (walking speed over 15.25 metres) (metres/second)

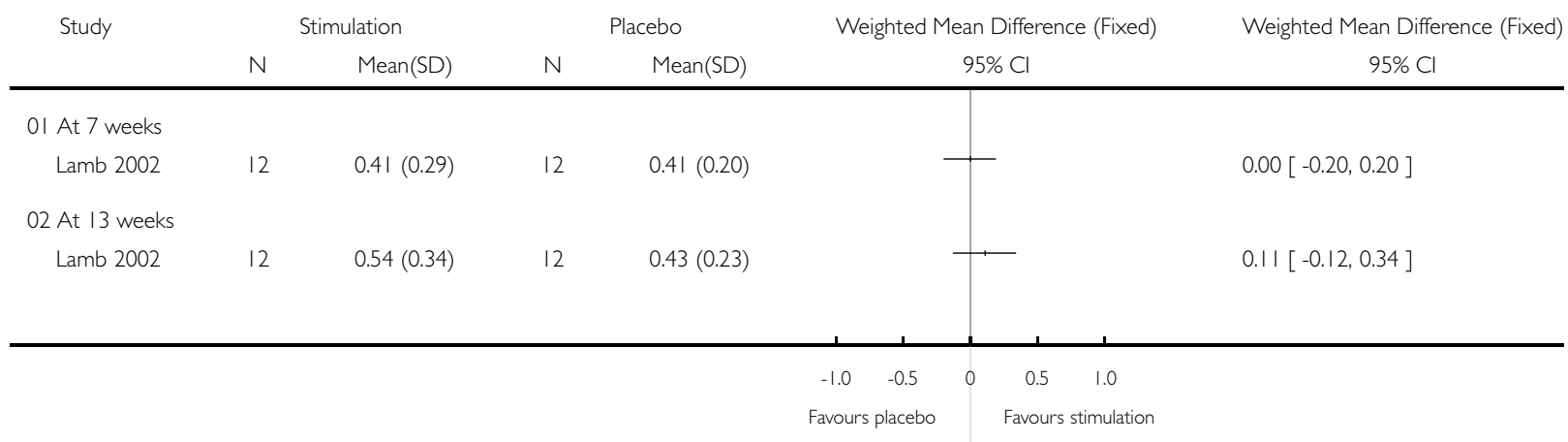

Analysis 06.04. Comparison 06 Neuromuscular stimulation versus placebo, Outcome 04 Leg extensor power (watts/kilogram)

Review: Mobilisation strategies after hip fracture surgery in adults

Comparison: 06 Neuromuscular stimulation versus placebo

Outcome: 04 Leg extensor power (watts/kilogram)

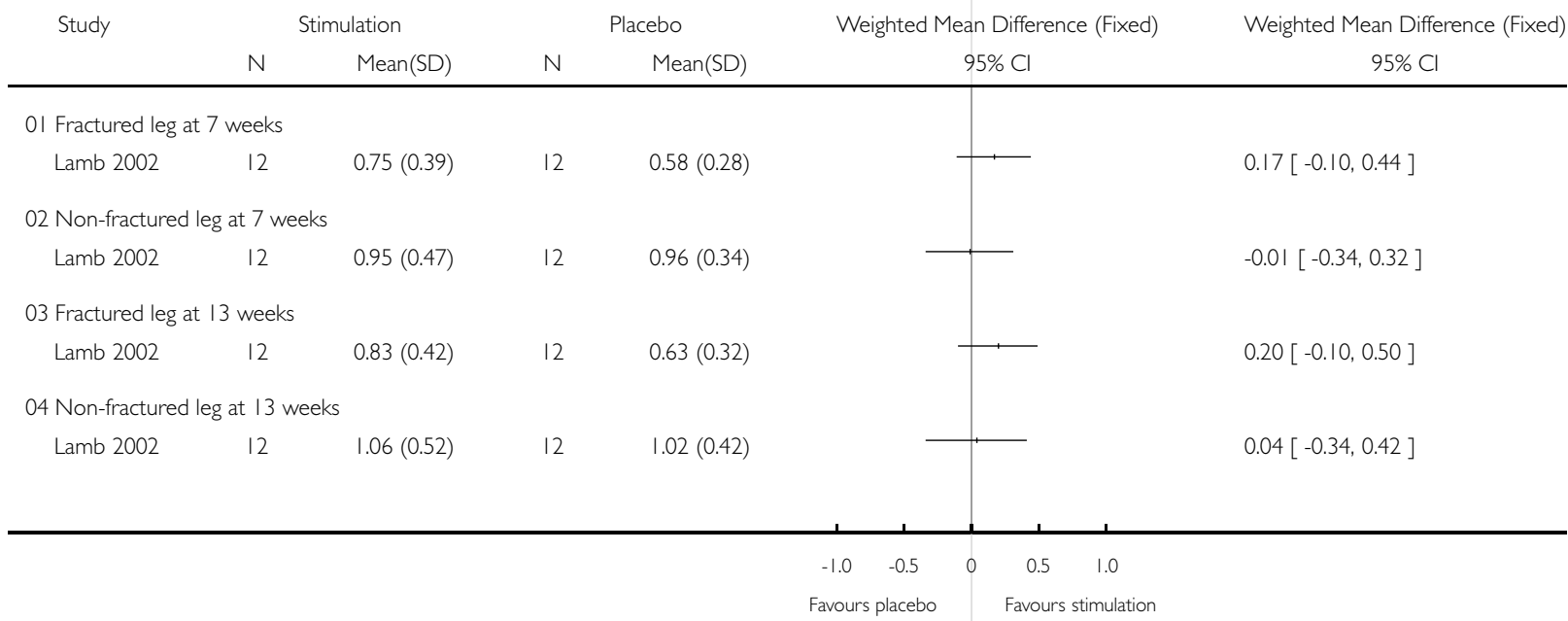


Analysis 06.05. Comparison 06 Neuromuscular stimulation versus placebo, Outcome 05 Pain (6 point scale: 6 = constant severe pain)

Review: Mobilisation strategies after hip fracture surgery in adults

Comparison: 06 Neuromuscular stimulation versus placebo

Outcome: 05 Pain (6 point scale: $6=$ constant severe pain)

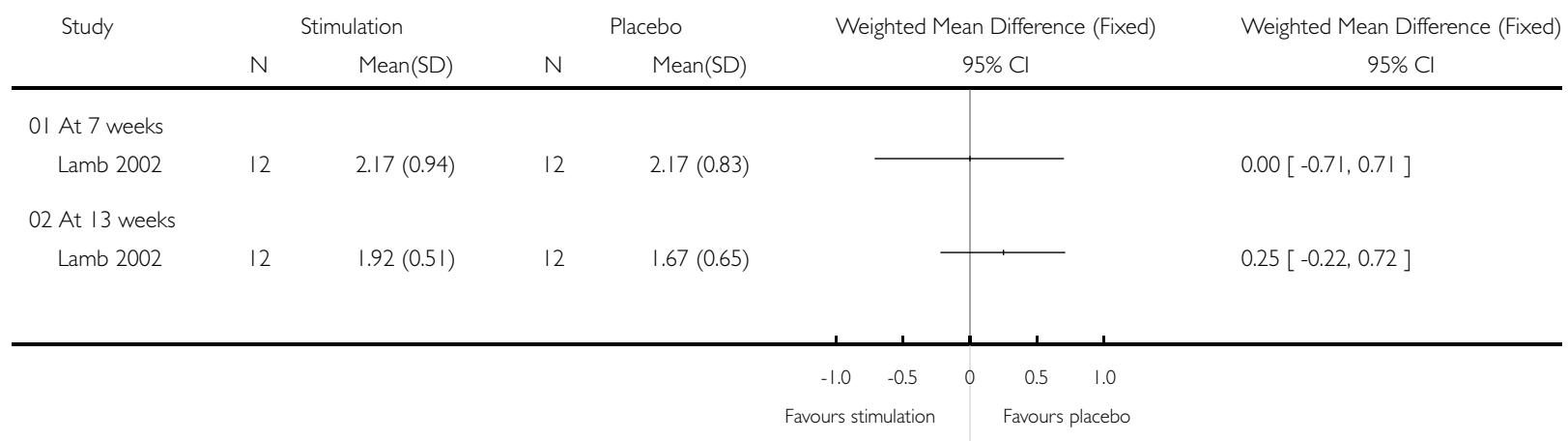

Analysis 07.01. Comparison 07 Intensive physical training versus placebo activities (started post-discharge), Outcome 0 I Gait parameters

Review: Mobilisation strategies after hip fracture surgery in adults

Comparison: 07 Intensive physical training versus placebo activities (started post-discharge)

Outcome: 01 Gait parameters

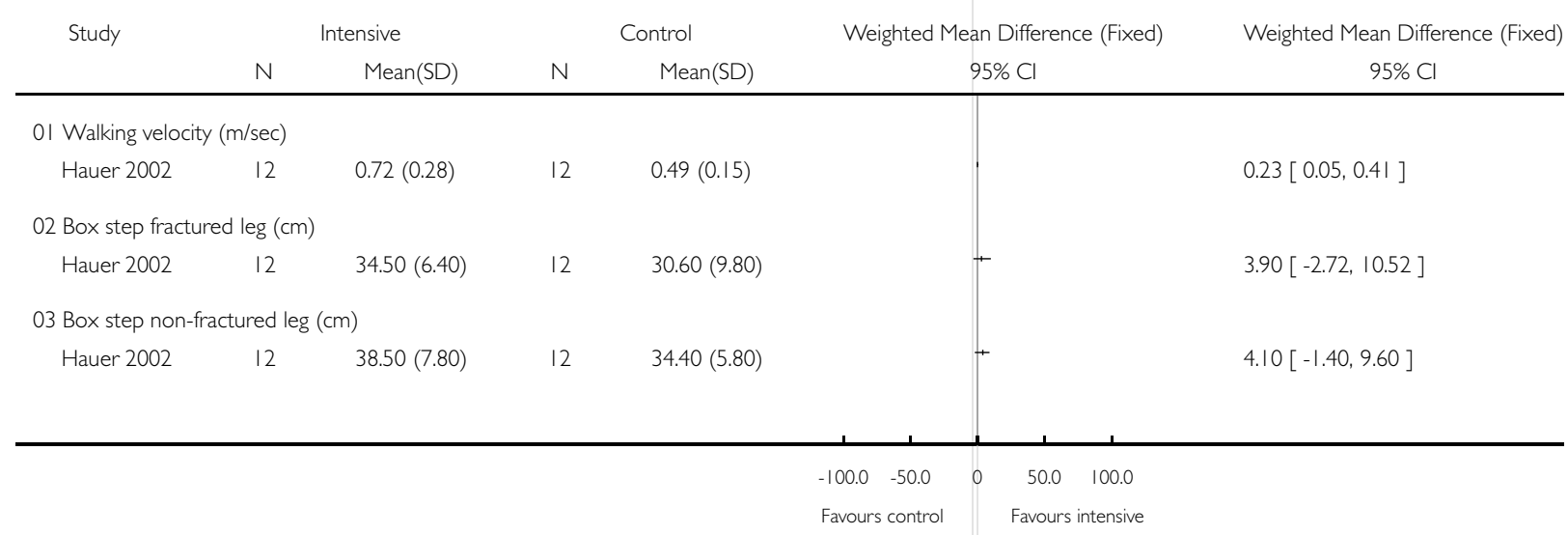


Analysis 07.02. Comparison 07 Intensive physical training versus placebo activities (started post-discharge), Outcome 02 Tinetti's POMA (Performance orientated mobility assessment)

Review: Mobilisation strategies after hip fracture surgery in adults

Comparison: 07 Intensive physical training versus placebo activities (started post-discharge)

Outcome: 02 Tinetti's POMA (Performance orientated mobility assessment)

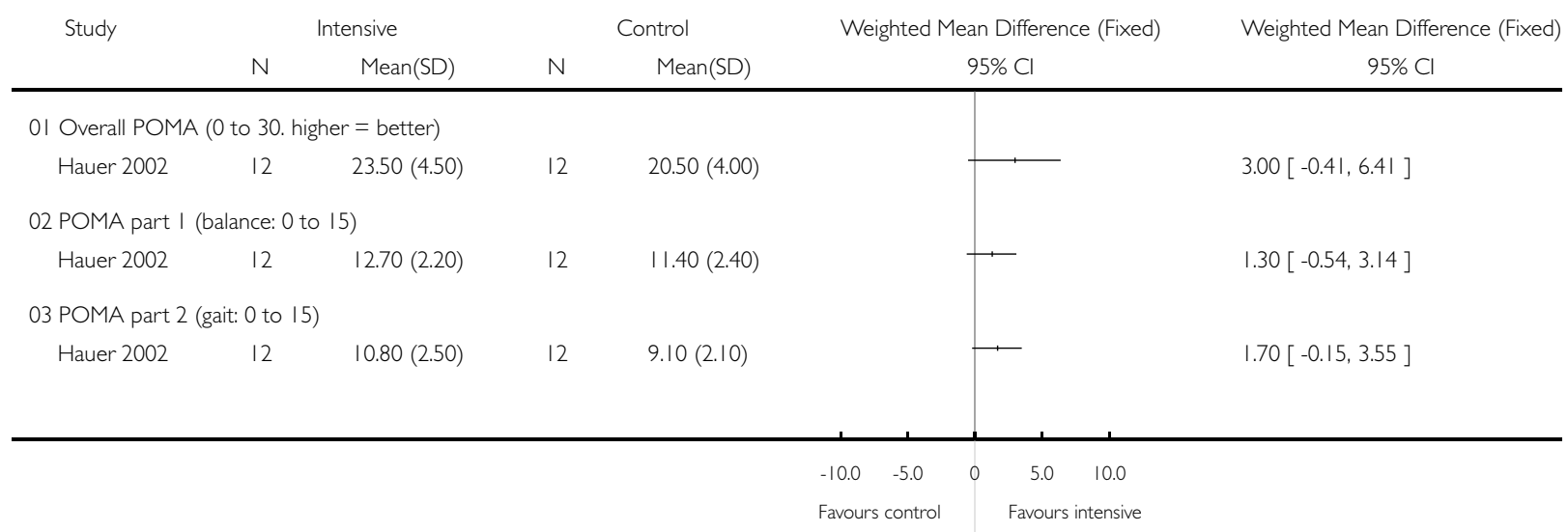

Analysis 07.03. Comparison 07 Intensive physical training versus placebo activities (started post-discharge), Outcome 03 Loss of social independence

Review: Mobilisation strategies after hip fracture surgery in adults

Comparison: 07 Intensive physical training versus placebo activities (started post-discharge)

Outcome: 03 Loss of social independence

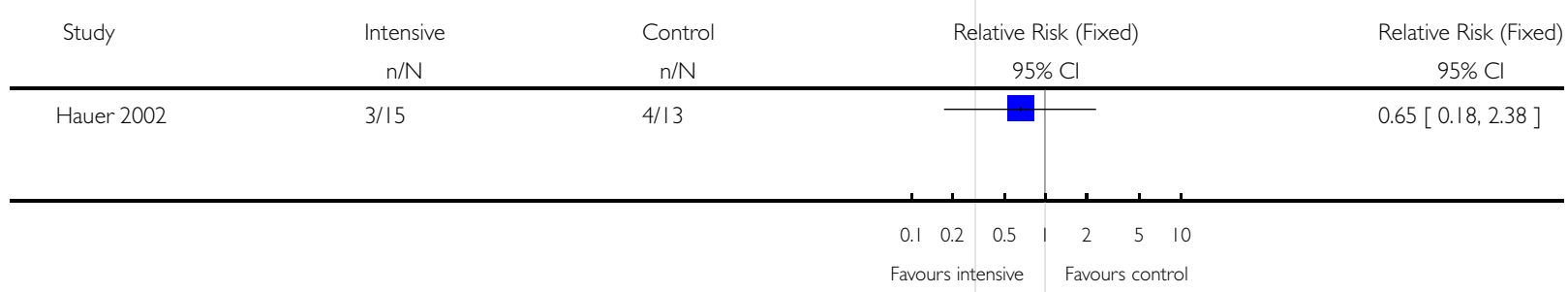


Analysis 07.04. Comparison 07 Intensive physical training versus placebo activities (started post-discharge), Outcome 04 Functional performance measures

Review: Mobilisation strategies after hip fracture surgery in adults

Comparison: 07 Intensive physical training versus placebo activities (started post-discharge)

Outcome: 04 Functional performance measures

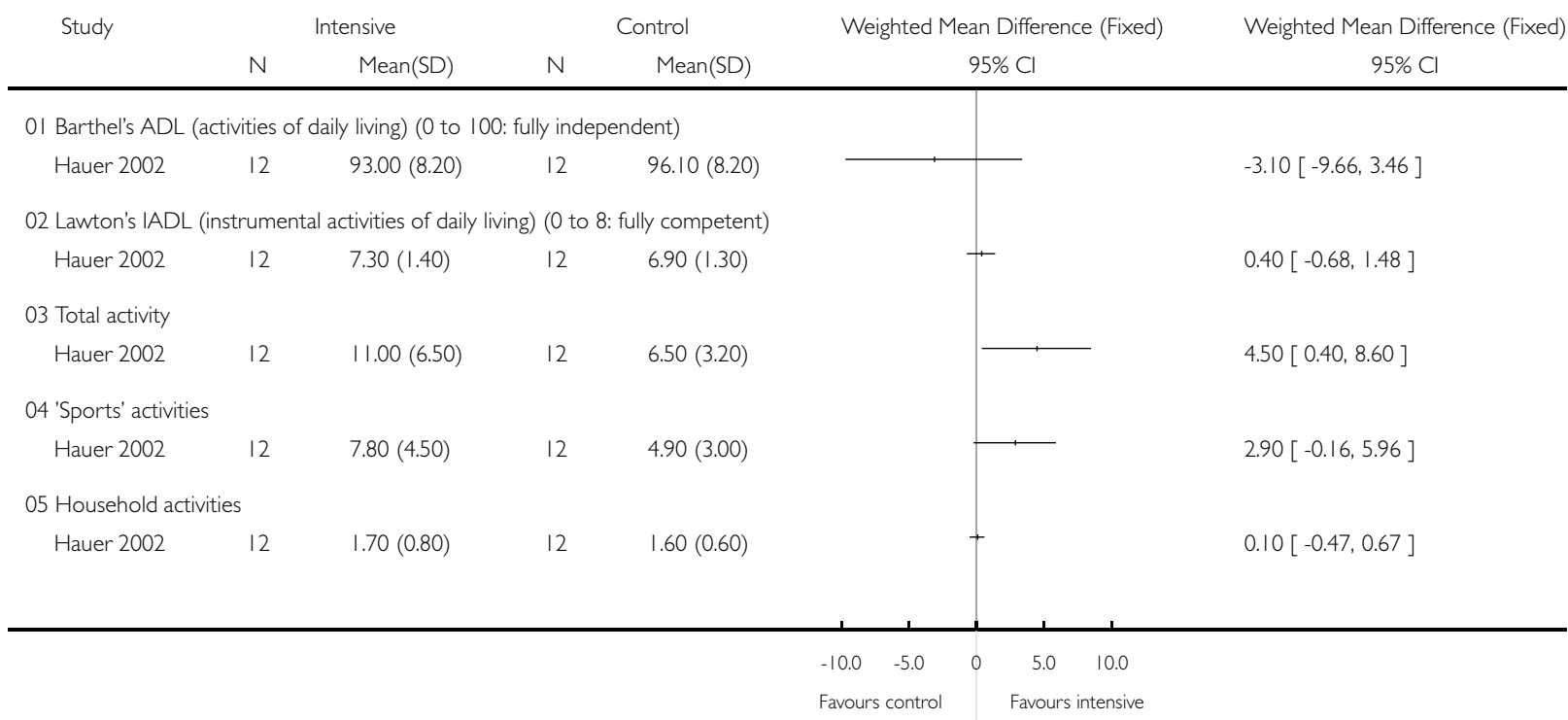

Analysis 07.05. Comparison 07 Intensive physical training versus placebo activities (started post-discharge), Outcome 05 Functional performance tests

Review: Mobilisation strategies after hip fracture surgery in adults

Comparison: 07 Intensive physical training versus placebo activities (started post-discharge)

Outcome: 05 Functional performance tests

$\begin{array}{cccccc} & \text { Intensive } & & \text { Control } & \text { Weighted Mean Difference (Fixed) } & \text { Weighted Mean Difference (Fixed) } \\ & N & \text { Mean(SD) } & N & \text { Mean(SD) } & 95 \% \mathrm{Cl}\end{array}$

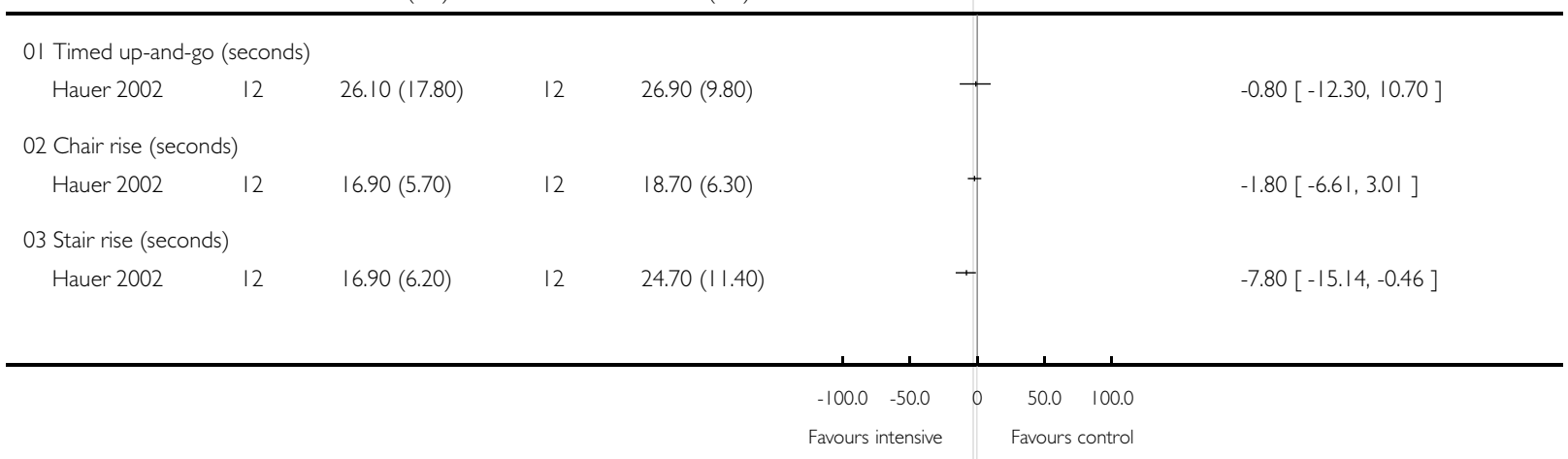


Analysis 07.06. Comparison 07 Intensive physical training versus placebo activities (started post-discharge), Outcome 06 Strength measures

Review: Mobilisation strategies after hip fracture surgery in adults

Comparison: 07 Intensive physical training versus placebo activities (started post-discharge)

Outcome: 06 Strength measures

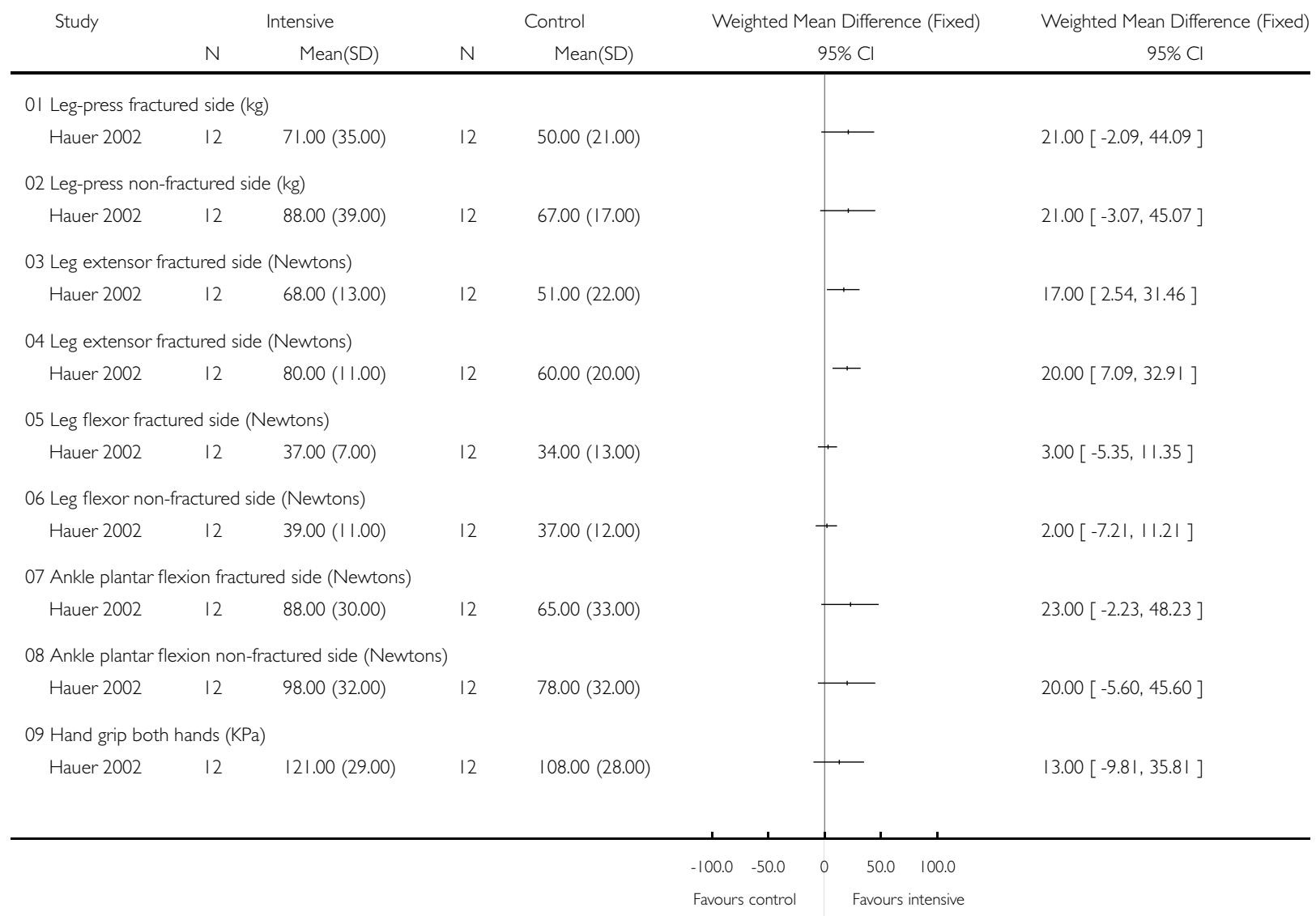


Analysis 07.07. Comparison 07 Intensive physical training versus placebo activities (started post-discharge), Outcome 07 Balance

Review: Mobilisation strategies after hip fracture surgery in adults

Comparison: 07 Intensive physical training versus placebo activities (started post-discharge)

Outcome: 07 Balance

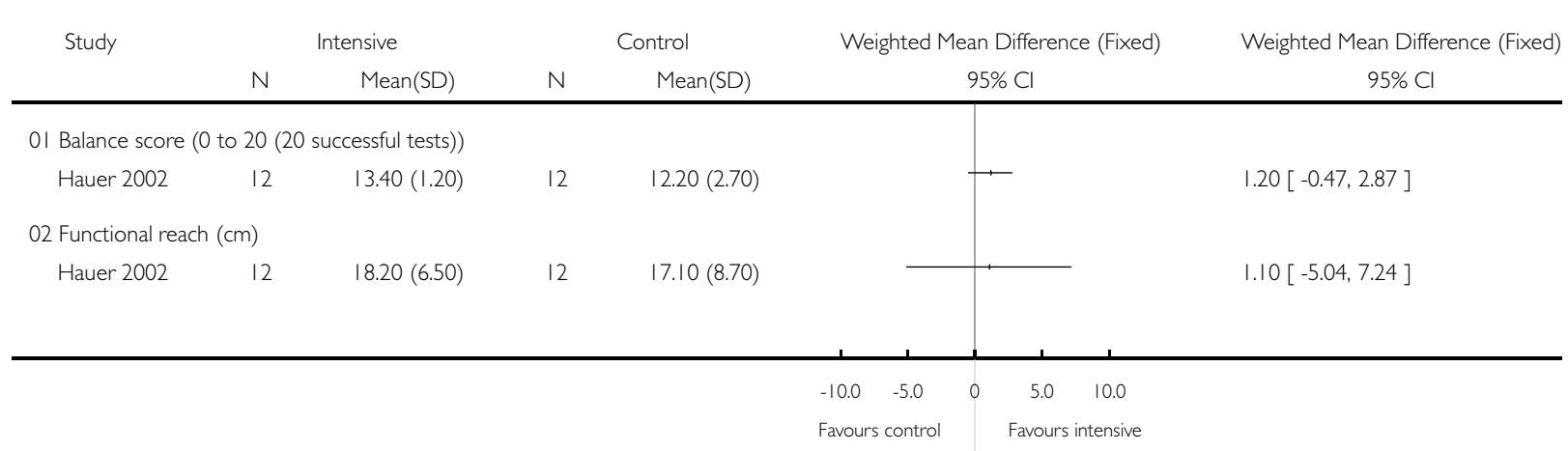

Analysis 07.08. Comparison 07 Intensive physical training versus placebo activities (started post-discharge), Outcome 08 Subjective/emotional state assessment, falls, balance and general

Review: Mobilisation strategies after hip fracture surgery in adults

Comparison: 07 Intensive physical training versus placebo activities (started post-discharge)

Outcome: 08 Subjective/emotional state assessment, falls, balance and general

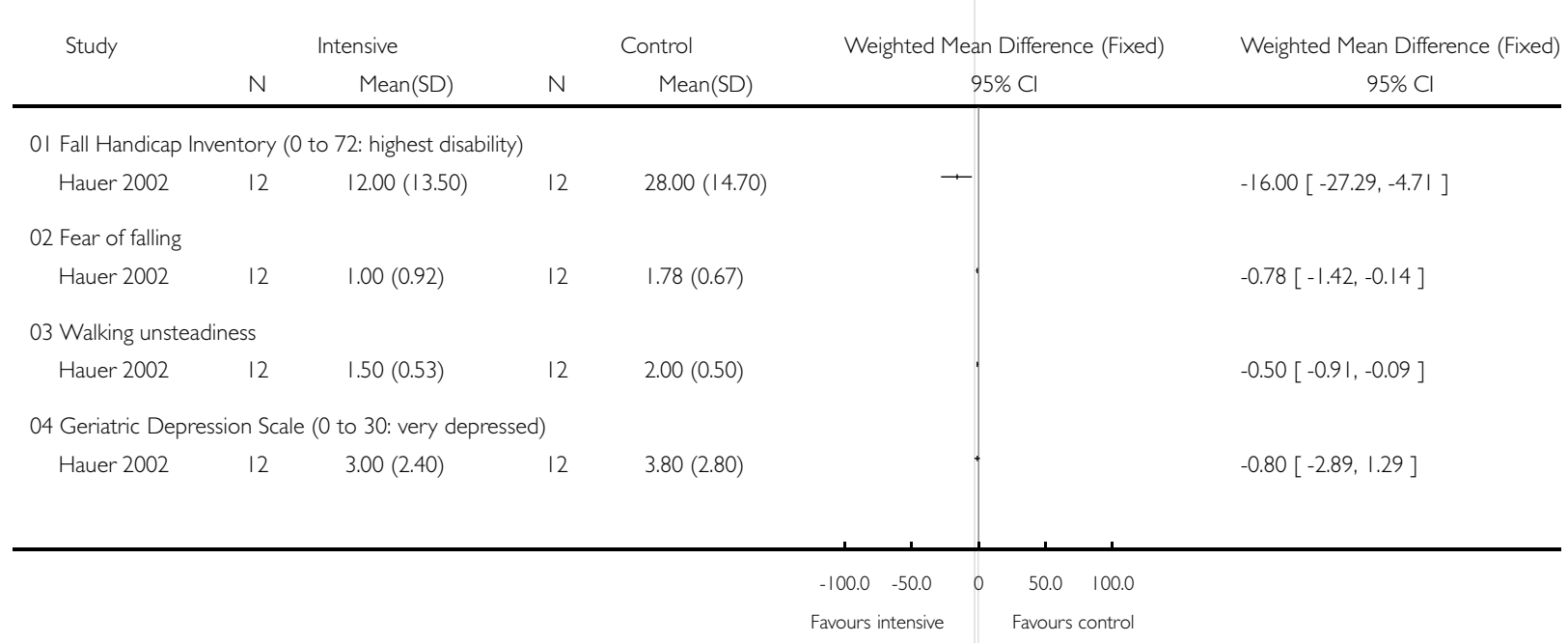


Analysis 07.09. Comparison 07 Intensive physical training versus placebo activities (started post-discharge), Outcome 09 Adherence

Review: Mobilisation strategies after hip fracture surgery in adults

Comparison: 07 Intensive physical training versus placebo activities (started post-discharge)

Outcome: 09 Adherence

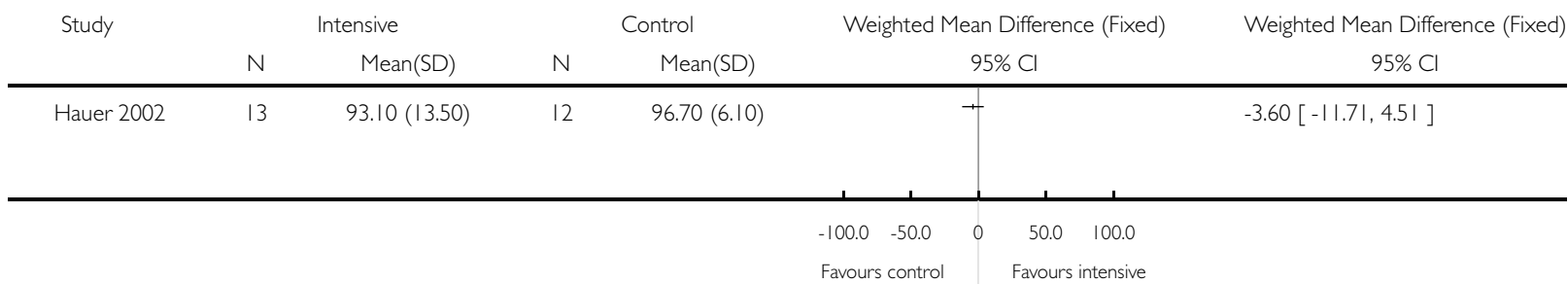

Analysis 08.0 I. Comparison 08 Home-based exercises programme (started at 22 weeks) versus control, Outcome 0I Mobility

Review: Mobilisation strategies after hip fracture surgery in adults

Comparison: 08 Home-based exercises programme (started at 22 weeks) versus control

Outcome: 01 Mobility

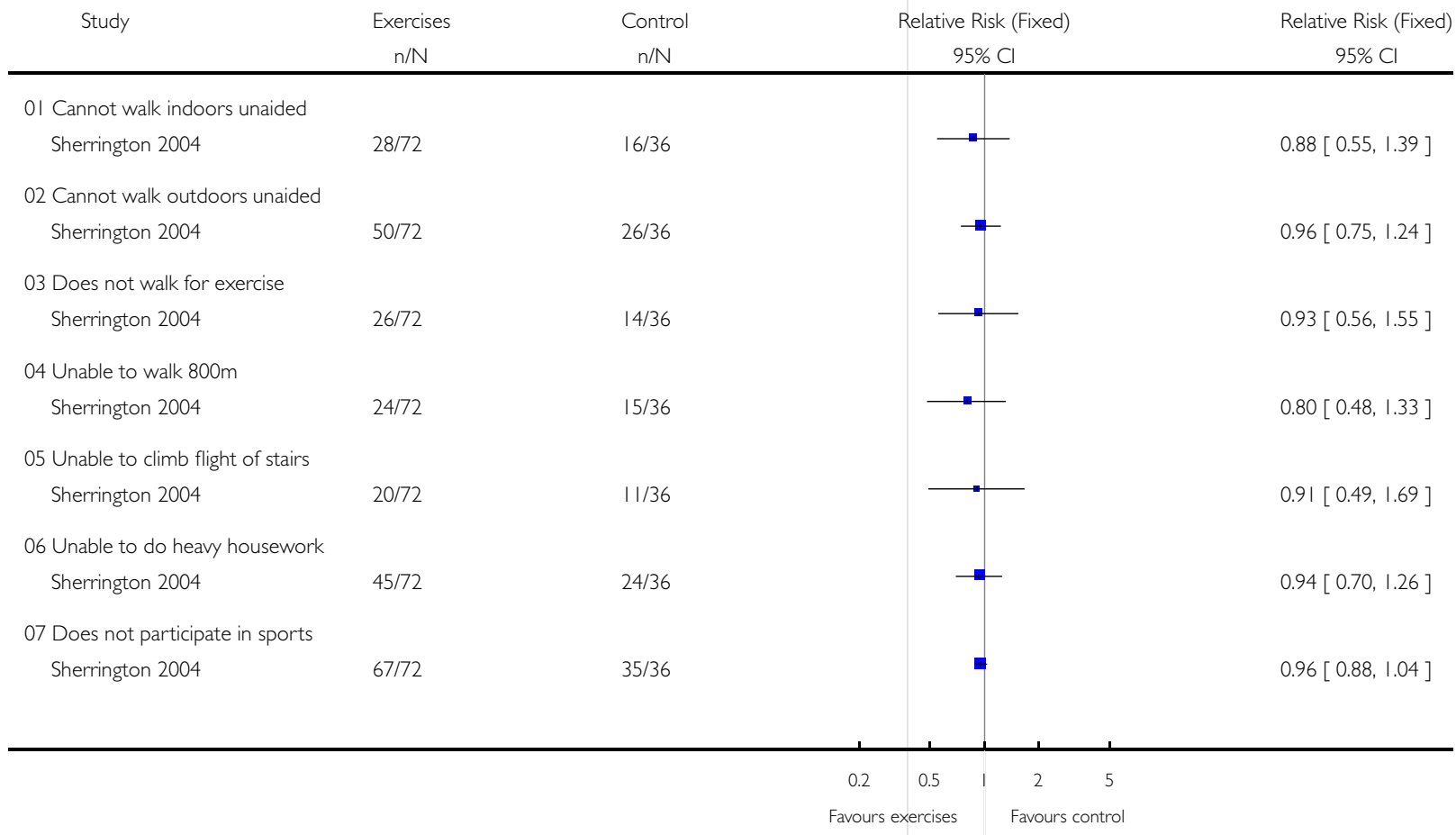


Analysis 08.02. Comparison 08 Home-based exercises programme (started at 22 weeks) versus control, Outcome 02 Gait parameters

Review: Mobilisation strategies after hip fracture surgery in adults

Comparison: 08 Home-based exercises programme (started at 22 weeks) versus control

Outcome: 02 Gait parameters

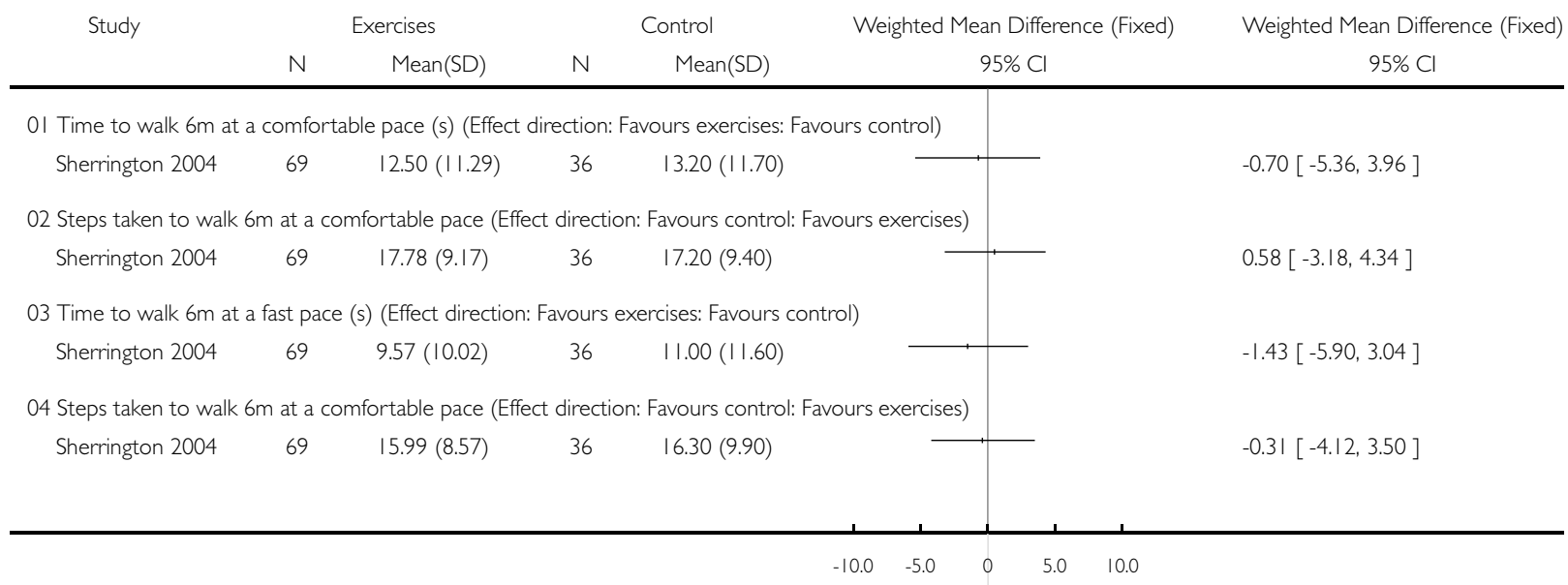

Analysis 08.03. Comparison 08 Home-based exercises programme (started at 22 weeks) versus control, Outcome 03 Physical Performance and Mobility Examination score (0:failure to I2:top score)

Review: Mobilisation strategies after hip fracture surgery in adults

Comparison: 08 Home-based exercises programme (started at 22 weeks) versus control

Outcome: 03 Physical Performance and Mobility Examination score (0:failure to 12:top score)

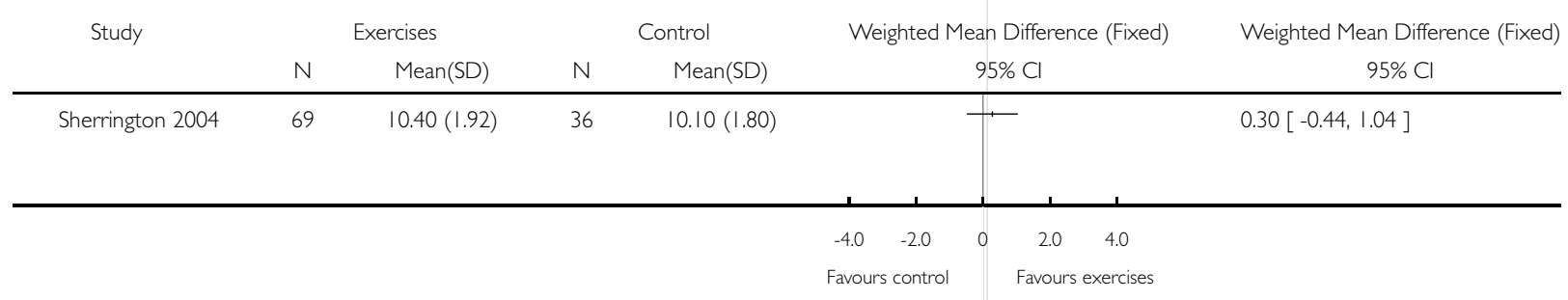


Analysis 08.04. Comparison 08 Home-based exercises programme (started at 22 weeks) versus control, Outcome 04 Functional performance tests

Review: Mobilisation strategies after hip fracture surgery in adults

Comparison: 08 Home-based exercises programme (started at 22 weeks) versus control

Outcome: 04 Functional performance tests

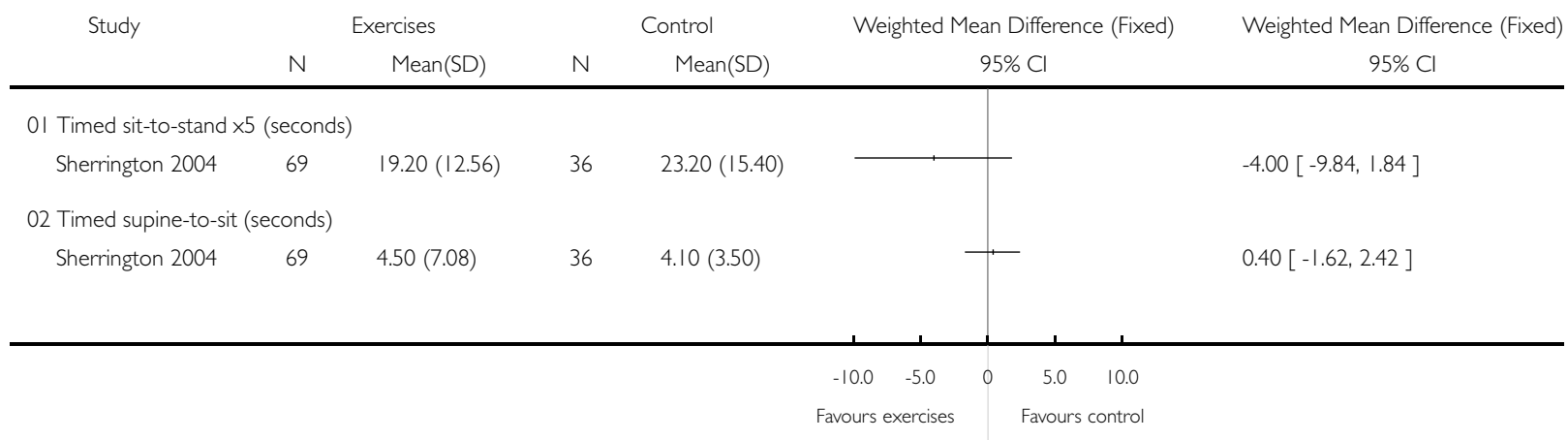

\section{Analysis 08.05. Comparison 08 Home-based exercises programme (started at 22 weeks) versus control,} Outcome 05 Strength measures (newtons)

Review: Mobilisation strategies after hip fracture surgery in adults

Comparison: 08 Home-based exercises programme (started at 22 weeks) versus control

Outcome: 05 Strength measures (newtons)

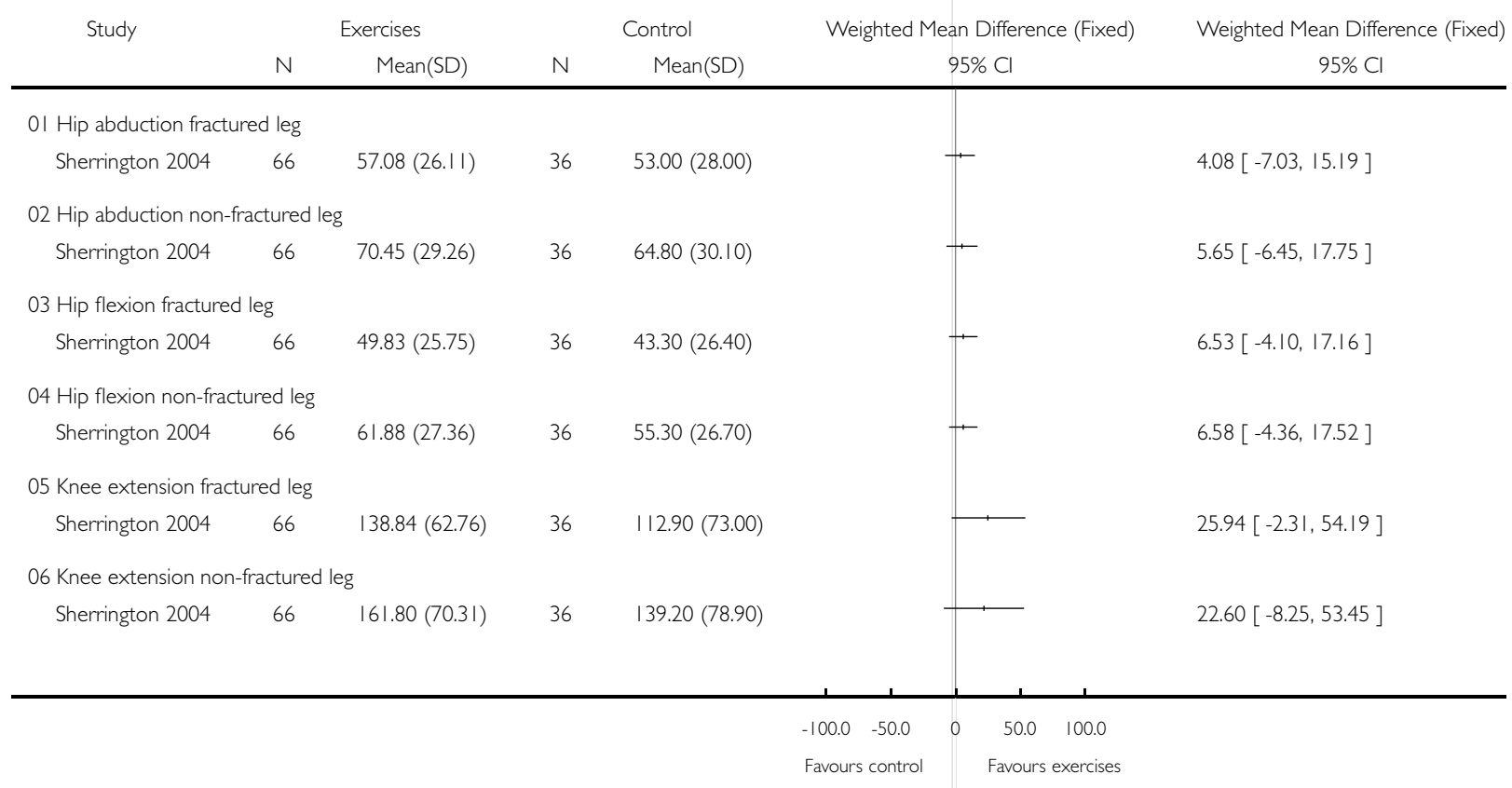


Analysis 08.06. Comparison 08 Home-based exercises programme (started at 22 weeks) versus control, Outcome 06 Balance

Review: Mobilisation strategies after hip fracture surgery in adults

Comparison: 08 Home-based exercises programme (started at 22 weeks) versus control

Outcome: 06 Balance

Study

Exercises

Control

Weighted Mean Difference (Fixed)

Weighted Mean Difference (Fixed)

N

Mean(SD)

N

Mean(SD) $95 \% \mathrm{Cl}$

0I Step test fractured leg (steps) (Effect direction: Favours control: Favours exercises)
Sherrington 2004
68
$10.18(6.51)$
$369.00(7.30)$

02 Step test non-fractured leg (steps) (Effect direction: Favours control: Favours exercises)

$$
\text { Sherrington } 2004 \quad 68 \quad 10.36(5.85) \quad 36 \quad 9.90(7.20)
$$

03 Functional reach (cm) (Effect direction: Favours control: Favours exercises)

$$
\text { Sherrington } 2004 \quad 68 \quad 22.28(8.45) \quad 36 \quad 19.40(10.00)
$$

04 Sway distance floor ( $\mathrm{mm}$ ) (Effect direction: Favours exercises: Favours control)

$$
\text { Sherrington } 2004 \quad 68 \quad 74.37(49.62) \quad 36 \quad 89.80(59.90)
$$

05 Sway distance foam $(\mathrm{mm})$ (Effect direction: Favours exercises: Favours control)
Sherrington 2004
68
। 18.94 (79.05)
36
I $29.00(79.40)$

$95 \% \mathrm{Cl}$
$1.18[-1.66,4.02]$

$0.46[-2.27,3.19]$

$2.88[-0.95,6.71]$

$-15.43[-38.28,7.42]$

$-10.06[-42.09,21.97]$

\section{Analysis 08.07. Comparison 08 Home-based exercises programme (started at 22 weeks) versus control,} Outcome 07 Subjective rating of pain, fall risk, balance, sleep quality and general health

Review: Mobilisation strategies after hip fracture surgery in adults

Comparison: 08 Home-based exercises programme (started at 22 weeks) versus control

Outcome: 07 Subjective rating of pain, fall risk, balance, sleep quality and general health

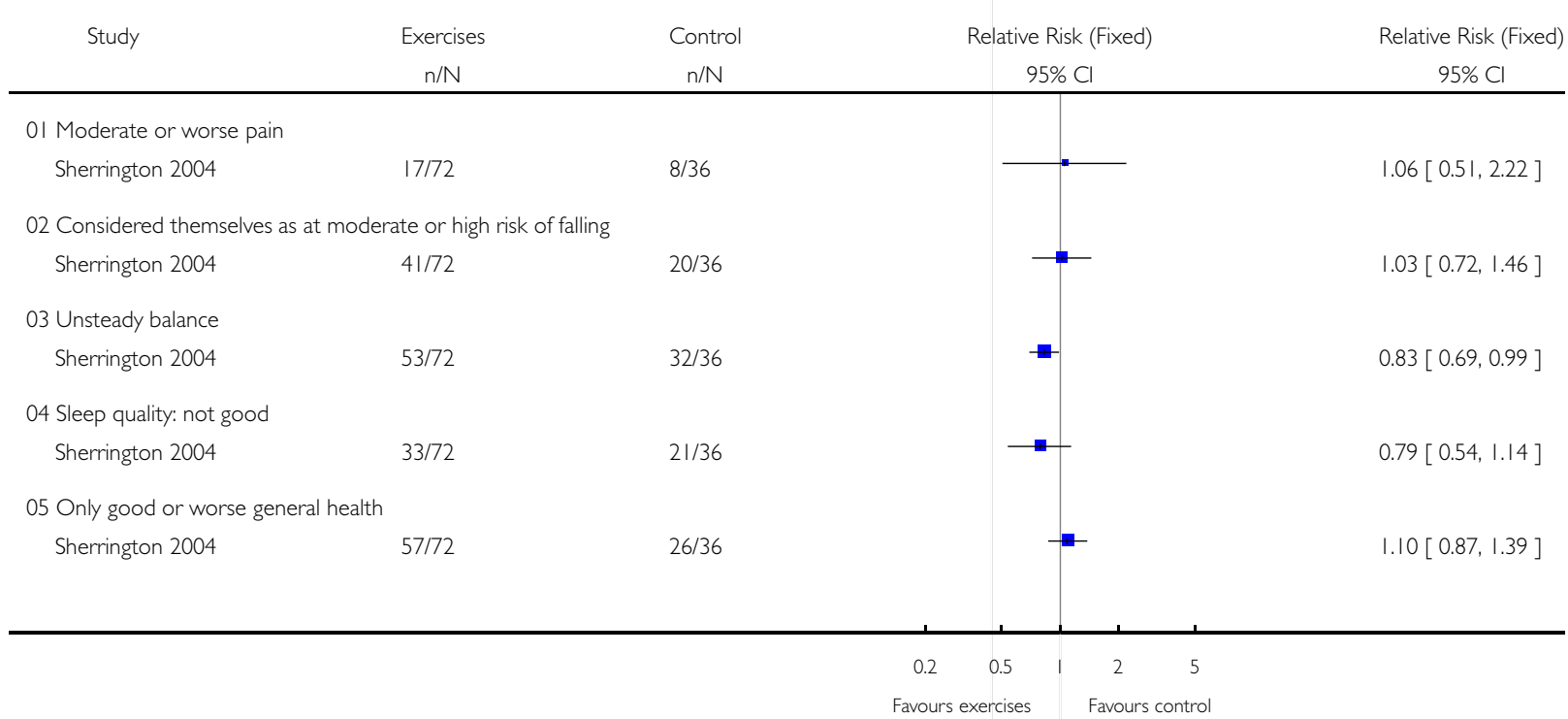


Analysis 08.08. Comparison 08 Home-based exercises programme (started at 22 weeks) versus control, Outcome 08 Fell at least once during intervention period (4 months)

Review: Mobilisation strategies after hip fracture surgery in adults

Comparison: 08 Home-based exercises programme (started at 22 weeks) versus control

Outcome: 08 Fell at least once during intervention period (4 months)

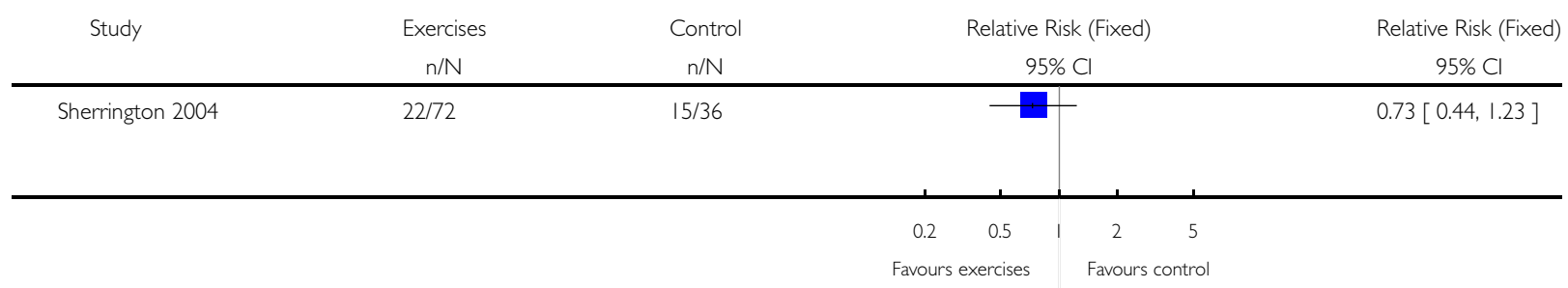

Analysis 08.09. Comparison 08 Home-based exercises programme (started at 22 weeks) versus control, Outcome 09 Mortality

Review: Mobilisation strategies after hip fracture surgery in adults

Comparison: 08 Home-based exercises programme (started at 22 weeks) versus control

Outcome: 09 Mortality

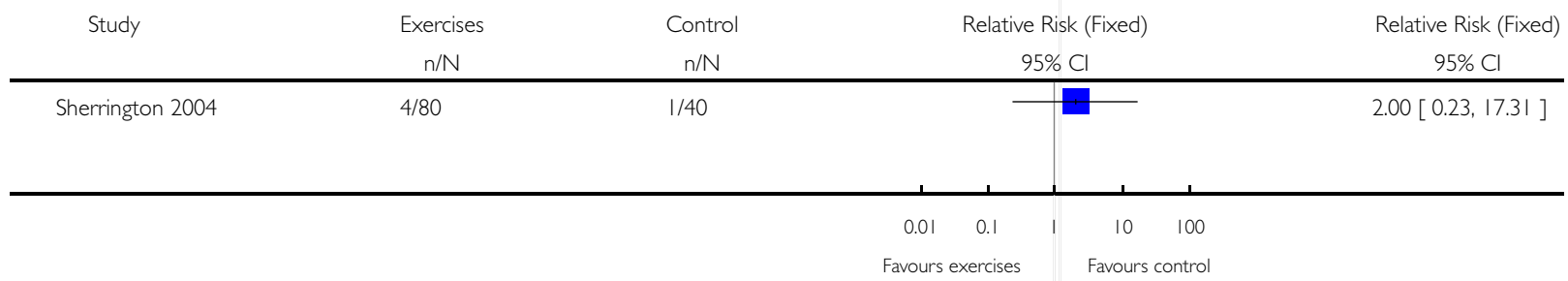




\section{Analysis 09.01. Comparison 09 Home-based weight bearing exercises programme (started at 22 weeks)}

versus control, Outcome $0 \mathrm{I}$ Mobility

Review: Mobilisation strategies after hip fracture surgery in adults

Comparison: 09 Home-based weight bearing exercises programme (started at 22 weeks) versus control

Outcome: 01 Mobility

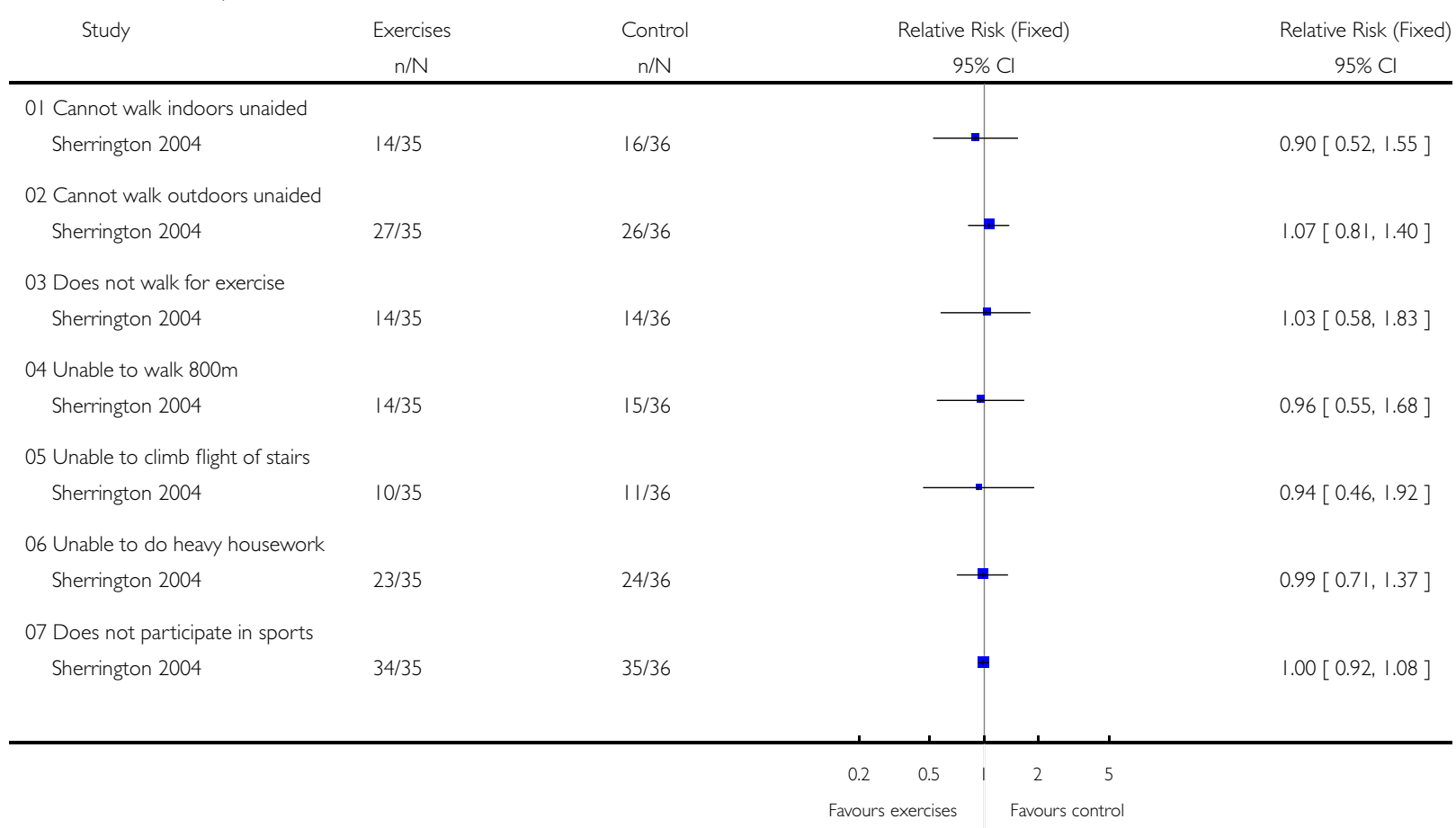

\section{Analysis 09.02. Comparison 09 Home-based weight bearing exercises programme (started at 22 weeks)} versus control, Outcome 02 Gait parameters

Review: Mobilisation strategies after hip fracture surgery in adults

Comparison: 09 Home-based weight bearing exercises programme (started at 22 weeks) versus control

Outcome: 02 Gait parameters

\begin{tabular}{|c|c|c|c|c|c|c|c|c|}
\hline \multirow[t]{2}{*}{ Study } & \multicolumn{2}{|c|}{ Exercises } & \multicolumn{2}{|c|}{ Control } & \multicolumn{3}{|c|}{ Weighted Mean Difference (Fixed) } & \multirow{2}{*}{$\begin{array}{l}\text { Weighted Mean Difference (Fixed) } \\
\qquad 95 \% \mathrm{Cl}\end{array}$} \\
\hline & $\mathrm{N}$ & Mean(SD) & $\mathrm{N}$ & Mean(SD) & & & $95 \% \mathrm{Cl}$ & \\
\hline \multicolumn{9}{|c|}{ 0I Time to walk $6 \mathrm{~m}$ at a comfortable pace (s) (Effect direction: Favours exercises: Favours control) } \\
\hline Sherrington 2004 & 33 & । $1.80(9.20)$ & 36 & |3.20 ( 11.70$)$ & & & & $-1.40[-6.35,3.55]$ \\
\hline \multicolumn{9}{|c|}{02 Steps taken to walk $6 \mathrm{~m}$ at a comfortable pace (Effect direction: Favours control: Favours exercises) } \\
\hline Sherrington 2004 & 33 & $18.30(\mid 1.00)$ & 36 & $17.20(9.40)$ & & & & $1.10[-3.75,5.95]$ \\
\hline \multicolumn{9}{|c|}{03 Time to walk $6 \mathrm{~m}$ at a fast pace (s) (Effect direction: Favours exercises: Favours control) } \\
\hline Sherrington 2004 & 33 & $9.20(9.10)$ & 36 & $11.00(11.60)$ & & & & $-1.80[-6.70,3.10]$ \\
\hline \multicolumn{9}{|c|}{04 Steps taken to walk $6 \mathrm{~m}$ at a comfortable pace (Effect direction: Favours control: Favours exercises) } \\
\hline \multirow[t]{2}{*}{ Sherrington 2004} & 33 & $16.30(10.70)$ & 36 & $16.30(9.90)$ & & & & $0.00[-4.88,4.88]$ \\
\hline & & & & & -10.0 & -5.0 & 10.0 & \\
\hline
\end{tabular}

Mobilisation strategies after hip fracture surgery in adults (Review) 
Analysis 09.03. Comparison 09 Home-based weight bearing exercises programme (started at 22 weeks) versus control, Outcome 03 Physical Performance and Mobility Examination score (0:failure to I 2:top score)

Review: Mobilisation strategies after hip fracture surgery in adults

Comparison: 09 Home-based weight bearing exercises programme (started at 22 weeks) versus control

Outcome: 03 Physical Performance and Mobility Examination score (0:failure to 12:top score)

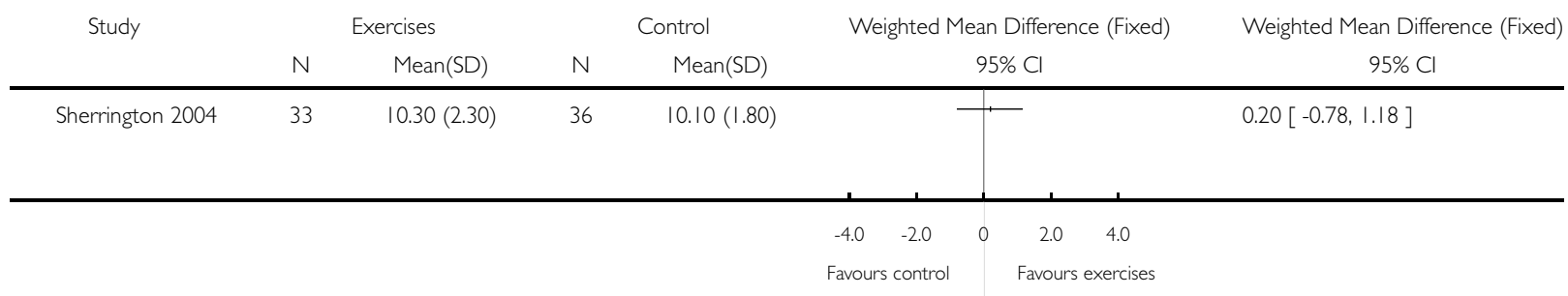

Analysis 09.04. Comparison 09 Home-based weight bearing exercises programme (started at 22 weeks) versus control, Outcome 04 Functional performance tests

Review: Mobilisation strategies after hip fracture surgery in adults

Comparison: 09 Home-based weight bearing exercises programme (started at 22 weeks) versus control

Outcome: 04 Functional performance tests

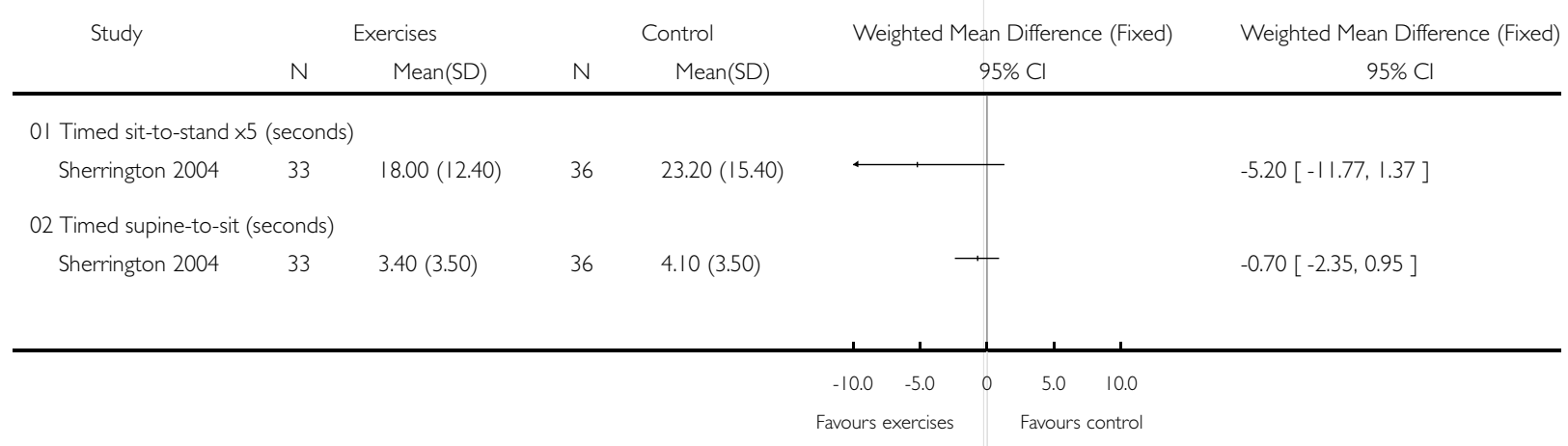




\section{Analysis 09.05. Comparison 09 Home-based weight bearing exercises programme (started at 22 weeks)} versus control, Outcome 05 Strength measures (newtons)

Review: Mobilisation strategies after hip fracture surgery in adults

Comparison: 09 Home-based weight bearing exercises programme (started at 22 weeks) versus control

Outcome: 05 Strength measures (newtons)

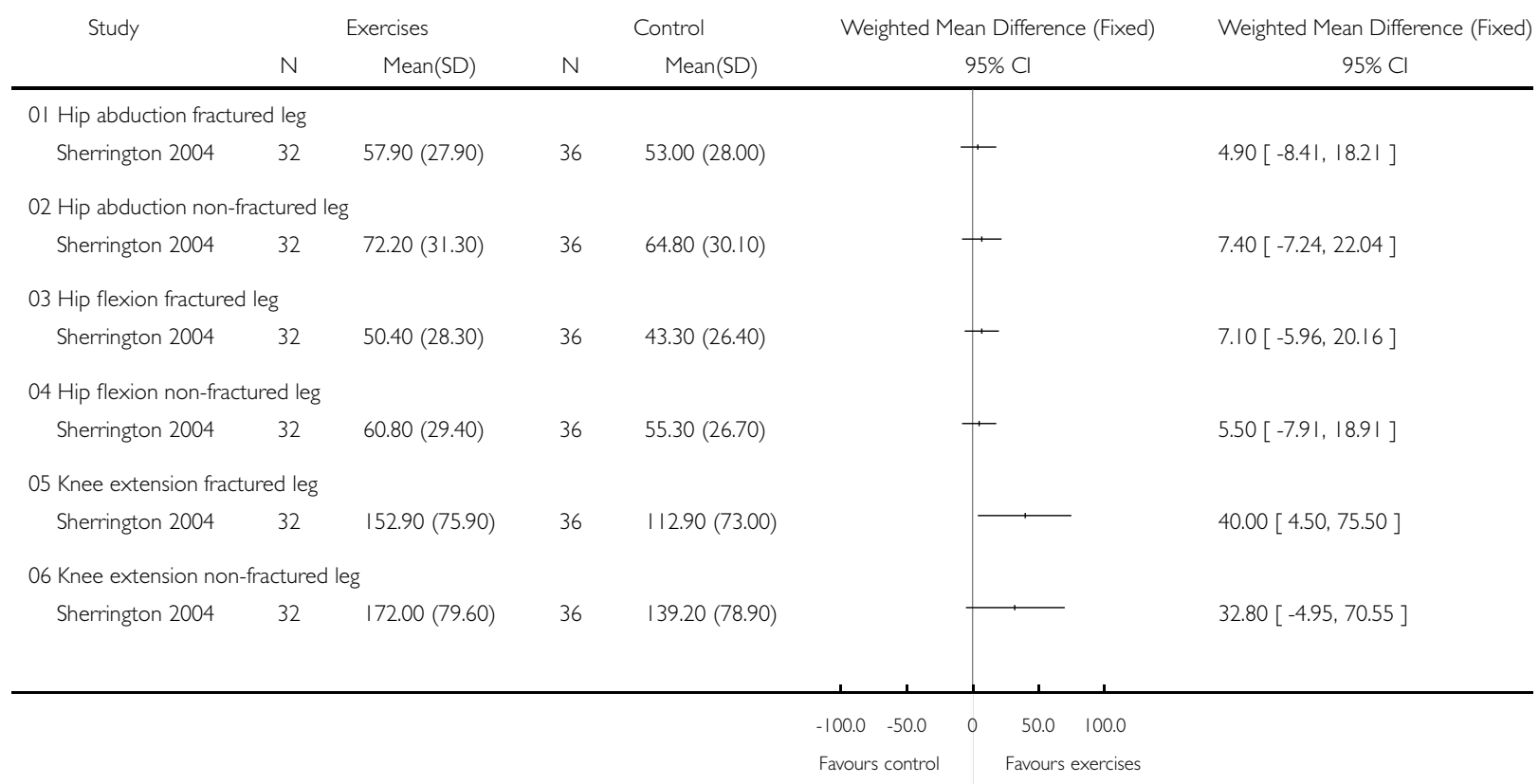

\section{Analysis 09.06. Comparison 09 Home-based weight bearing exercises programme (started at 22 weeks) versus control, Outcome 06 Balance}

Review: Mobilisation strategies after hip fracture surgery in adults

Comparison: 09 Home-based weight bearing exercises programme (started at 22 weeks) versus contro

Outcome: 06 Balance

\begin{tabular}{|c|c|c|c|c|c|c|}
\hline \multirow[t]{2}{*}{ Study } & \multicolumn{2}{|c|}{ Exercises } & \multicolumn{2}{|c|}{ Control } & Weighted Mean Difference (Fixed) & Weighted Mean Difference (Fixed) \\
\hline & $N$ & Mean(SD) & $\mathrm{N}$ & Mean(SD) & & $95 \% \mathrm{Cl}$ \\
\hline
\end{tabular}

0I Step test fractured leg (steps) (Effect direction: Favours control: Favours exercises)

$$
\text { Sherrington } 2004 \quad 33 \quad 11.00(6.30) \quad 36 \quad 9.00(7.30)
$$

02 Step test non-fractured leg (steps) (Effect direction: Favours control: Favours exercises)

$$
\text { Sherrington } 2004 \quad 33 \quad 11.70(5.90) \quad 36 \quad 9.90(7.20)
$$

03 Functional reach (cm) (Effect direction: Favours control: Favours exercises)

$$
\text { Sherrington } 2004 \quad 33 \quad 24.80(8.80) \quad 36 \quad 19.40(10.00)
$$

04 Sway distance floor ( $\mathrm{mm}$ ) (Effect direction: Favours exercises: Favours control)

$$
\text { Sherrington } 2004 \quad 33 \quad 79.00(46.00) \quad 36 \quad 89.80(59.90)
$$

05 Sway distance foam $(\mathrm{mm})$ (Effect direction: Favours exercises: Favours control)

$$
\begin{array}{lllll}
\text { Sherrington } 2004 \quad 33 & \text { I I } 5.70(73.30) & 36 & \text { I29.00 (79.40) }
\end{array}
$$

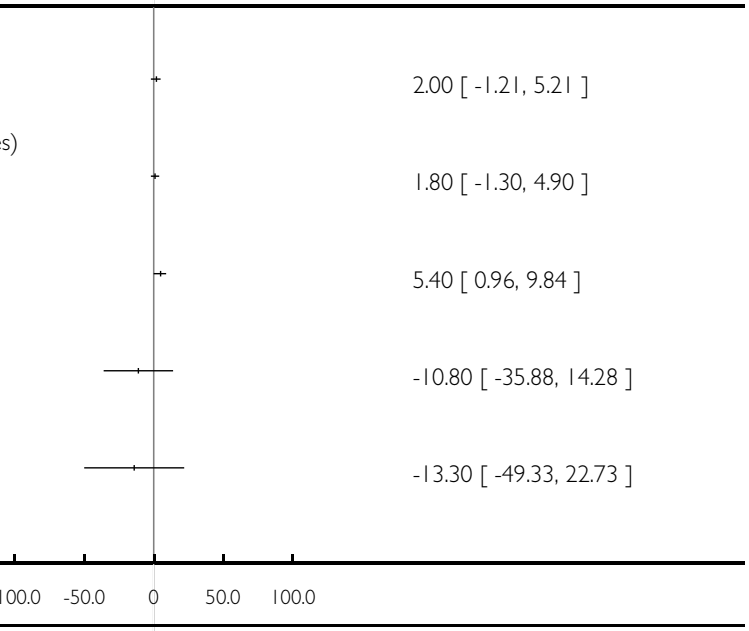

Mobilisation strategies after hip fracture surgery in adults (Review)

Copyright (๑) 2006 The Cochrane Collaboration. Published by John Wiley \& Sons, Ltd 
Analysis 09.07. Comparison 09 Home-based weight bearing exercises programme (started at 22 weeks) versus control, Outcome 07 Subjective rating of pain, fall risk, balance, sleep quality and general health

Review: Mobilisation strategies after hip fracture surgery in adults

Comparison: 09 Home-based weight bearing exercises programme (started at 22 weeks) versus control

Outcome: 07 Subjective rating of pain, fall risk, balance, sleep quality and general health

Study Exercises Control Relative Risk (Fixed) Relative Risk (Fixed)

$\mathrm{n} / \mathrm{N} \quad \mathrm{n} / \mathrm{N} \quad 95 \% \mathrm{Cl} \quad 95 \% \mathrm{Cl}$

OI Moderate or worse pain

Sherrington $2004 \quad 10 / 35$

02 Considered themselves as at moderate or high risk of falling

Sherrington 2004

$21 / 35$

$20 / 36$

03 Unsteady balance

Sherrington 2004

$26 / 35$

$32 / 36$

$1.29[0.57,2.88]$

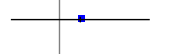

04 Sleep quality: not good

Sherrington 2004

$17 / 35$

$21 / 36$

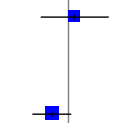

$1.08[0.73,1.61]$

$0.84[0.67,1.05]$

05 Only good or worse general health

Sherrington 2004

$29 / 35$

$26 / 36$

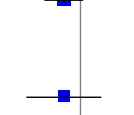

$0.83[0.54,1.29]$

$1.15[0.89,1.48]$

Analysis 09.08. Comparison 09 Home-based weight bearing exercises programme (started at 22 weeks) versus control, Outcome 08 Fell at least once during intervention period (4 months)

Review: Mobilisation strategies after hip fracture surgery in adults

Comparison: 09 Home-based weight bearing exercises programme (started at 22 weeks) versus control

Outcome: 08 Fell at least once during intervention period (4 months)

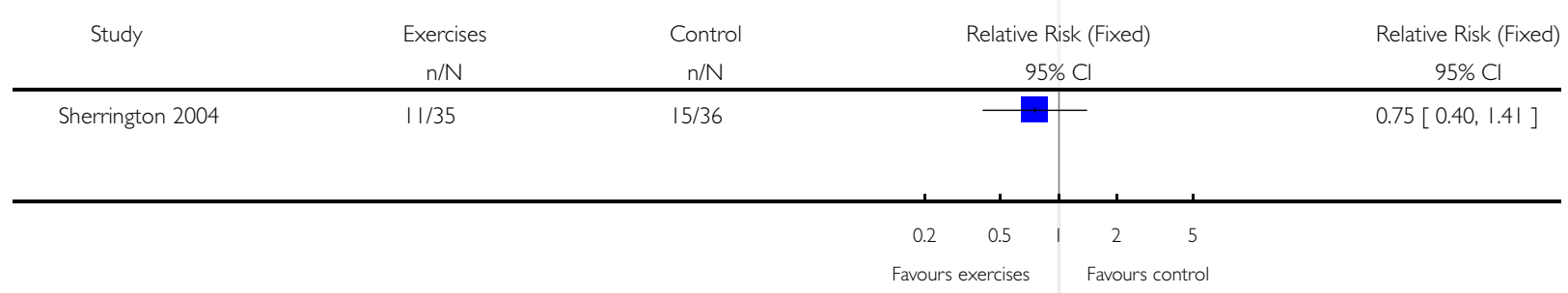


Analysis 09.09. Comparison 09 Home-based weight bearing exercises programme (started at 22 weeks) versus control, Outcome 09 Mortality

Review: Mobilisation strategies after hip fracture surgery in adults

Comparison: 09 Home-based weight bearing exercises programme (started at 22 weeks) versus control

Outcome: 09 Mortality

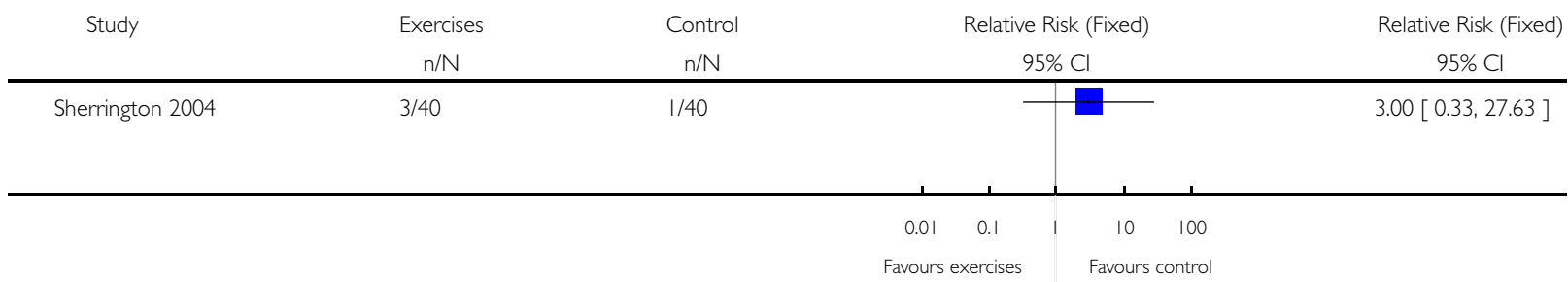

Analysis 10.01. Comparison 10 Home-based non-weight bearing exercises programme (started 22 at weeks) versus control, Outcome 0 I Mobility

Review: Mobilisation strategies after hip fracture surgery in adults

Comparison: 10 Home-based non-weight bearing exercises programme (started 22 at weeks) versus control

Outcome: 01 Mobility

Study

Exercises

Control

Relative Risk (Fixed)

Relative Risk (Fixed)

$n / N$

$\mathrm{n} / \mathrm{N}$

95\% Cl

$95 \% \mathrm{Cl}$

OI Cannot walk indoors unaided

Sherrington 2004

14/37

$16 / 36$

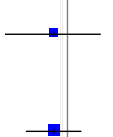

$0.85[0.49,1.48]$

02 Cannot walk outdoors unaided

Sherrington 2004

$23 / 37$

$26 / 36$

03 Does not walk for exercise

Sherrington 2004

12/37

14/36

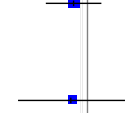

$0.86[0.62,1.19]$

4 Unable to walk $800 \mathrm{~m}$

Sherrington 2004

10/37

$15 / 36$

05 Unable to climb flight of stairs

Sherrington 2004

10/37

$11 / 36$

06 Unable to do heavy housework

Sherrington 2004

22/37

$24 / 36$

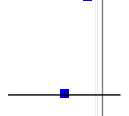

$0.83[0.45,1.55]$

07 Does not participate in sports

Sherrington 2004

$35 / 36$

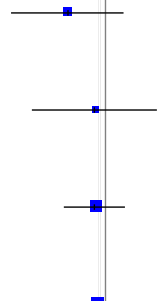

$0.65[0.34,1.25]$

$0.88[0.43,1.82]$

$0.89[0.63,1.27]$

$0.92[0.81,1.04]$ 
Analysis 10.02. Comparison 10 Home-based non-weight bearing exercises programme (started 22 at weeks) versus control, Outcome 02 Gait parameters

Review: Mobilisation strategies after hip fracture surgery in adults

Comparison: 10 Home-based non-weight bearing exercises programme (started 22 at weeks) versus control

Outcome: 02 Gait parameters

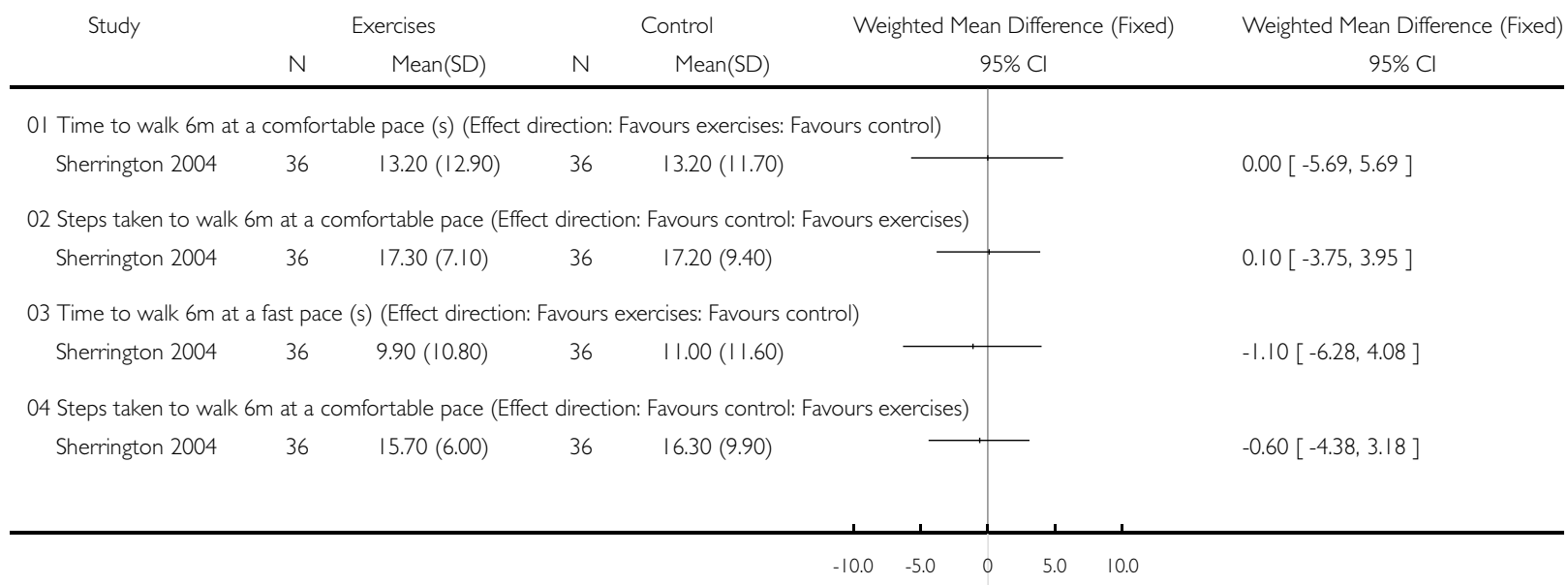

Analysis 10.03. Comparison 10 Home-based non-weight bearing exercises programme (started 22 at weeks) versus control, Outcome 03 Physical Performance and Mobility Examination score (0:failure to I 2:top score)

Review: Mobilisation strategies after hip fracture surgery in adults

Comparison: 10 Home-based non-weight bearing exercises programme (started 22 at weeks) versus control

Outcome: 03 Physical Performance and Mobility Examination score (0:failure to 12:top score)

\begin{tabular}{|c|c|c|c|c|c|c|c|c|c|}
\hline \multirow[t]{2}{*}{ Study } & \multicolumn{2}{|c|}{ Exercises } & \multicolumn{2}{|c|}{ Control } & \multirow{2}{*}{\multicolumn{4}{|c|}{$\begin{array}{l}\text { Weighted Mean Difference (Fixed) } \\
\qquad 95 \% \mathrm{Cl}\end{array}$}} & \multirow{2}{*}{$\begin{array}{l}\text { Weighted Mean Difference (Fixed) } \\
\qquad 95 \% \mathrm{Cl}\end{array}$} \\
\hline & $N$ & Mean(SD) & $N$ & Mean(SD) & & & & & \\
\hline \multirow[t]{2}{*}{ Sherrington 2004} & 36 & $10.50(1.50)$ & 36 & $10.10(1.80)$ & & & 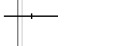 & & $0.40[-0.37,1.17]$ \\
\hline & & & & & -4.0 & -2.0 & 2.0 & 4.0 & \\
\hline
\end{tabular}


Analysis 10.04. Comparison 10 Home-based non-weight bearing exercises programme (started 22 at weeks) versus control, Outcome 04 Functional performance tests

Review: Mobilisation strategies after hip fracture surgery in adults

Comparison: 10 Home-based non-weight bearing exercises programme (started 22 at weeks) versus control

Outcome: 04 Functional performance tests

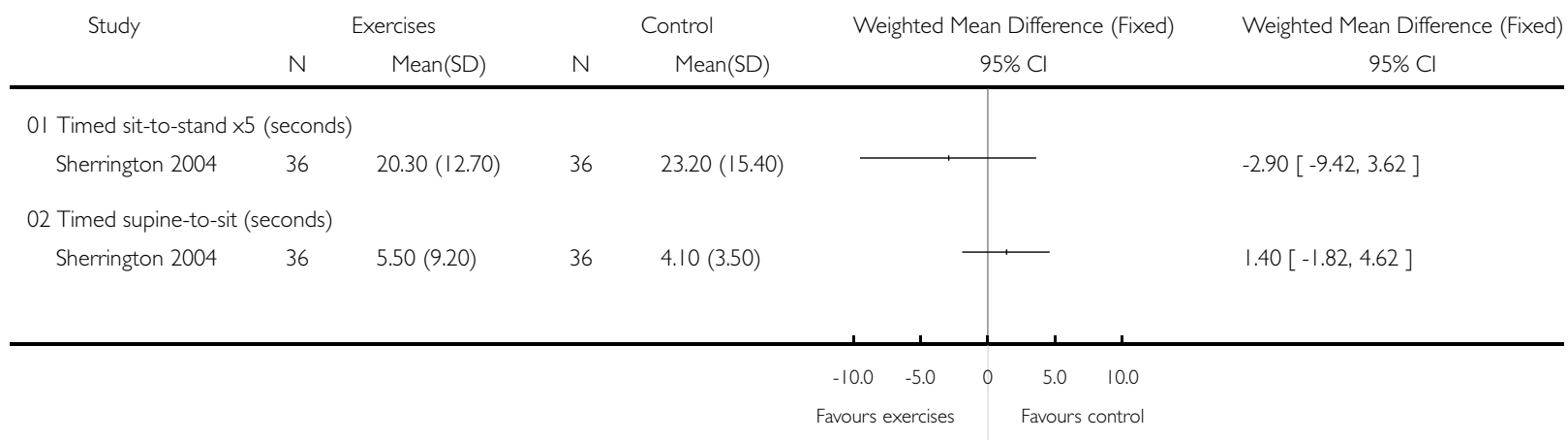

Analysis 10.05. Comparison 10 Home-based non-weight bearing exercises programme (started 22 at weeks) versus control, Outcome 05 Strength measures (newtons)

Review: Mobilisation strategies after hip fracture surgery in adults

Comparison: 10 Home-based non-weight bearing exercises programme (started 22 at weeks) versus control

Outcome: 05 Strength measures (newtons)

\begin{tabular}{|c|c|c|c|c|c|c|c|}
\hline \multirow[t]{2}{*}{ Study } & \multicolumn{2}{|c|}{ Exercises } & \multicolumn{2}{|r|}{ Control } & \multirow{2}{*}{\multicolumn{2}{|c|}{$\begin{array}{l}\text { Weighted Mean Difference (Fixed) } \\
\qquad 95 \% \mathrm{Cl}\end{array}$}} & \multirow{2}{*}{$\begin{array}{l}\text { Weighted Mean Difference (Fixed) } \\
\qquad 95 \% \mathrm{Cl}\end{array}$} \\
\hline & $\mathrm{N}$ & Mean(SD) & $N$ & Mean(SD) & & & \\
\hline \multicolumn{8}{|c|}{ 0I Hip abduction fractured leg } \\
\hline Sherrington 2004 & 34 & $56.30(24.30)$ & 36 & $53.00(28.00)$ & & + & $3.30[-8.96,15.56]$ \\
\hline \multicolumn{8}{|c|}{02 Hip abduction non-fractured leg } \\
\hline Sherrington 2004 & 34 & $68.80(27.20)$ & 36 & $64.80(30.10)$ & & 7 & $4.00[-9.43,17.43]$ \\
\hline \multicolumn{8}{|c|}{03 Hip flexion fractured leg } \\
\hline Sherrington 2004 & 34 & $49.30(23.10)$ & 36 & $43.30(26.40)$ & & + & $6.00[-5.60,17.60]$ \\
\hline \multicolumn{8}{|c|}{04 Hip flexion non-fractured leg } \\
\hline Sherrington 2004 & 34 & $62.90(25.30)$ & 36 & $55.30(26.70)$ & & + & $7.60[-4.58,19.78]$ \\
\hline \multicolumn{8}{|c|}{05 Knee extension fractured leg } \\
\hline Sherrington 2004 & 34 & I $25.60(47.20)$ & 36 & । $12.90(73.00)$ & & + & $12.70[-15.94,41.34]$ \\
\hline \multicolumn{8}{|c|}{06 Knee extension non-fractured leg } \\
\hline \multirow[t]{3}{*}{ Sherrington 2004} & 34 & $152.20(60.30)$ & 36 & $139.20(78.90)$ & & - & $13.00[-19.79,45.79]$ \\
\hline & & & & & $-100.0-50.0$ & $50.0 \quad 100.0$ & \\
\hline & & & & & Favours control & Favours exercises & \\
\hline
\end{tabular}


Analysis 10.06. Comparison 10 Home-based non-weight bearing exercises programme (started 22 at weeks) versus control, Outcome 06 Balance

Review: Mobilisation strategies after hip fracture surgery in adults

Comparison: 10 Home-based non-weight bearing exercises programme (started 22 at weeks) versus control

Outcome: 06 Balance

Study

Exercises

Control

Weighted Mean Difference (Fixed)

Weighted Mean Difference (Fixed)

N Mean(SD)

N Mean(SD)
95\% Cl $95 \% \mathrm{Cl}$

0I Step test fractured leg (steps) (Effect direction: Favours control: Favours exercises)

$$
\text { Sherrington } 2004 \quad 35 \quad 9.40(6.70) \quad 36 \quad 9.00(7.30)
$$

02 Step test non-fractured leg (steps) (Effect direction: Favours control: Favours exercises)

$$
\text { Sherrington } 2004 \quad 35 \quad 9.10(5.80) \quad 36 \quad 9.90(7.20)
$$

03 Functional reach $(\mathrm{cm})$ (Effect direction: Favours control: Favours exercises)

$$
\begin{array}{lllll}
\text { Sherrington } 2004 & 35 & 19.90(8.10) & 36 & 19.40(10.00)
\end{array}
$$

04 Sway distance floor ( $\mathrm{mm}$ ) (Effect direction: Favours exercises: Favours control)

$$
\text { Sherrington } 2004 \quad 35 \quad 70.00(52.80) \quad 36 \quad 89.80(59.90)
$$

05 Sway distance foam $(\mathrm{mm})$ (Effect direction: Favours exercises: Favours control)

$$
\begin{array}{lllll}
\text { Sherrington } 2004 & 35 & 122.00(84.10) & 36 & 129.00(79.40)
\end{array}
$$

$95 \% \mathrm{Cl}$

$0.40[-2.86,3.66]$

$-0.80[-3.84,2.24]$

$0.50[-3.73,4.73]$

$-19.80[-46.05,6.45]$

Analysis 10.07. Comparison 10 Home-based non-weight bearing exercises programme (started 22 at weeks) versus control, Outcome 07 Subjective rating of pain, fall risk, balance, sleep quality and general health

Review: Mobilisation strategies after hip fracture surgery in adults

Comparison: 10 Home-based non-weight bearing exercises programme (started 22 at weeks) versus control

Outcome: 07 Subjective rating of pain, fall risk, balance, sleep quality and general health

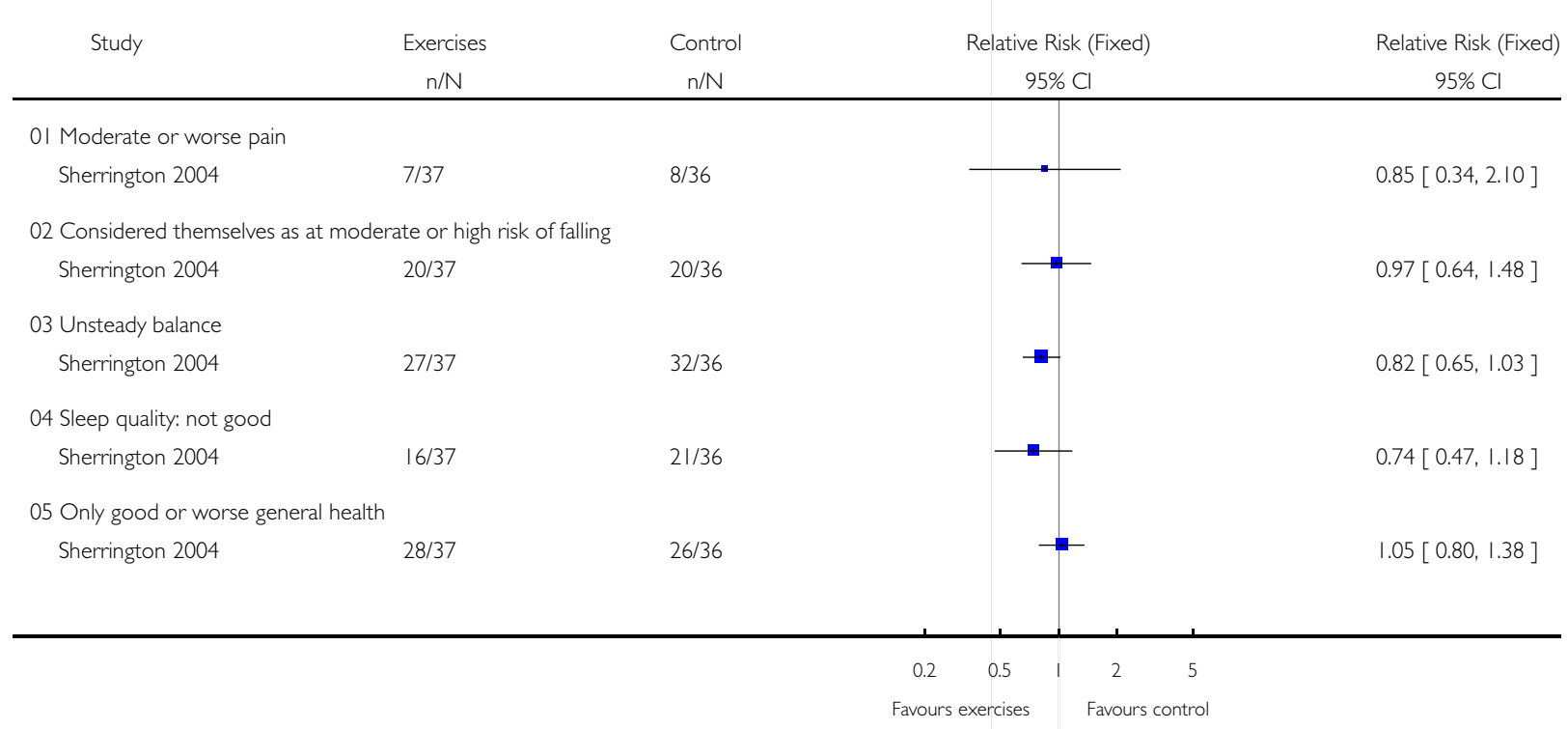


Analysis 10.08. Comparison 10 Home-based non-weight bearing exercises programme (started 22 at weeks) versus control, Outcome 08 Fell at least once during intervention period (4 months)

Review: Mobilisation strategies after hip fracture surgery in adults

Comparison: 10 Home-based non-weight bearing exercises programme (started 22 at weeks) versus control

Outcome: 08 Fell at least once during intervention period (4 months)

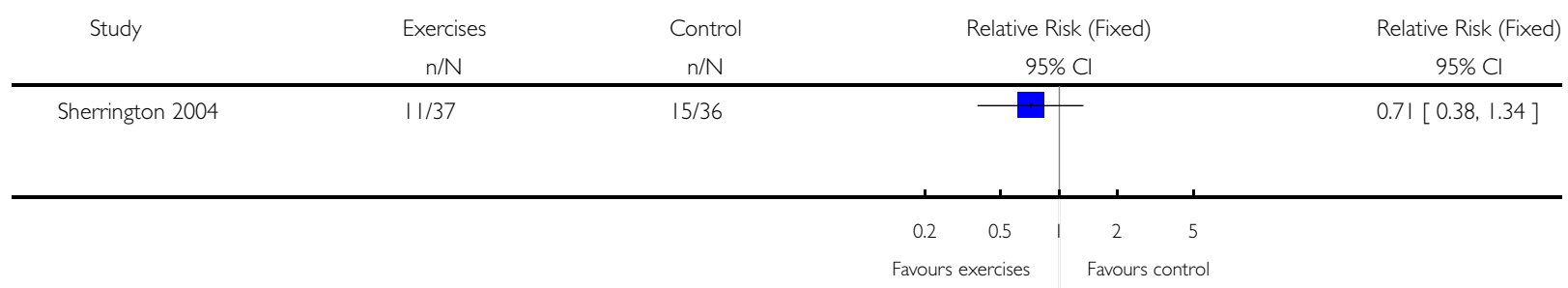

Analysis 10.09. Comparison 10 Home-based non-weight bearing exercises programme (started 22 at weeks) versus control, Outcome 09 Mortality

Review: Mobilisation strategies after hip fracture surgery in adults

Comparison: 10 Home-based non-weight bearing exercises programme (started 22 at weeks) versus control

Outcome: 09 Mortality

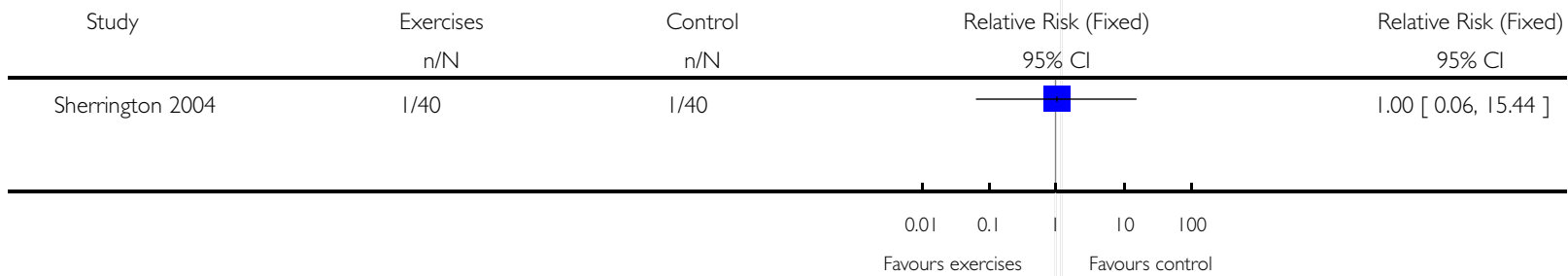




\section{Analysis II.0I. Comparison II Home-based weight bearing versus non-weight-bearing exercises programme}

(started at 22 weeks), Outcome 0 I Mobility

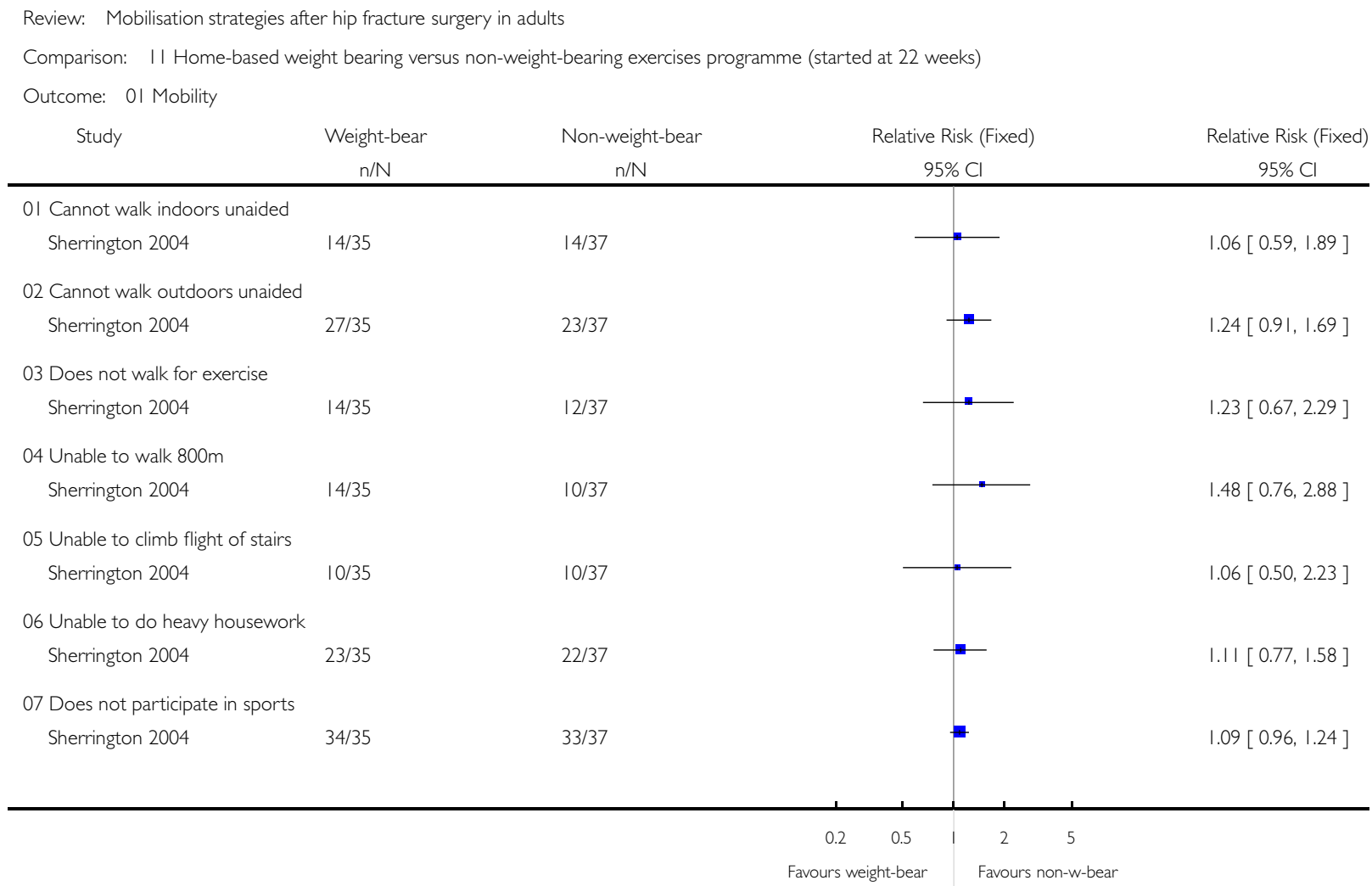

\section{Analysis II.02. Comparison II Home-based weight bearing versus non-weight-bearing exercises programme (started at 22 weeks), Outcome 02 Gait parameters}

Review: Mobilisation strategies after hip fracture surgery in adults

Comparison: 11 Home-based weight bearing versus non-weight-bearing exercises programme (started at 22 weeks)

Outcome: 02 Gait parameters

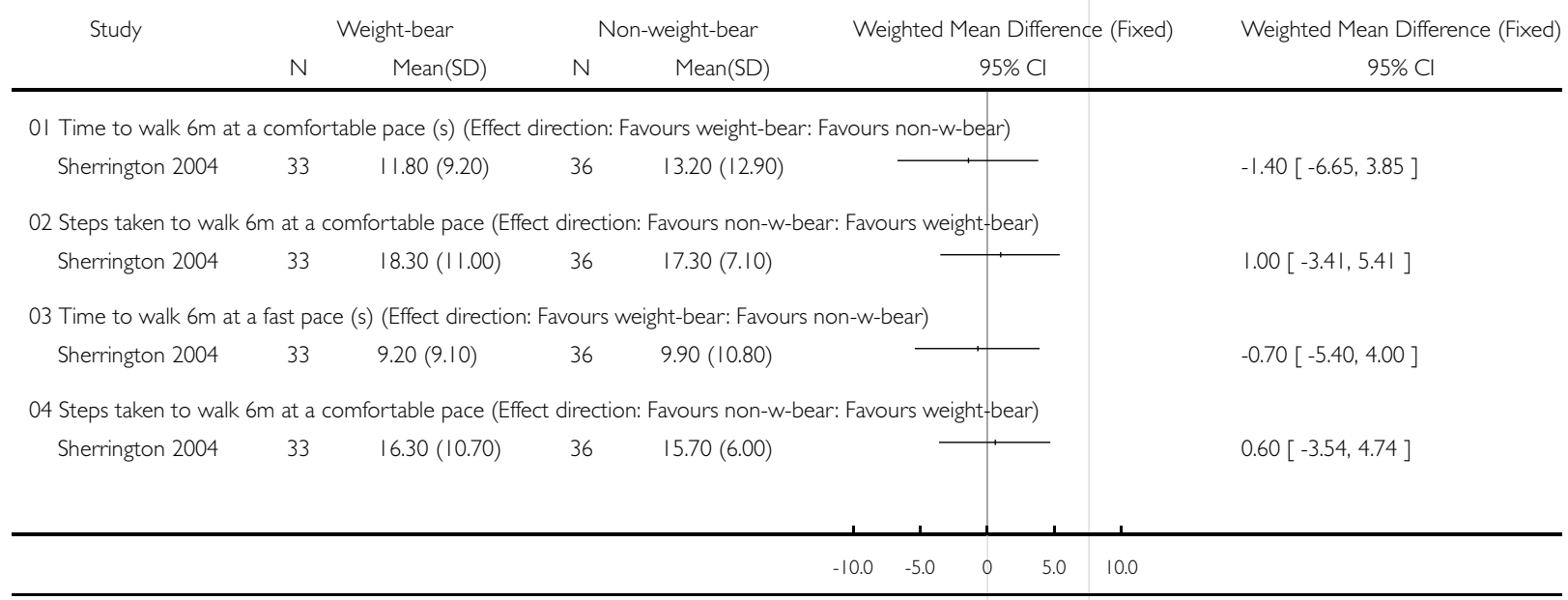

Mobilisation strategies after hip fracture surgery in adults (Review) 
Analysis II.03. Comparison II Home-based weight bearing versus non-weight-bearing exercises programme (started at 22 weeks), Outcome 03 Physical Performance and Mobility Examination score (0:failure to I 2:top score)

Review: Mobilisation strategies after hip fracture surgery in adults

Comparison: II Home-based weight bearing versus non-weight-bearing exercises programme (started at 22 weeks)

Outcome: 03 Physical Performance and Mobility Examination score (0:failure to 12:top score)

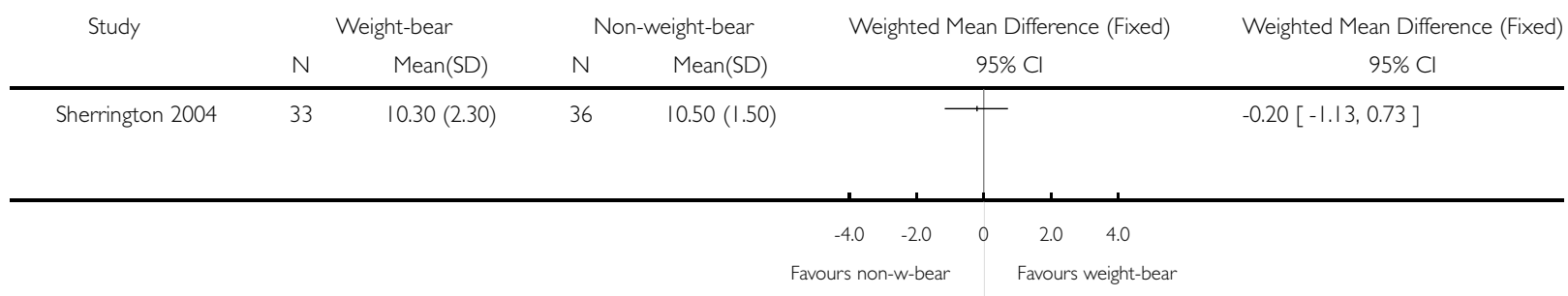

Analysis II.04. Comparison II Home-based weight bearing versus non-weight-bearing exercises programme (started at 22 weeks), Outcome 04 Functional performance tests

Review: Mobilisation strategies after hip fracture surgery in adults

Comparison: II Home-based weight bearing versus non-weight-bearing exercises programme (started at 22 weeks)

Outcome: 04 Functional performance tests

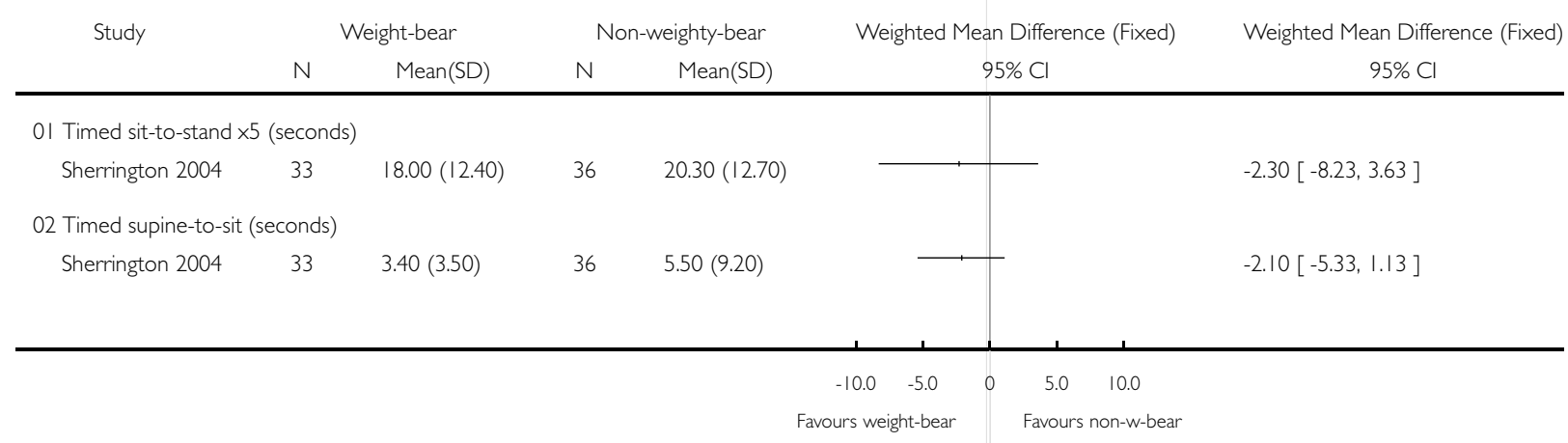


Analysis I I.05. Comparison I I Home-based weight bearing versus non-weight-bearing exercises programme (started at 22 weeks), Outcome 05 Strength measures (newtons)

Review: Mobilisation strategies after hip fracture surgery in adults

Comparison: II Home-based weight bearing versus non-weight-bearing exercises programme (started at 22 weeks)

Outcome: 05 Strength measures (newtons)

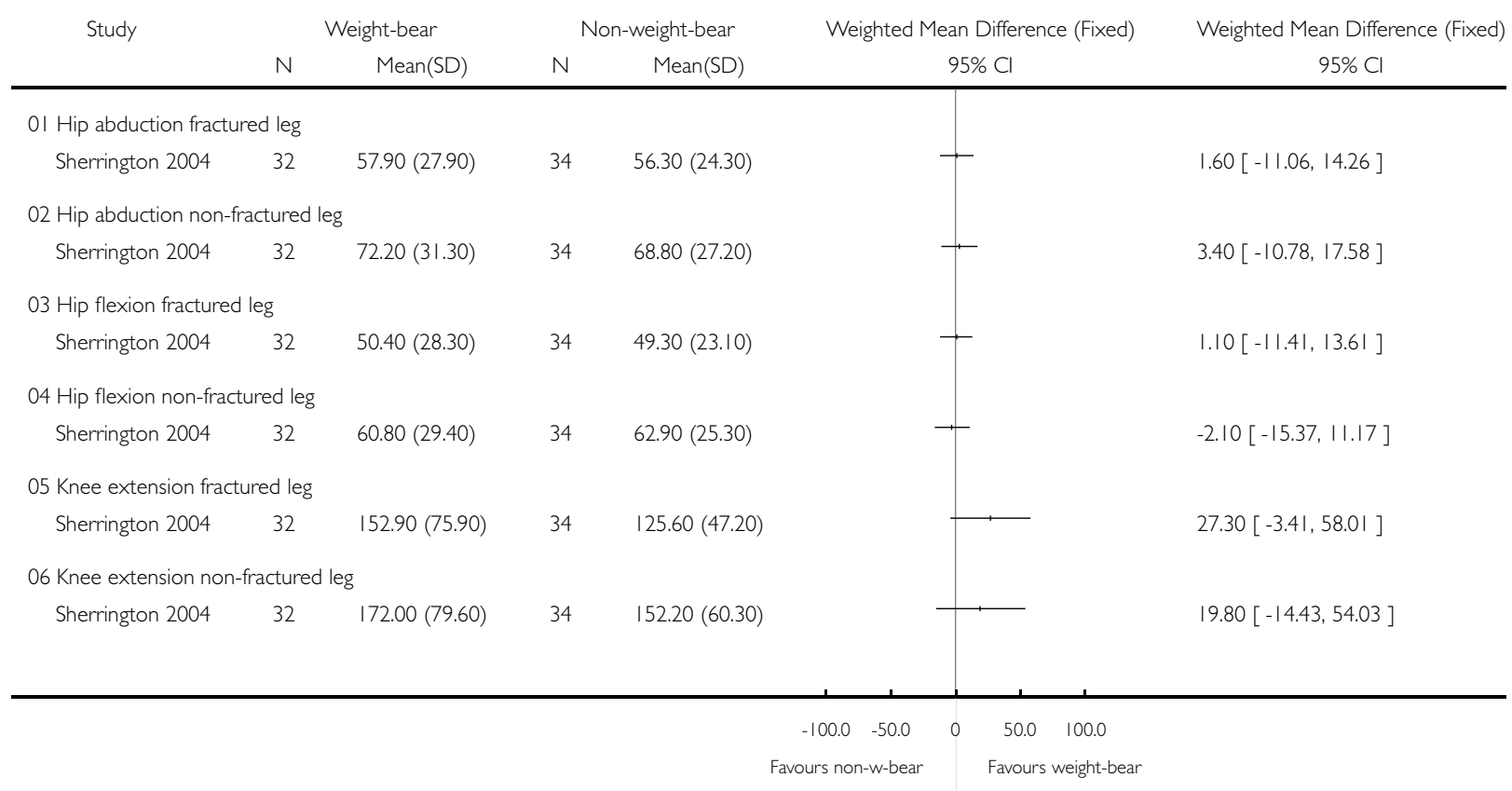

Analysis I I.06. Comparison II Home-based weight bearing versus non-weight-bearing exercises programme (started at 22 weeks), Outcome 06 Balance

Review: Mobilisation strategies after hip fracture surgery in adults

Comparison: II Home-based weight bearing versus non-weight-bearing exercises programme (started at 22 weeks)

Outcome: 06 Balance

\begin{tabular}{|c|c|c|c|c|c|c|}
\hline \multirow[t]{2}{*}{ Study } & \multicolumn{2}{|c|}{ Weight-bear } & \multicolumn{2}{|c|}{ Non-weight-bear } & Weighted Mean Difference (Fixed) & Weighted Mean Difference (Fixed) \\
\hline & $N$ & Mean(SD) & $\mathrm{N}$ & Mean(SD) & $95 \% \mathrm{Cl}$ & $95 \% \mathrm{Cl}$ \\
\hline
\end{tabular}

0I Step test fractured leg (steps) (Effect direction: Favours non-w-bear: Favours weight-bear)

$$
\text { Sherrington } 2004 \quad 33 \quad 11.00(6.30) \quad 35 \quad 9.40(6.70)
$$

02 Step test non-fractured leg (steps) (Effect direction: Favours non-w-bear: Favours weigh-bear)

$$
\text { Sherrington } 2004 \quad 33 \quad 11.70(5.90) \quad 35 \quad 9.10(5.80)
$$

03 Functional reach (cm) (Effect direction: Favours non-w-bear: Favours weight-bear)

$$
\text { Sherrington } 2004 \quad 33 \quad 24.80(8.80) \quad 35 \quad 19.90(8.10)
$$

04 Sway distance floor ( $\mathrm{mm}$ ) (Effect direction: Favours weight-bear: Favours non-w-bear)

$$
\text { Sherrington } 2004 \quad 33 \quad 79.00(46.00) \quad 35 \quad 70.00(52.80)
$$

05 Sway distance foam $(\mathrm{mm})$ (Effect direction: Favours weight-bear: Favours non-w-bear)

$$
\begin{array}{lllll}
\text { Sherrington } 2004 & 33 & \text { I I } 5.70(73.30) & 35 & \text { I22.00 (84.10) }
\end{array}
$$

$1.60[-1.49,4.69]$

$2.60[-0.18,5.38]$

$4.90[0.87,8.93]$

$9.00[-14.50,32.50]$

$-6.30[-43.74,31.14]$ 
Analysis I I.07. Comparison II Home-based weight bearing versus non-weight-bearing exercises programme (started at 22 weeks), Outcome 07 Subjective rating of pain, fall risk, balance, sleep quality and general health

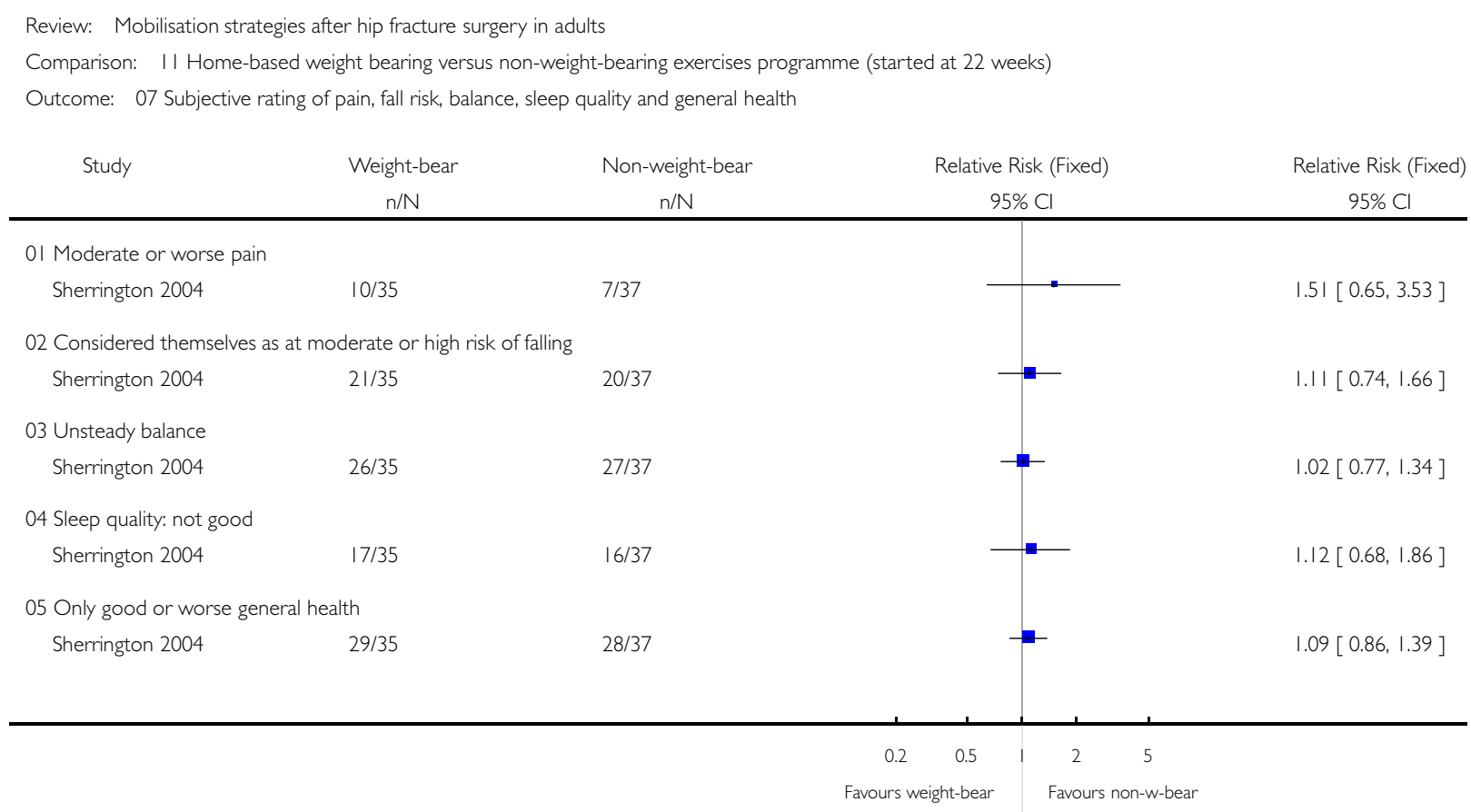

Analysis I I.08. Comparison II Home-based weight bearing versus non-weight-bearing exercises programme (started at 22 weeks), Outcome 08 Fell at least once during intervention period (4 months)

Review: Mobilisation strategies after hip fracture surgery in adults

Comparison: 11 Home-based weight bearing versus non-weight-bearing exercises programme (started at 22 weeks)

Outcome: 08 Fell at least once during intervention period (4 months)

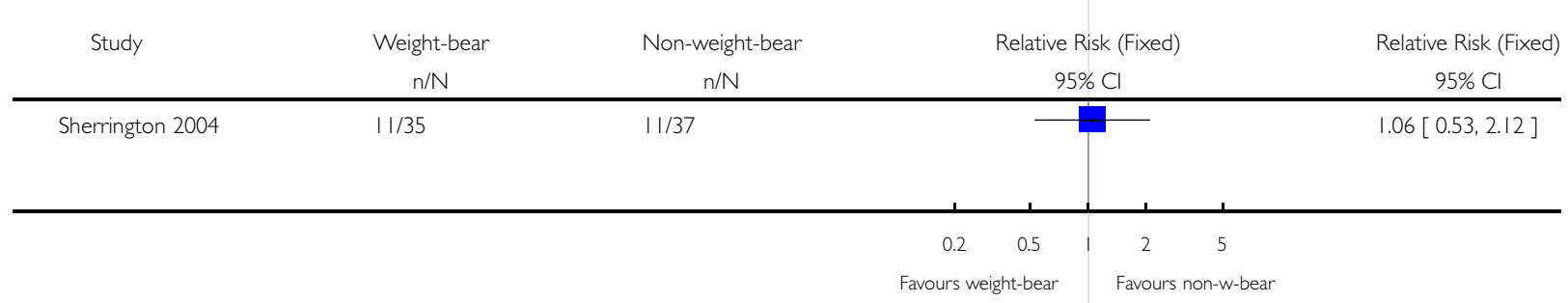


Analysis I I.09. Comparison II Home-based weight bearing versus non-weight-bearing exercises programme (started at 22 weeks), Outcome 09 Mortality

Review: Mobilisation strategies after hip fracture surgery in adults

Comparison: II Home-based weight bearing versus non-weight-bearing exercises programme (started at 22 weeks)

Outcome: 09 Mortality

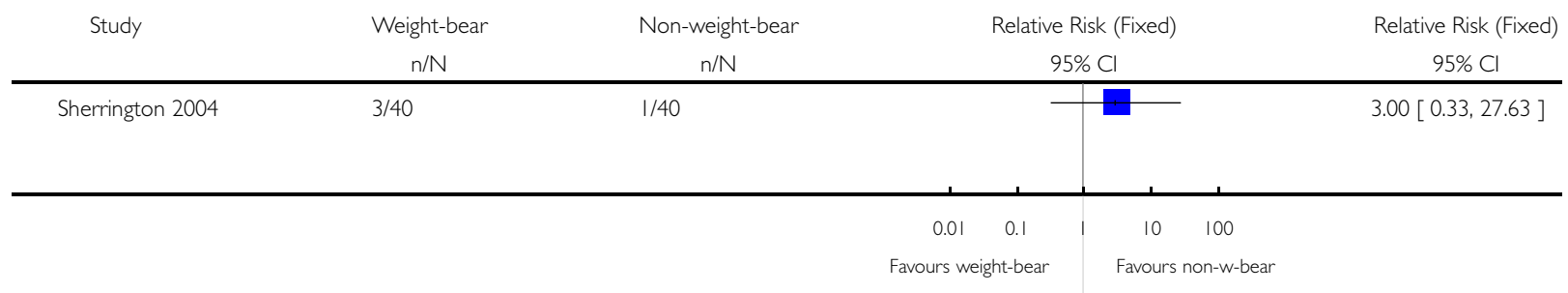

Analysis II.I0. Comparison II Home-based weight bearing versus non-weight-bearing exercises programme (started at 22 weeks), Outcome 10 Participant's participation in and perception of exercise programmes

Review: Mobilisation strategies after hip fracture surgery in adults

Comparison: II Home-based weight bearing versus non-weight-bearing exercises programme (started at 22 weeks)

Outcome: 10 Participant's participation in and perception of exercise programmes

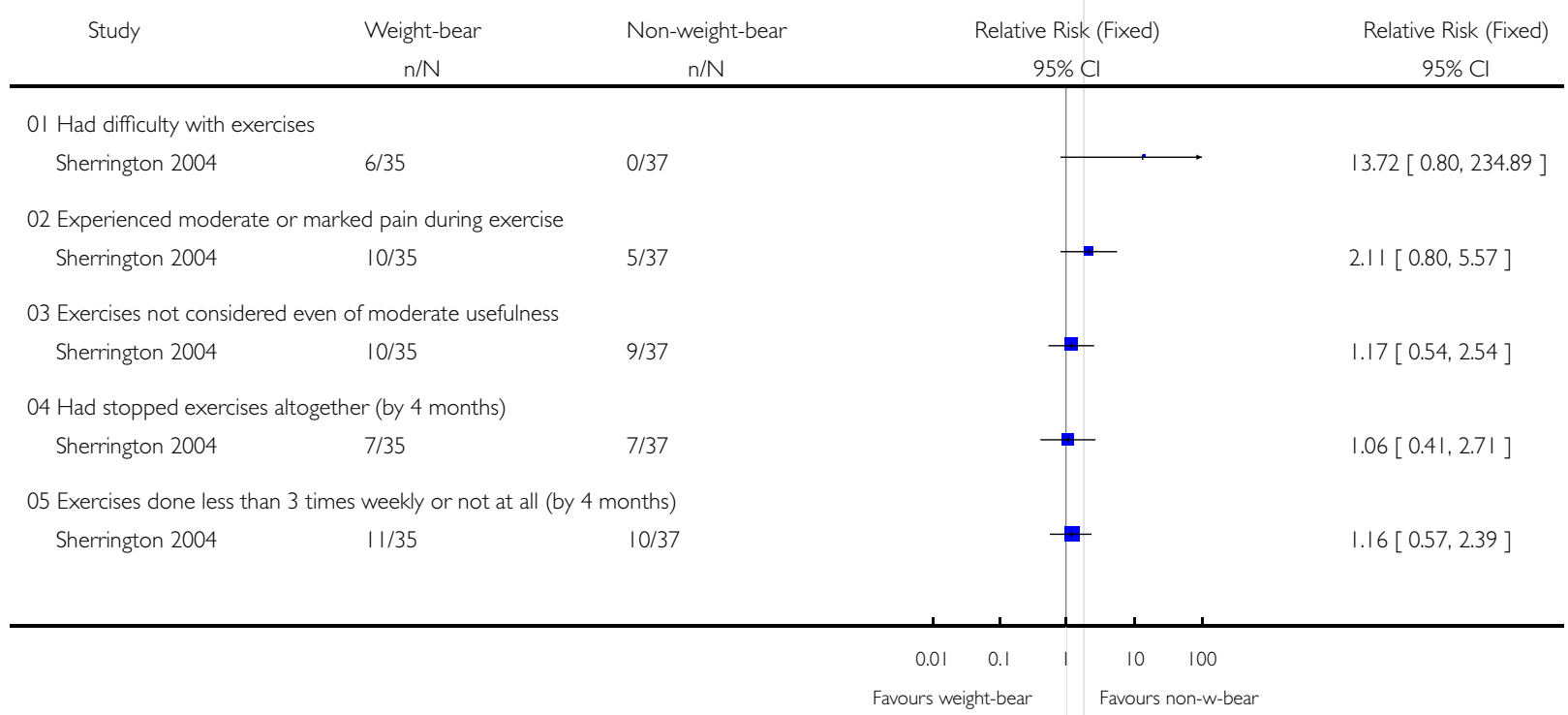




\section{Analysis 12.0I. Comparison I 2 Home-based exercises programme (started at 7 months), Outcome 0 I}

Inability to perform weight-bearing test without hand support

Review: Mobilisation strategies after hip fracture surgery in adults

Comparison: 12 Home-based exercises programme (started at 7 months)

Outcome: 0 I Inability to perform weight-bearing test without hand support

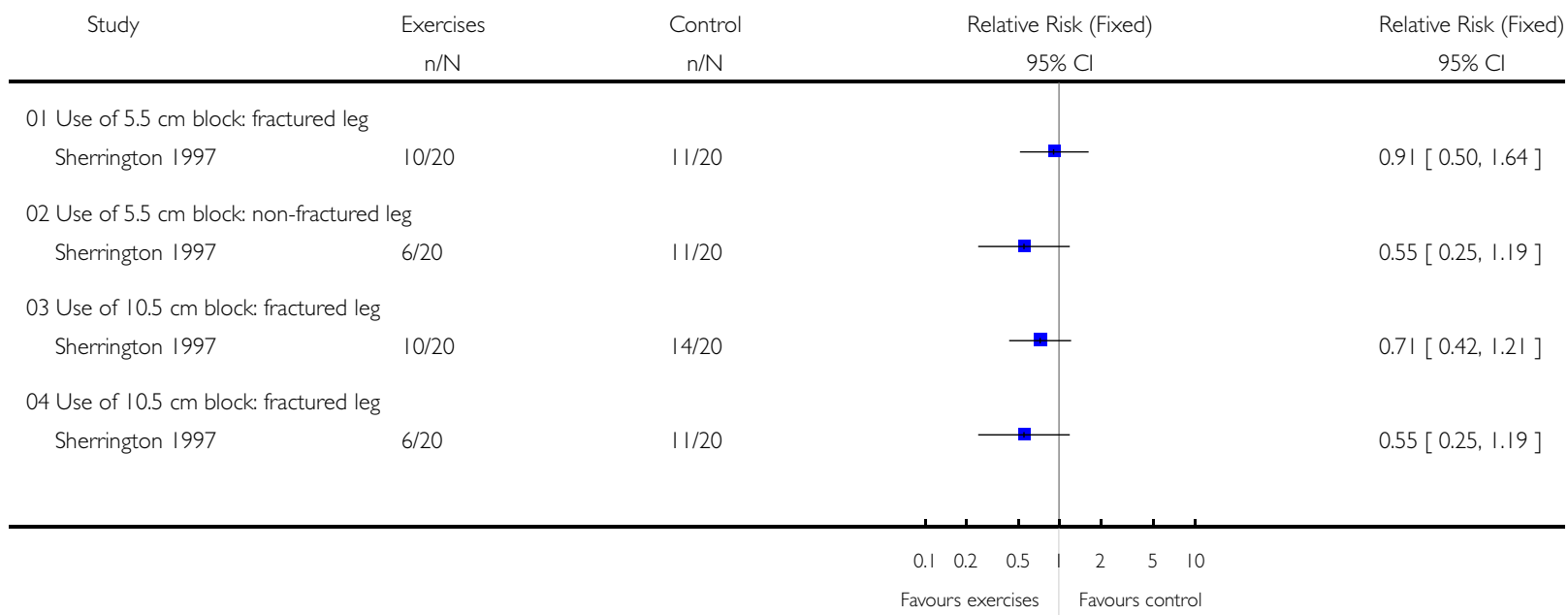

Analysis 12.02. Comparison 12 Home-based exercises programme (started at 7 months), Outcome 02 Gait parameters

Review: Mobilisation strategies after hip fracture surgery in adults

Comparison: 12 Home-based exercises programme (started at 7 months)

Outcome: 02 Gait parameters

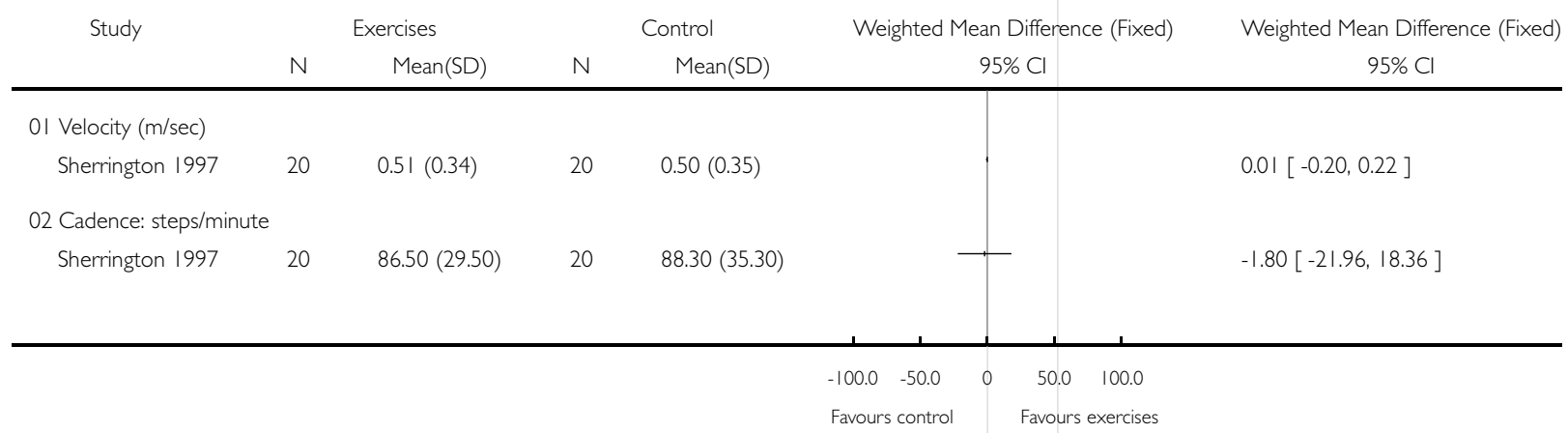


Analysis 12.03. Comparison 12 Home-based exercises programme (started at 7 months), Outcome 03 Strength (kg)

Review: Mobilisation strategies after hip fracture surgery in adults

Comparison: 12 Home-based exercises programme (started at 7 months)

Outcome: 03 Strength $(\mathrm{kg})$

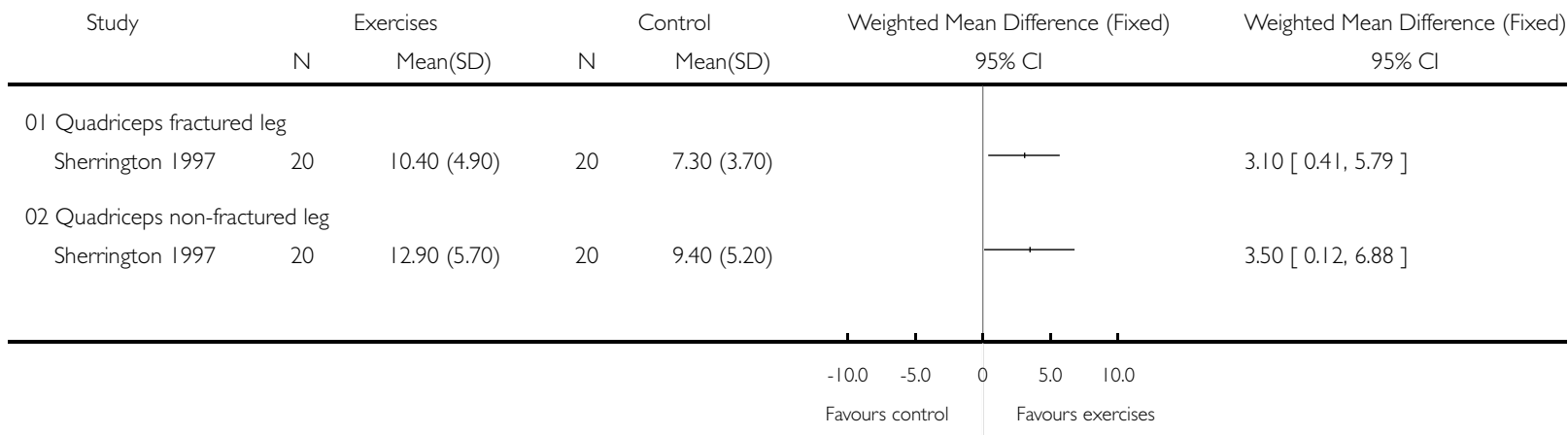

Analysis 12.04. Comparison 12 Home-based exercises programme (started at 7 months), Outcome 04 Balance (postural control)

Review: Mobilisation strategies after hip fracture surgery in adults

Comparison: 12 Home-based exercises programme (started at 7 months)

Outcome: 04 Balance (postural control)

\begin{tabular}{|c|c|c|c|c|c|c|}
\hline \multirow[t]{2}{*}{ Study } & \multicolumn{2}{|r|}{ Exercises } & \multicolumn{2}{|r|}{ Control } & \multirow{2}{*}{$\begin{array}{l}\text { Weighted Mean Difference (Fixed) } \\
\qquad 95 \% \mathrm{Cl}\end{array}$} & \multirow{2}{*}{$\begin{array}{l}\text { Weighted Mean Difference (Fixed) } \\
\qquad 95 \% \mathrm{Cl}\end{array}$} \\
\hline & $\mathrm{N}$ & Mean(SD) & $\mathrm{N}$ & Mean(SD) & & \\
\hline \multicolumn{7}{|c|}{ OI Sway on floor (mm) (Effect direction: Favours exercises: Favours control) } \\
\hline Sherrington 1997 & 20 & $124.00(69.00)$ & 20 & | $36.00(87.00)$ & & $-12.00[-60.66,36.66]$ \\
\hline \multicolumn{7}{|c|}{02 Sway on foam (mm) (Effect direction: Favours exercises: Favours control) } \\
\hline Sherrington 1997 & 20 & $298.00(161.00)$ & 20 & $285.00(159.00)$ & & $13.00[-86.17,112.17]$ \\
\hline \multicolumn{7}{|c|}{03 Functional reach $(\mathrm{cm})$ (Effect direction: Favours control: Favours exercises) } \\
\hline Sherrington 1997 & 20 & $15.70(7.90)$ & 20 & $16.90(7.70)$ & & $-1.20[-6.03,3.63]$ \\
\hline
\end{tabular}


Analysis 12.05. Comparison I 2 Home-based exercises programme (started at 7 months), Outcome 05 Subjective rating of balance and fall risk

Review: Mobilisation strategies after hip fracture surgery in adults

Comparison: 12 Home-based exercises programme (started at 7 months)

Outcome: 05 Subjective rating of balance and fall risk

\begin{tabular}{|c|c|c|c|c|}
\hline Study & $\begin{array}{c}\text { Exercises } \\
n / N\end{array}$ & $\begin{array}{c}\text { Control } \\
n / N\end{array}$ & $\begin{array}{c}\text { Relative Risk (Fixed) } \\
\qquad 95 \% \mathrm{Cl}\end{array}$ & $\begin{array}{c}\text { Relative Risk (Fixed) } \\
95 \% \mathrm{Cl}\end{array}$ \\
\hline \multicolumn{5}{|c|}{ 0I Balance: not always steady } \\
\hline Sherrington 1997 & $12 / 20$ & $15 / 20$ & 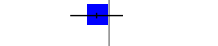 & $0.80[0.52,1.24]$ \\
\hline \multicolumn{5}{|c|}{02 Self-perceived moderate or high risk of fall } \\
\hline Sherrington 1997 & $9 / 20$ & $10 / 20$ & - & $0.90[0.47,1.73]$ \\
\hline
\end{tabular}

